\title{
Modeling Water Yield: Assessing the Role of Site and Region-Specific Attributes in Determining Model Performance of the InVEST Seasonal Water Yield Model
}

\author{
Facundo Scordo ${ }^{1,2, *}$, Thomas Michael Lavender ${ }^{3}\left(\mathbb{D}\right.$, Carina Seitz $^{1,4} \mathbb{D}^{\mathbb{D}}$, Vanesa L. Perillo ${ }^{1,5}{ }^{\mathbb{D}}$, \\ James A. Rusak ${ }^{3,6}{ }^{(\mathbb{D}}$, M. Cintia Piccolo ${ }^{1,2}$ and Gerardo M. E. Perillo ${ }^{1,4}$ \\ 1 Consejo Nacional de Investigaciones Científicas y Técnicas-Instituto Argentino de Oceanografía, \\ Florida 8000, Bahía Blanca, B8000BFW Buenos Aires, Argentina; cseitz@iado-conicet.gob.ar (C.S.); \\ vperillo@criba.edu.ar (V.L.P.); mcpiccol@gmail.com (M.C.P.); gmeperillo@criba.edu.ar (G.M.E.P.) \\ 2 Departamento de Geografía y Turismo, Universidad Nacional del Sur, 12 de Octubre and San Juan, \\ Bahía Blanca, B8000CTD Buenos Aires, Argentina \\ 3 Department of Biological Sciences, Queen's University, Kingston, ON K7L 3N6, Canada; \\ mike.lavender@queensu.ca (T.M.L.); Jim.Rusak@ontario.ca or james.rusak@gmail.com (J.A.R.) \\ 4 Departamento de Geología, Universidad Nacional del Sur, Av. Alem 1253, $2^{\text {do }}$ Cuerpo, Bahía Blanca, \\ B8000BFW Buenos Aires, Argentina \\ 5 Departamento de Biología, Bioquímica y Farmacia, Universidad Nacional del Sur, San Juan 670, \\ B8000DIC Bahía Blanca, Argentina \\ 6 Dorset Environmental Science Centre, Ontario Ministry of the Environment, Conservation, \\ and Parks, P.O. Box 39, Dorset, ON P0A 1E0, Canada \\ * Correspondence: fscordo@criba.edu.ar or scordo@agro.uba.ar
}

Received: 31 August 2018; Accepted: 16 October 2018; Published: 23 October 2018

\begin{abstract}
Simple hydrological models, such as the Seasonal Water Yield Model developed by the Natural Capital Project (InVEST SWYM), are attractive as data requirements are relatively easy to satisfy. However, simple models may produce unrealistic results when the underlying hydrological processes are inadequately described. We used the variation in performance of the InVEST SWYM across watersheds to identify correlates of poorly modeled outcomes of InVEST SWYM. We grouped 749 watersheds from across North America into five bioclimatic regions using nine environmental variables. For each region, we compared the predicted flow patterns to actual flow conditions over a 15-year period. The correlation between the modeled and actual flows was highly dispersed and relatively poor, with $92 \%$ of $r^{2}$ values less than 0.5 and $42 \%$ less than 0.1 . We linked cryospheric variables to model performance in the bioclimatic region with the poorest model performance (the Low elevation Boreal Sub-humid region-LeBSh). After incorporating cryospheric conditions into the InVEST SWYM, predictions improved significantly in 30\% of the LeBSh watersheds. We provide a relatively straightforward approach for identifying processes that simple hydrological models may not consider or which need further attention or refinement.
\end{abstract}

Keywords: hydrological models; InVEST SWYM Natural Capital Project; model processes; model fit; environmental regions

\section{Introduction}

Globally, human populations are dependent upon water resources for their life-sustaining supply of fresh water as well as for their economic value [1]. The ability to reliably model watershed processes is a critical component in allowing decision-makers and managers to maintain and improve aquatic 
ecosystem services (e.g., drinking water supply, recreational opportunities, and energy production) [2]. The use of such models is also beneficial for predicting potential outcomes resulting from changes in precipitation or extreme climate events. For example, models can be used to identify areas susceptible to flooding or drought [3] under changing climate scenarios. However, hydrological processes are difficult to model as they are affected by complex factors such as climatic conditions, soil characteristics, land cover type, and topographic features, which vary spatially and temporally [4,5]. In the last 20 years, the geographic information system technology has allowed the development of physical hydrological models to enable the inclusion of these complex factors [6] such as Penn State Integrated Hydrologic Modeling System Soil and Water (PHIM), the Soil and Water Assessment Tool (SWAT) [7] and the Soil and Water Integrated Model (SWIM) [8]. Models can perform well when the appropriate data is available. Nevertheless, in the absence of robust and readily available datasets, simpler models are attractive to guide management and mitigation efforts aimed at optimizing ecosystem services.

All hydrological models present uncertainty related to their modeled processes and underlying structure [9-11]. While the performance of process-based models should be robust against changing conditions, model structures can become invalid if the dominant processes underlying the model change $[10,11]$. As above, the data requirements needed to run some of these models, and obtain useful results, are sometimes complex and/or difficult to satisfy. These requirements can make them difficult or even impossible to use for some regions, primarily due to the lack of available data for the region being studied. Therefore, before applying a hydrological model, it is necessary to verify the transferability of the model structures under different environmental conditions [11-13] and to determine which inputs have the greatest effect on the model results for each region. This verification would allow users to focus their efforts on collecting key data of sufficient quality to obtain meaningful results.

In this context, simpler models are potentially more attractive due to their ease of use and reduced data requirements [14]. For example, a suite of tools developed by the Natural Capital Project as the Integrated Valuation of Ecosystem Services and Tradeoffs (InVEST) framework [15] have become a popular choice in the analysis of a diverse set of ecosystem services. Ochoa and Cardona [16] found that, since 2009, InVEST has been the most used tool for modeling ecosystem services. The InVEST Seasonal Water Yield Model (SWYM) component has been used to asses water yield [16] in geographically diverse locations such as Hawaii, Indonesia, and China $[6,17,18]$. The use of InVEST SWYM allows the exploration of different scenarios such as climate and/or land use change $[19,20]$ as do other complex models such as SWAT. However, complex models need post-processing to allow decision-makers to assess the ecosystem services studied. In contrast, the InVEST SWYM model produces results that ultimately refer to the ecosystem services themselves and present them graphically for ease of visualization, permitting decision-makers to focus on the outcomes quickly and easily $[6,14]$. Nonetheless, the minimal data requirements of a simpler model, particularly in combination with poor quality data, may produce results that do not represent reality, demanding extensive and complicated calibration and verification processes that may or may not improve results significantly. This result would ultimately defeat the purpose of using an easily applied model and is particularly important when applying the same model structure across regions with different environmental conditions.

For the purposes of our study, we focused on the InVEST SWYM as this model allows users to rank specific parcels (or pixels) of land for conservation or development based on their relative contributions to specific components of the hydrological cycle [15]. That is, the InVEST SWYM model partitions precipitation into either quick flow or base flow (runoff versus groundwater recharge) by calculating a water balance for each individual pixel of the watershed of interest [14,21]. The information required by the SWYM is easily obtained globally from publicly available data sources and includes monthly precipitation, topography, evapotranspiration, land-use, soil type, and land-cover data. Our objective was to analyze the performance of the InVEST SWYM across several environmental regions and use differences in performance across regions to isolate key variables that would improve the model. We propose that the results will differ depending on regional differences in environmental 
features, which will be especially critical in widely applied models such as InVEST SWYM due to the simplification of their processes, variables, and the parameters they incorporate in order to facilitate implementation. To test our hypothesis, we grouped 749 watersheds from across North America into five groups according to nine environmental variables and analyzed (1) how well the river flows modeled with InVEST SWYM corresponded with historical data in a regional context, and (2) assessed which environmental variables had the greatest influence on the modeled results.

\section{Materials and Methods}

Our methodological approach followed three main steps, which we detail below and outline in Figure 1.

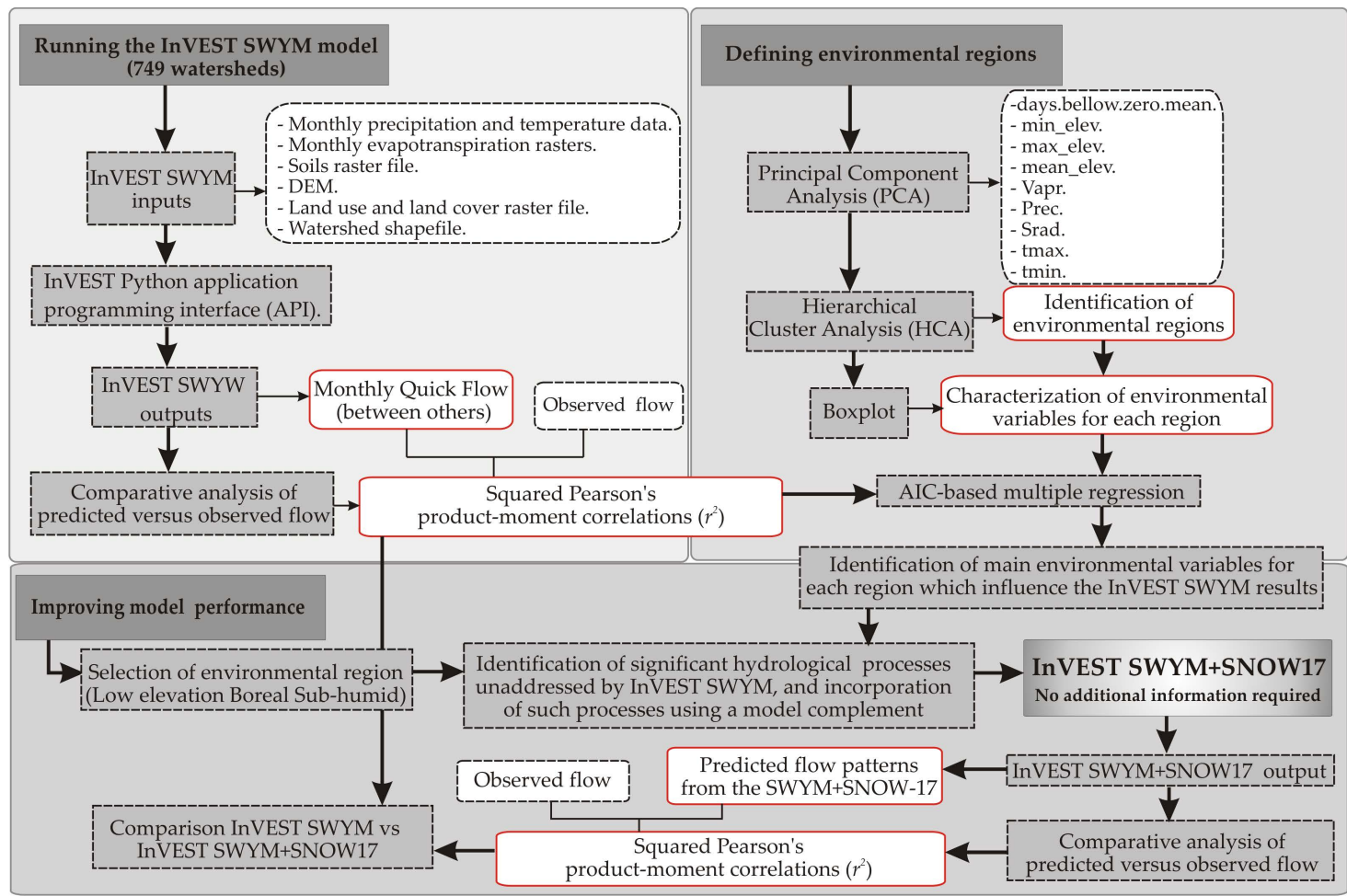

Figure 1. Flowchart of methods. The main steps of the methodology (dark grey boxes without outline), sub-steps of the methodology within the main steps (light grey boxes with black dashed outline), data collected (white boxes with black dashed outline), methodology results (white boxes with red solid outline).

\subsection{Running the InVEST Model}

The data required to run the InVEST SWYM (Figure 1 and Appendix A, Table A1) were collected for a 15-year time period, spanning 1 January 2000 to 31 December 2014. Data were gathered to allow for the analysis of watersheds ranging in size from $174 \mathrm{~km}^{2}$ to $10,814 \mathrm{~km}^{2}$ with a geographic distribution covering most of North America between $26.9^{\circ}$ and $60.9^{\circ} \mathrm{N}$ and $53.6^{\circ}$ and $137.1^{\circ} \mathrm{W}$. We used the daily Climate Prediction Center (CPC) Global Unified Precipitation and Temperature data (https://www.esrl.noaa.gov/psd/) and MOD16 monthly reference evapotranspiration rasters from the Numerical Terradynamic Simulation Group (NTSD; http:/ / www.ntsg.umt.edu) for our analyses. The climate data were the only data that varied with each run of the model. All other data required by the InVEST SWYM stayed constant for the duration of the runs. This allowed us to use single global rasters for soils [22], the digital elevation model (DEM), and land use/land cover [23]. The soil data were available at seven different depths ranging from $0 \mathrm{~cm}$ to $200 \mathrm{~cm}$. For our analyses, we selected the $30 \mathrm{~cm}$ depth as we felt it was a reasonable transition point between runoff versus groundwater recharge. A quick comparison between the surface layers $(0 \mathrm{~cm}$ and $30 \mathrm{~cm})$ found that, in general, 
they had similar soil classifications. For the DEM data, we used the HydroSHEDS [24] hydrologically conditioned elevation data. The individual $5 \times 5$ tiles were stitched together using GDAL Warp [25] to produce a single North American DEM. See Appendix A, Table A1 for a complete list of data sources and attributions.

We selected watersheds for inclusion in our analysis based on a list of 1545 gauging stations with validated flow data (available from The Global Runoff Data Centre, 56,068 Koblenz, Germany (GRDC)). Gauging station data were limited to stations in North America with daily flow data from 1 January 2000 to 31 December 2014. The GRDC also provides watershed boundaries for each of the gauging stations. That is, each gauging station is the pour point for the associated watershed shapefile [26]. We used each gauging station specific watershed shapefile to clip the global raster files (e.g., DEM, precipitation, temperature, soils, evapotranspiration and land use/land cover) during each run of the InVEST model to ensure that the results were specific to the watershed being modeled. The resulting 749 modeled watersheds represent a broad range of environmental conditions (e.g., annual precipitation, the annual number of days with below freezing temperatures, thermal amplitude, and altitudinal difference), which can be observed in Appendix A, Table A1.

The InVEST SWYM model requires monthly total precipitation and not daily totals; however, it also requires the number of precipitation events per month for the watershed that is being modeled as data input. To calculate the number of precipitation events per month, we averaged the total daily precipitation across all pixels contained within the boundaries of each GRDC watershed shape file. Days with an average precipitation per pixel of greater than $0.1 \mathrm{~mm}$ were counted as precipitation events and monthly totals were tabulated for inclusion in the SWYM run. Due to the requirement for monthly precipitation, we converted daily total precipitation to monthly total precipitation by summing the daily precipitation values at each pixel of the raster to create monthly precipitation rasters.

Running the InVEST SWYM model for a single watershed or set of parameters is easily accomplished through the graphical user interface of the application; however, as we wanted to run the model for 749 watersheds over a 15-year period we used the InVEST Python application programming interface (API) (Figure 1). Details of the API are available from http:/ / invest.readthedocs.io/en/latest/. Using the InVEST API allowed us to easily clip the rasters for each watershed to the boundaries and to re-project it to the relevant UTM based coordinate reference system (CRS) of each watershed prior to running the model. It also allowed us to programmatically update the parameters so that we could step through all combinations of watershed $\times$ year. As part of the re-projection step, we also resampled the DEM rasters to a pixel size of $90 \times 90 \mathrm{~m}$ because the InVEST model expects the pixels of the DEM raster to have sides of equal length. The InVEST SWYM has several parameters that can be optimized to improve model performance $(\alpha, \beta, \gamma$ and flow accumulation threshold). As we ran the model for 749 watersheds, it was not feasible to optimize these parameters for each watershed. As such we used the default settings from the SWYM for $\alpha, \beta$ and $\gamma(\alpha=1 / 12, \beta=1.0, \gamma=1.0)$. We did set the threshold value to 125 , which coincides with a $1 \mathrm{~km}^{2}$ contribution area. Explanations of each of the parameters can be found on the Natural Capital Projects website (http:/ / data.naturalcapitalproject.org/nightlybuild/invest-users-guide/html/seasonal_water_yield.html).

\subsection{InVEST Model Output}

Among several other model outputs, the InVEST SWYM produces 12-monthly raster files (per year run) of predicted total monthly Quick Flow (QF or runoff) per pixel (Figure 1). The total predicted monthly runoff $(\mathrm{QF})$ for the watershed is then calculated as the sum of all pixels within the monthly $\mathrm{QF}$ raster. We extracted these monthly predicted QF values for every combination of watershed $\times$ year $\times$ month. This provided us with a set of monthly predicted flow for each watershed over the 15-year period. These data were then compared to GRDC gauging station data of observed monthly flow for each watershed (Figure 1). 


\subsection{Comparative Analysis of Predicted versus Observed Flow}

To compare the predicted flow from the InVEST SWYM model to the observed flow of the gauging station data, we squared the Pearson's product-moment correlation $(r)$ for each watershed (Figure 1) to create a simple standardized measure of model performance. A squared Pearson's product-moment correlation allowed us to focus on the strength and not the direction (positive or negative) of the predicted flow patterns. As we were not examining the significance of $r$, normality was not required in the underlying data. This straightforward approach allowed us to determine whether the predicted flow from the SWYM co-varied with the actually observed flow for each month of the study period for each watershed and to test for regional patterns in SWYM performance with respect to broad-scale climate variables.

\subsection{Defining Regions and Characterization of Climate Variables for Each Region}

We used a Principal Component Analysis (PCA) and a Hierarchical Cluster Analysis (HCA) to examine how the model results were influenced by climate (minimum and maximum temperature, precipitation, vapor pressure, solar radiation, and days below zero) and geographical variables (mean, maximum, and minimum elevation) for each watershed (Figure 1). This combined analytical approach has been shown to be efficient in uncovering patterns in climatic and geographic variables (e.g., References $[27,28])$. Before running the PCA, we standardized all environmental variables of the watersheds (Appendix B, Table A2) using the "scale" function in base R. We did this to ensure that all the terms were non-dimensional and the significant differences in the magnitude between variables were minimized. We then used the PCA analysis from the "vegan" package [29] to summarize the significant environmental variability. We used significant PCA axes selected by the Broken Stick method [30], using the "bstick" and "screeplot" functions of "vegan" [29]. Subsequently, we retained only these significant axes of the PCA site scores to perform the HCA based on Euclidean distances. For this, we employed the "agnes" function of the "cluster" package [31]. We visually assessed the dendrogram to determine which tree produced distinct groups and minimized noise when plotting. We used the "cutree" function of the "cluster" package [31] to produce the groups. All analyses were performed using $\mathrm{R}$ version 3.4.0 [32]. We created boxplots of the environmental variables for each bioclimatic region, which allowed us to explore the variation between regions and to visualize five summary statistics (the median, two hinges (first and third quartiles) and two whiskers). We also created boxplots for the results for each region of the InVEST SWYM.

Finally, we performed an AIC-based multiple regression to analyze which environmental variables (independent variables) affected the results of the hydrological model in each bioclimatic region (measured above as $r^{2}$ between observed and predicted flow; dependent variable) (Figure 1). The AIC analysis allowed us to determine the most parsimonious group of variables that best predicted the fit of the model for each environmental region. Once defined, we conducted a targeted multiple regression analysis to identify which of the AIC-derived variables explained most of the variance in the model fit (Figure 1). Each independent variable in the multiple regressions had an associated beta coefficient $(\beta)$ indicating how much the standard deviation of the dependent variable increased when the independent variable was increased by one standard deviation (SD), assuming other variables in the model were unchanged. The net values of $\beta$ are a measure of the total effect of the independent variables, so the independent variable with the highest net value of $\beta$ is the one with the greatest total effect over the dependent variable. Thus, in this study, the analysis of net values of $\beta$ showed the relative importance of the environmental variables for the variability of $r^{2}$ between observed and model-predicted flow. We also used partial correlations to verify our results. This analysis was carried out using the software Statistica 7. 


\subsection{Improving Model Performance}

After analyzing the InVEST SWYM results and determining the key environmental factors associated with each of the bioclimatic regions, we then carried out a case study (Figure 1) to re-evaluate model performance when additional parameters were included. To do this, we selected the bioclimatic region containing the most watersheds in this study. This region, the Low elevation Boreal Sub-humid (LeHSh) one, was also the region in which the InVEST SWYM had the lowest mean $r^{2}$ values (Figure 1). The environmental variables associated with this region suggested cryospheric conditions might be an important factor.

The InVEST SWYM assumes that precipitation falls as rain and is immediately available for partitioning into the different hydrological pathways [15]. However, precipitation that falls as snow or ice can accumulate and act as a reservoir in watersheds that experience periods of below freezing temperatures [33]. The accumulated ice and snow can be released either gradually, as a single pulse, or be locked away for prolonged periods of time (e.g., glaciers). Consequently, we coupled a snow accumulation and ablation model to the InVEST Seasonal Water Yield Model (SWYM + SNOW17) to account for the effect of cryospheric conditions when using the water yield model [34]. This resulted in a second set of predicted flows for each watershed in the LeHSh region that had been cryospherically conditioned by the SNOW-17 model. The predicted flow patterns from the SWYM + SNOW-17 model were compared to the observed flow patterns of the gauging station data using the squared Pearson's product-moment correlations for each watershed (Figure 1).

The SNOW-17 snow accumulation and ablation model [34] uses temperature and precipitation data to model how much precipitation accumulates as snow or ice versus falling as rain. It also models the conversion of accumulated snow or ice to either water or water vapor. For the purposes of our study, the SNOW-17 model was used to determine how much precipitation fell as rain, which was available to the InVEST SWYM immediately; how much accumulated as snow and was unavailable to the InVEST SWYM; the conversion of accumulated snow to water, which was available to the InVEST SWYM for flow partitioning versus being lost to evaporative processes. The additional data requirements of the SNOW-17 model were easily satisfied by using the daily climate data already collected for the InVEST model as discussed in the analysis of the fit of the hydrological model section above.

\section{Results}

\subsection{Analysis of the Fit of the InVEST SWYM}

When analyzing 749 watersheds from across North America, we found the correlations between modeled flows and actual flows to be highly dispersed and relatively poor. Ninety-two percent of the $r^{2}$ values were less than 0.5 and $42 \%$ were less than 0.1 (Figure 2). 


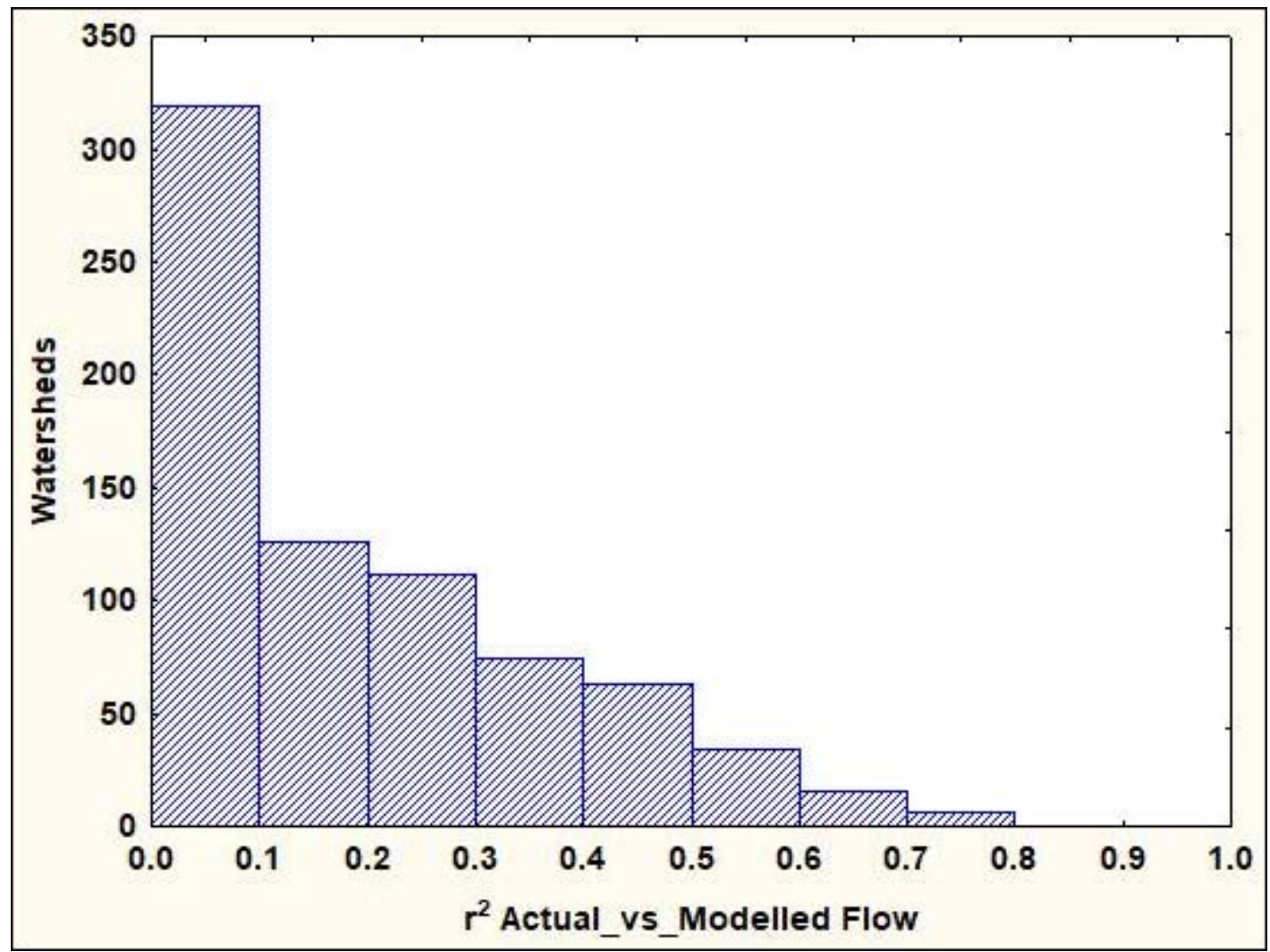

Figure 2. Histogram of the watersheds grouped by the $r^{2}$ values of the correlation between actual and modeled flow. The interval size is $10 \%$.

\subsection{Analysis of the Fit of InVEST SWYM by Region}

The first two components of the PCA analysis explained $81 \%$ of the total variance within the watersheds (Figure 3 and Table 1). The first PCA axis explains 53\% of the variance (Figure 3C and Table 1) and is associated with climatic variability; positive scores occur for vapor pressure, minimum, and maximum temperature, whereas negative scores were associated with the number of days with below zero temperatures (Figure $3 \mathrm{C}$ and Table 2). The PCA axis 2 explains $28 \%$ of the variance and is mainly associated with elevation (Figure 3B and Table 1); positive loadings occur for mean, minimum, and maximum elevation (Figure $3 \mathrm{C}$ and Table 2). Thus, we interpret axis 1 of the PCA as representative of climatic variability and axis 2 as representative of a topographic gradient.

The cluster analysis based on the two first components of the PCA allowed us to identify five distinct environmental regions across our study area (Figure 3A,B). Their geographic distribution can be observed in Figure 4 and their environmental characteristic in Figure 5. Clusters 1 and 2 comprised all watersheds under Boreal Sub-humid conditions. Cluster 1 grouped 108 watersheds on the North Western mountain areas of the continent (Mountain Boreal Sub-humid, Figures 3A and 4) and cluster 2 grouped 383 basins on low lands of the North Central and North Eastern regions of North America (Low elevation Boreal Sub-humid, Figures 3A, 4 and 5). Clusters 3, 4, and 5 comprised all watersheds under temperate conditions. Cluster 3 is composed of 165 basins located in low elevation humid areas in Southeastern North America (Low elevation Temperate Humid, Figures 3A, 4 and 5). Cluster 4 grouped 73 basins on mountain arid areas on the Center and Southwest of the continent (Mountain Temperate Arid, Figures 3A, 4 and 5). Finally, cluster 5 included 22 watersheds under Oceanic Hyper-humid conditions on mid-elevation areas in the Northwest of the continent (Mid-elevation Temperate Hyper-humid, Figures 3A, 4 and 5). 


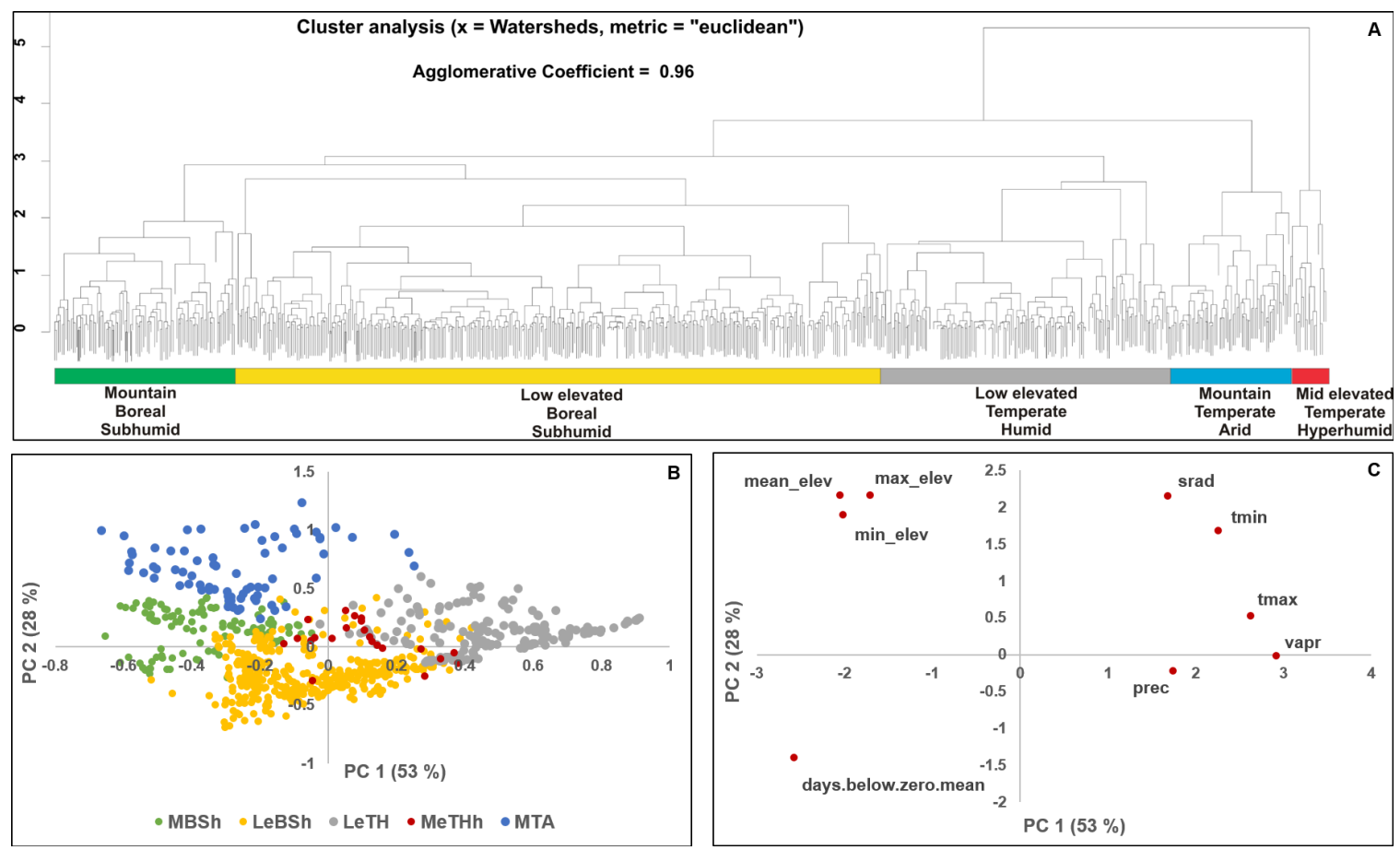

Figure 3. Results of the combined approach of cluster analysis using Principal Component Analysis PCA site scores as inputs (A), and PCA ordination with the analyzed environmental variables (B,C). (B) watershed scores labeled by regions. (C) factor scores of the environmental variables. Environmental regions: Mountain Boreal Sub-humid (MBSh); Low elevation Boreal Sub-humid (LeBSh); Low elevation Temperate Humid (LeTH); Mountain Temperate Arid (MTA); Mid-elevation Temperate Hyper-humid (MeTHh). Environmental variables: mean_elev, max_elev, min_elev (mean, maximum, and minimum elevation); srad (solar radiation); tmin, tmax (minimum and maximum annual temperature); vapr (vapor pressure); prec (precipitation); days.below.zero.mean (annual mean days with below zero temperatures).

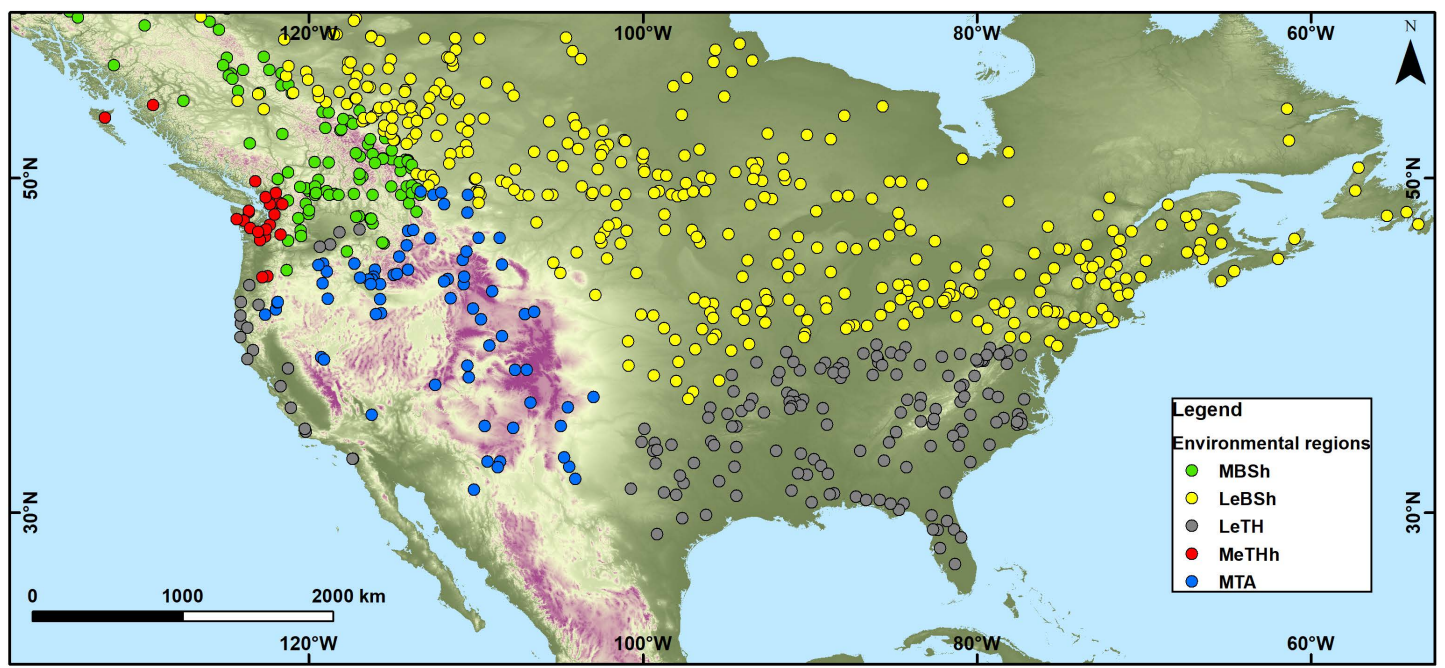

Figure 4. Geographic distribution of watersheds included in the study. The color of the dot indicates the environmental region each watershed was grouped into by the cluster analysis based on environmental conditions. 


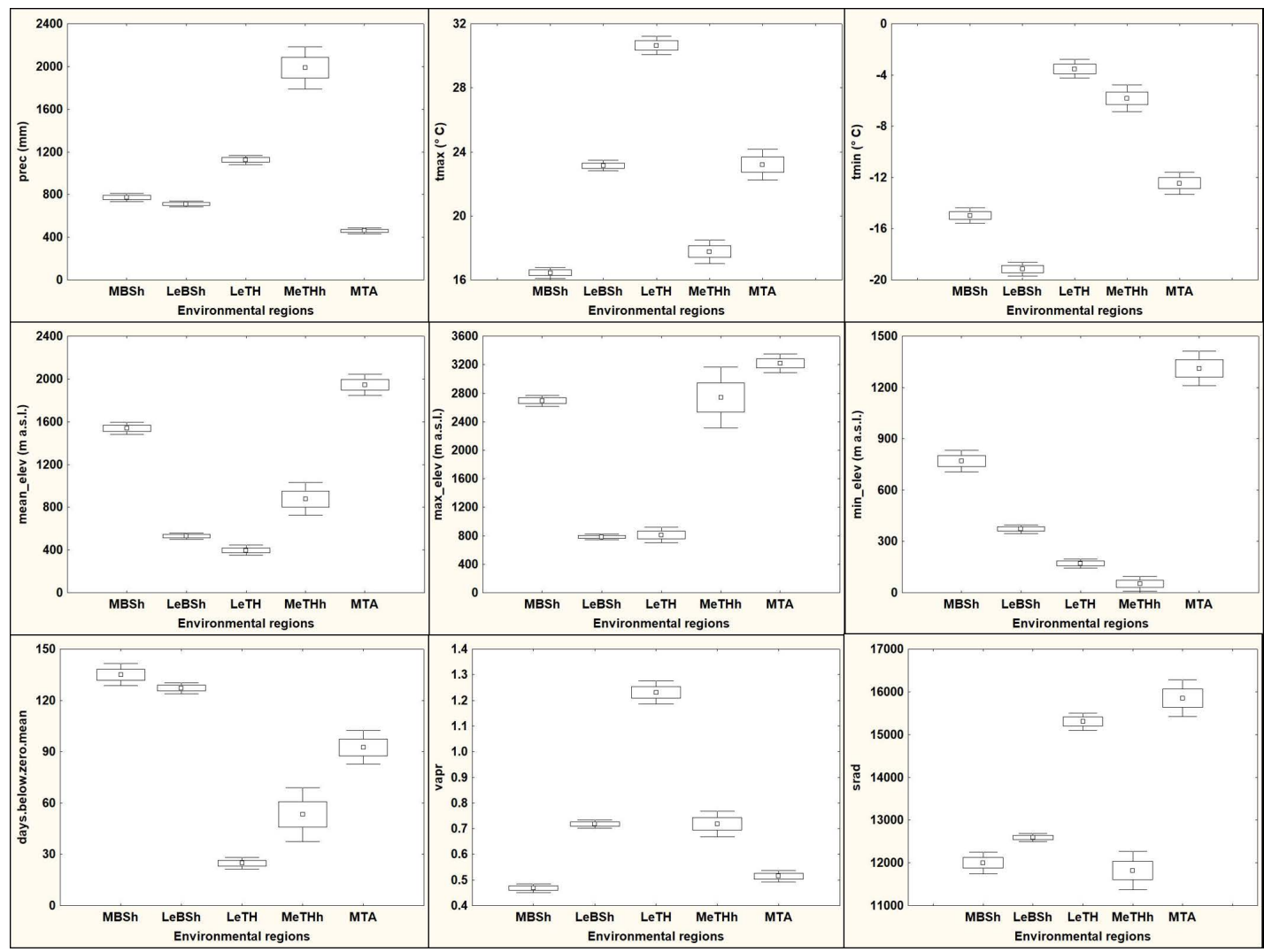

Figure 5. Mean (Inner Square), standard error (bar), 95\% confident interval (whisker) of each of the variables in the environmental regions. From left to right, and top to bottom: precipitation (prec; $\mathrm{mm}$ ); maximum temperature $\left(\operatorname{tmax} ;{ }^{\circ} \mathrm{C}\right)$; minimum temperature $\left(\operatorname{tmin} ;{ }^{\circ} \mathrm{C}\right)$; mean elevation (mean_elev; ma.s.l.); maximum elevation (max_elev; ma.s.l.); minimum elevation (min_elev; ma.s.l.); amount of days with below zero temperatures (days.below.zero.mean; days); vapor pressure (vapr; $\mathrm{kPa}$ ); solar radiation ( $\mathrm{srad} ; \mathrm{kJ} \mathrm{m}^{-2}$ day $^{-1}$ ).

Table 1. Importance of components.

\begin{tabular}{ccccccc}
\hline Component & PC1 & PC2 & PC3 & PC4 & PC5 & PC6 \\
\hline Eigenvalue & 4.84 & 2.50 & 1.17 & 0.20 & 0.13 & 0.07 \\
$\begin{array}{c}\text { Proportion of the } \\
\text { variance explained }\end{array}$ & 0.53 & 0.28 & 0.13 & 0.02 & 0.01 & 0.01 \\
Cumulative Proportion & 0.53 & 0.81 & 0.94 & 0.96 & 0.98 & 1 \\
\hline
\end{tabular}

Table 2. Factor loadings of the environmental variables on Principal Component (PC) axes 1 (PC1) and 2 (PC2), expressed as correlations between a variable and a particular axis.

\begin{tabular}{ccc}
\hline Environmental Variable & PC1 & PC2 \\
\hline Days below $0{ }^{\circ} \mathrm{C}$ & -0.85 & -0.46 \\
Total precipitation & 0.58 & -0.07 \\
Minimum temperature & 0.75 & 0.56 \\
Maximum temperature & 0.87 & 0.17 \\
Vapor pressure & 0.97 & -0.01 \\
Solar radiation & 0.56 & 0.71 \\
Mean elevation & -0.68 & 0.72 \\
Minimum elevation & -0.67 & 0.63 \\
Maximum elevation & -0.57 & 0.72 \\
\hline
\end{tabular}

The InVEST SWYM model produced better results in some regions (LeTH and MeTHh) than in others (MBSh, LeBSh, and MTA) (Figure 6). The $r^{2}$ value between actual and modeled flow in LeTH 
was $0.3 \pm 0.01$ (mean \pm standard error, respectively), while in the MeTHh the $r^{2}$ was $0.35 \pm 0.05$ (Figure 6). These watersheds are under temperate, humid or hyper-humid climate conditions and mid to low elevation lands (Figure 5). The $r^{2}$ values between actual and modeled flow were low in LeBSh $(0.16 \pm 0.01)$, MBSh $(0.17 \pm 0.2)$, and MTA $(0.16 \pm 0.2)$ (Figure 6). In contrast to the former two environmental regions, where the hydrological model produced better results, the LeBSh and MBSh were under cold climate conditions, while the LeBSh and MTA were mountainous regions (Figure 5). In addition, the $r^{2}$ values between observed and modeled flow were significantly correlated with different environmental variables in each of the five climatic regions (Table 3).

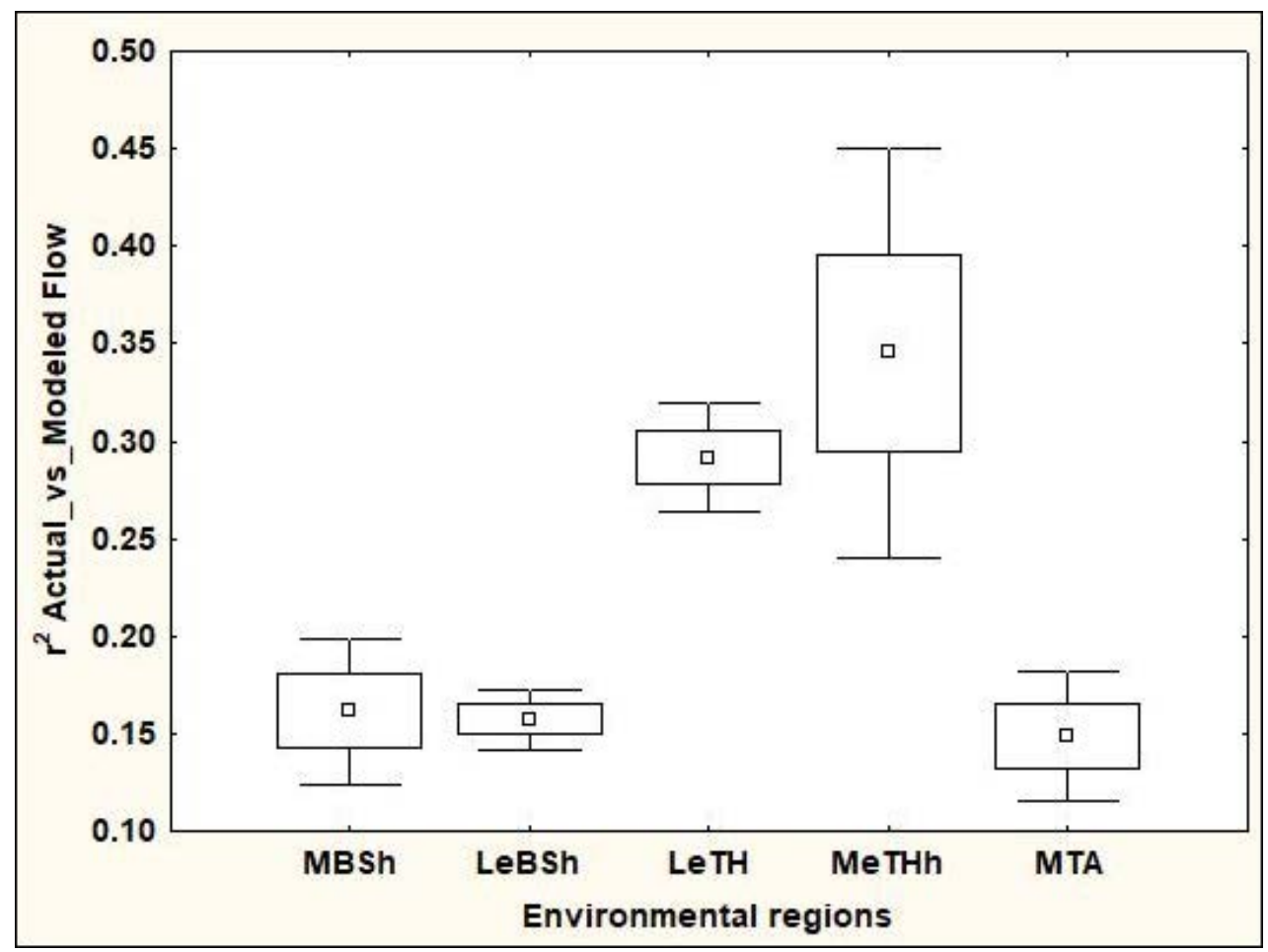

Figure 6. Mean (Inner Square), standard error (bar), 95\% confident interval (whisker) of the $r^{2}$ values of the correlation between actual and modeled flow in each of the environmental regions.

\subsection{Analyzing Environmental Features to Improve InVEST SWYM Results}

The watersheds in the LeBSh environmental region had the lowest mean $r^{2}$ values of the correlation between actual and modeled flows (Figure 6). This region contained climatic features related to cryospheric conditions (Figure 5). The watersheds in this region had more than 120 days with below zero temperatures and the second highest number of days with below zero temperatures between the five environmental areas defined in this study, with temperatures reaching $-20^{\circ} \mathrm{C}$ (the lowest compared with the other four environmental groups) (Figure 5).

For LeBSh, the AIC-based multiple regression indicated that $\sim 12 \%$ (adjusted $r^{2}=0.12 ; p<0.001$ ) of the variance of the model fit (measured as $r^{2}$ between observed and model-predicted flow) could be accounted for by a linear combination of the independent variables defined by the AIC analysis (minimum and maximum temperature, precipitation, days below zero, maximum and minimum elevation, and vapor pressure) (Table 3). Net values of the beta coefficient ( $\beta$ ) show the importance of the variables in a linear multiple regression. The variables that best explained the model fit for LeBSh were the number of days with below zero temperatures $(\beta=-0.18)$ and the minimum temperature ( $\beta=-0.57$ ); both related by cryospheric conditions (Table 3). Partial correlation shows the same results as the net values of the $\beta$ (Table 3 ). Variables related to topographic features were also important in explaining the model fit in this region (minimum elevation, $\beta=0.53$; maximum elevation, $\beta=0.46$ ). The number of days with below zero temperatures was negatively correlated with the model results. 
This indicates the model performance degrades as the number of days of below freezing temperatures increases (Table 3). In addition, the minimum temperature was negatively correlated with the model results, indicating that when minimum temperatures increase, the model results were poorer.

When comparing the LeBSh with the MeTHh group (which is the environmental region where the model produced the best results), we found that the LeBSh region had poorer model predictions $\left(r^{2}=0.16\right)$ than the MeTHh group $\left(r^{2}=0.35\right)$ (Figure 6). For MeTHh, the AIC-based multiple regression indicated that $\sim 80 \%$ (adjusted $R^{2}=0.8 ; p<0.001$ ) of the variance of the model fit could be accounted for by a linear combination of the independent variables defined by the AIC analysis (precipitation, maximum temperature, solar radiation, and vapor pressure) (Table 3$)$. The variable that best described the model fit for MeTHh was the maximum temperature $(\beta=0.67)$ (Table 3). The maximum temperature was positively correlated with the model results, indicating that when maximum temperatures increased, the model results improved.

In addition, in the MeTHh region, the mean number of days with below zero temperatures was 53 (67 days less than in LeBSh) and the mean minimum temperature was $-5.5^{\circ} \mathrm{C}\left(14.5^{\circ} \mathrm{C}\right.$ higher than in LeBSh) (Figure 5). The InVEST SWYM, therefore, performed better in regions with a fewer number of days of below zero temperature and a higher minimum temperature. These results suggest that cryospheric conditions might be influencing the results of the hydrological model.

After accounting for cryospheric conditions and running the SWYM (SWYM + SNOW-17) for the watersheds located inside the LeBSh region, correlation values between the actual and modeled flows improved in 30\% (114 watersheds) of the watersheds (Table 4). These improvements can also be observed in a shift of the histogram distribution, with considerably fewer watersheds in the first bin ( 0 to 0.1 ) and increased in all other bins (Figure 7). The mean $r^{2}$ value between real and modeled flow increased by $10 \%$.

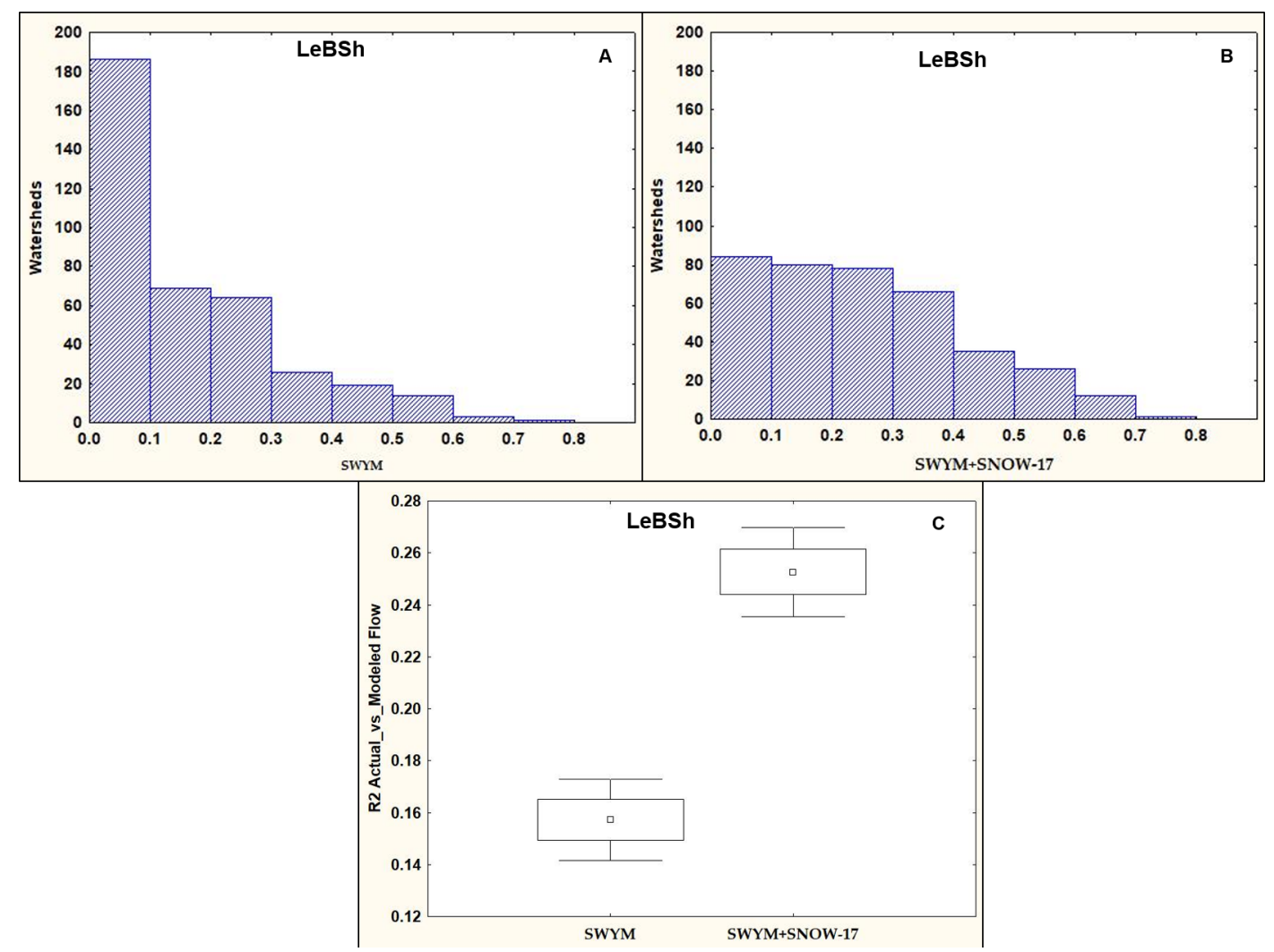

Figure 7. Histograms of the correlation values $\left(r^{2}\right)$ between actual and modeled flow with the SWYM (A) and with the SWYM+SNOW17 (B). (C) Mean (Inner Square), standard error (bar), 95\% confident interval (whisker) of the correlation between actual and modeled flow in the LeBSh environmental regions with SWYM and SWYM + SNOW17. 
Table 3. AIC-based multiple regression analysis of the $r^{2}$ between observed and model-predicted flow in the environmental regions. Adjusted $r^{2}$ of the multiple regression, $\beta$ coefficient, and partial correlations (in brackets) for the variables used in the multiple regression. $\beta$ coefficients and partial correlations values marked in red are significant at $p<0.05$.

\begin{tabular}{|c|c|c|c|c|c|c|c|c|c|c|}
\hline \multirow[b]{2}{*}{ Climatic Regions } & \multirow[b]{2}{*}{ Adjusted $r^{2}$} & \multicolumn{9}{|c|}{ Variables } \\
\hline & & Days below Zero Mean & min_elev & max_elev & mean_elev & vapr & prec & srad & $\operatorname{tmax}$ & tmin \\
\hline MBSh & 0.46 & & $\begin{array}{c}0.58 \\
(0.40)\end{array}$ & $\begin{array}{c}0.67 \\
(0.41)\end{array}$ & $\begin{array}{c}-1.10 \\
(-0.49)\end{array}$ & $\begin{array}{c}-0.55 \\
(-0.22)\end{array}$ & $\begin{array}{l}-22.00 \\
(-0.22)\end{array}$ & $\begin{array}{c}0.40 \\
(0.17)\end{array}$ & & $\begin{array}{c}0.21 \\
(0.11)\end{array}$ \\
\hline LeBSh & 0.12 & $\begin{array}{c}-0.58 \\
(-0.16)\end{array}$ & $\begin{array}{c}0.43 \\
(0.10)\end{array}$ & $\begin{array}{c}0.46 \\
(0.14)\end{array}$ & $\begin{array}{c}-0.35 \\
(-0.06)\end{array}$ & $\begin{array}{c}0.13 \\
(0.03)\end{array}$ & $\begin{array}{c}0.17 \\
(0.09)\end{array}$ & & & $\begin{array}{c}-0.57 \\
(-0.17)\end{array}$ \\
\hline LeTh & 0.06 & & $\begin{array}{c}0.01 \\
(0.01)\end{array}$ & $\begin{array}{c}-0.22 \\
(-0.12) \\
\end{array}$ & & $\begin{array}{c}-0.47 \\
(-0.20) \\
\end{array}$ & $\begin{array}{c}0.37 \\
(0.25) \\
\end{array}$ & $\begin{array}{c}0.40 \\
(0.25)\end{array}$ & & \\
\hline MeTHh & 0.80 & & & & & & $\begin{array}{c}0.52 \\
(0.69)\end{array}$ & $\begin{array}{c}0.09 \\
(0.17)\end{array}$ & $\begin{array}{c}0.67 \\
(0.71)\end{array}$ & $\begin{array}{c}0.17 \\
(0.24)\end{array}$ \\
\hline MTA & 0.17 & $\begin{array}{c}-0.37 \\
(-0.19)\end{array}$ & $\begin{array}{c}0.21 \\
(0.16)\end{array}$ & & & & $\begin{array}{c}0.19 \\
(0.18)\end{array}$ & $\begin{array}{c}-1.00 \\
(-0.44)\end{array}$ & $\begin{array}{c}0.76 \\
(0.31)\end{array}$ & \\
\hline
\end{tabular}


Table 4. Number and percentages of watersheds where the correlation between the actual and modeled flows improved (Fisher $r$ to $Z$ transform, $\alpha=0.05$ ) after running the SWYM accounting for cryospheric conditions (SWYM + SNOW-17).

\begin{tabular}{|c|c|c|c|}
\hline \multicolumn{4}{|c|}{ Watersheds } \\
\hline $\begin{array}{c}\text { Deteriorated } \\
3\end{array}$ & $\begin{array}{c}\text { No Change } \\
266\end{array}$ & $\begin{array}{c}\text { Improved } \\
114\end{array}$ & $\begin{array}{c}\text { Total } \\
383\end{array}$ \\
\hline \multicolumn{4}{|c|}{ Percentages (\%) } \\
\hline 0.8 & 69.5 & 29.8 & 100 \\
\hline
\end{tabular}

\section{Discussion}

Our assessment of the performance of the InVEST SWYM across the differing environmental regions demonstrated that the correlation between the modeled and actual flows was highly variable and relatively poor. To investigate the regional differences further, we grouped the watersheds into five different environmental regions within North America, similar to those proposed for North America by Rivas-Martinez [35] and evaluated the differences in model performance to identify key variables. The results of this analysis indicated that identifying features such as bioclimatic regions and accounting for these differences can substantially improve the model output. We readily demonstrated this by examining performance gains due to the incorporation of cryospheric conditions associated with the region with the poorest model performance (the Low elevation Boreal Sub-humid region-LeBSh). In this region, the SWYM results were significantly improved by the addition of cryospheric variables.

After we applied a snow accumulation and ablation component (SNOW-17) to the InVEST SWYM, runoff predictions significantly improved in 30\% of the watersheds in the LeBSh region. Our results, thus, highlight that the benefits of incorporating additional processes, such as the SNOW-17 accumulation and ablation model, into the simple hydrological model can be large relative to the cost of implementing them. For example, the SNOW-17 model required very little additional data in the form of daily versus monthly temperature and precipitation data to run. These data are available for most regions of the world from publicly available sources (see Appendix A, Table A1). Although the SNOW-17 model did not require a great deal of additional data, it does take into account most of the physical processes that occur within snow cover [34] and implementing the model was straightforward with available existing code sources available (e.g., https://github.com/UW-Hydro/tonic/blob/ master/tonic/models/snow17/snow17.py).

It is worth noting that the correlation between the predicted flows using the InVEST SWYM and the actual flows was overall relatively poor, with $90 \%$ of the $r^{2}$ values less than 0.5 . In regions under temperate climate conditions, the correlation between the predicted and actual flows was less than 0.5 in $77 \%$ of the watersheds. Clearly, variables other than those related to cryospheric conditions were affecting hydrological model results. As an example, in our study, vapor pressure and variables related with terrain slope (e.g., mean, min and max elevation) were highly correlated with the hydrological results in some specific environmental regions (MBSh, and LeBSh). In other studies, landscape characteristics related to terrain topography (e.g., slope) have been shown to produce major changes in the hydrological model results [36]. Furthermore, for three environmental regions (LeBSh, LeTh, and MeTHh), the environmental variables used in this study explain a low percentage of the variance in model fit suggesting that other variables (e.g., land cover, dams, soil characteristics, etc.) might be affecting hydrological model results. Under such conditions, the model may need to be expanded or to consider specific parameters that were not originally incorporated here.

Our results are similar to other studies that highlight the importance of climatic inputs for hydrological models [37,38]. In particular, the hydrological model we used (InVEST SWYM) is most sensitive to uncertainty in climate forcing such as precipitation [39-41]. As described by Hamel and Guswa [41], errors in climate data are spatially heterogeneous and can lead to differences in the model results in diverse environmental regions, as was the case here. In that regard, there are 
other global products that provide monthly climate information in raster format (e.g., CHELSA; http:/ / chelsa-climate.org/). It would be worth comparing the results from the InVEST SWYM using another input dataset to investigate if poor model results are related to data source issues. It is clear from our work, however, that accounting for unaddressed hydrological processes, or by improving existing processes in the InVEST SWYM, significant gains in model performance can be made.

Optimizing available model parameters for each watershed may help to account for the variation within a watershed and improve model performance; however, as mentioned previously, this can be a time consuming and difficult process. In situations where reliable data do not exist, model calibration may not be possible. As such, improving the base model by identifying critical limitations through this type of analysis (versus optimizing for individual watersheds) may prove to be more broadly beneficial and applicable. We have assumed that the global datasets that we have used (precipitation, soils, and flow data) are all reasonably accurate for each of the watersheds included in the study and acknowledge that they may not be the best data to use; however, as mentioned above, some regions are data poor and these are likely to be the data sets that they turn to for such an analysis. Furthermore, improving the models based on broadly available data is likely to benefit more end users than to focus on improvements at the level of the individual watershed.

While our results seem to indicate that the InVEST SWYM performs poorly, it should be made clear that our analyses were not designed to address this question. We did not explicitly test the performance of the SWYM. That is, we did not optimize the run parameters $(\alpha, \beta, \gamma$ and flow accumulation threshold) for any of the watersheds and used the model with all of its default settings, as optimizing for each watershed was not feasible. More importantly, we were looking for indicators of broad-scale environmental factors that influence hydrologic processes that the model may not incorporate. Our multiple regression results (Table 3) give some indication of what these variables might be. Days below zero clearly indicated the importance of cryospheric conditions but the consistent significant values of variables related to evaporation processes (such as vapor pressure and temperature) in the regression results indicated that evapotranspiration in certain environmental regions might be inadequately addressed by the InVEST SWYM (Table 3). To make a robust assessment of the InVEST SWYMs performance, a careful benchmarking study that involves watershed-specific variable optimization is required.

Finally, it should be acknowledged that we made several efforts to include Central and South America's watersheds in this study with little success. We limited our data acquisition to watersheds with both flow and climate data covering the 15-year period between 1 January 2000 and 31 December 2014. This excluded all but two watersheds for South America (SA) as most data for this region did not comply with our criteria. When analyzing the two South American watersheds, we found they had environmental conditions similar to those of the MTA region (northern watersheds in Figure 8) and the LeTH region (southern watersheds in Figure 8). The model fits $\left(r^{2}\right)$ in these watersheds were 0.33 and 0.24 respectively. However, due to the lack of SA sites, it was not possible to specifically discuss how the InVEST model performed in this part of the continent but many of the same hydrological and climate variables may be important in this region where conditions are similar. However, as mentioned previously, hydrological models have uncertainty related to model structure and their performance might not be appropriate if the model structure is based on incorrect dominant processes. Thus, it is necessary to test the transferability of the model structures under the specified environmental conditions in a particular region. When comparing the Northern with the Southern Hemisphere, the former is water-rich and contains the majority of the world's fresh water with $60 \%$ of watersheds experiencing cryospheric conditions versus the Southern Hemisphere, which is water poor, tends to be more arid and has significantly fewer lakes and rivers [42]. Including South America's watersheds could provide greater insights into important hydrological processes by providing additional data characterizing conditions that are not overwhelmingly moist and cool. However, as demonstrated by our results, running this model with global data is not always possible in SA, further highlighting 
the problem of obtaining quality data for these types of analyses and the need for improved data availability in data-poor regions of the world.

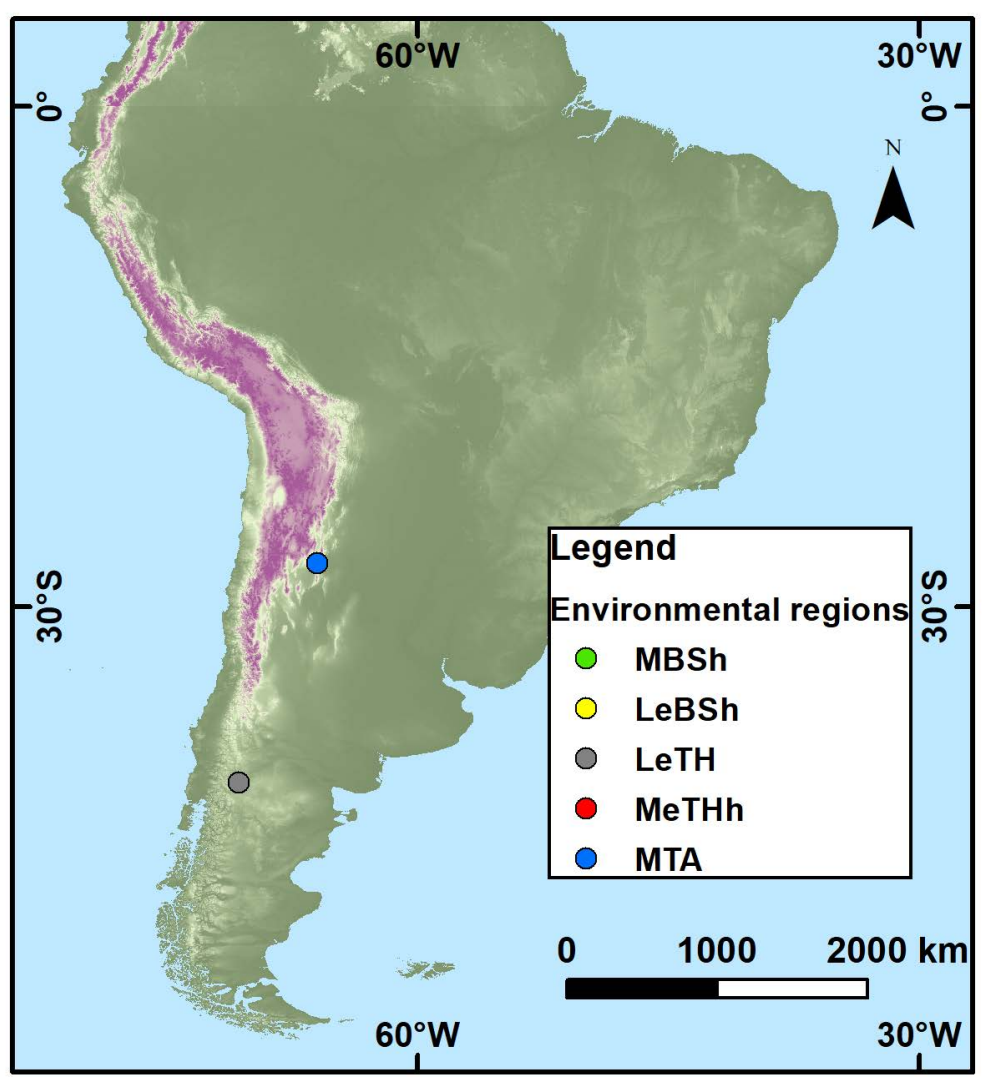

Figure 8. Geographic localization of the two South American watersheds included in the study.

\section{Conclusions}

Our analyses demonstrated that the correlation between actual flow patterns and predicted flow patterns from the Natural Capital Project's InVEST SWYM varied depending on the environmental conditions. However, by isolating the environmental factors that caused the model to generate poorer results, we were able to identify important environmental variables and improve the performance of the model. For example, in the Low elevation Boreal Sub-humid region (LeBSh) of North America, the model produced the poorest results and these were correlated with the cryospheric conditions in the region (days below freezing temperature and minimum temperature). After we applied a specific cryospheric model (SNOW-17) to the SWYM, runoff predictions significantly improved in the 30\% of the watersheds included in the aforementioned region, underlining the need to incorporate this and other standard models of watershed processes into the InVEST SWYM framework whenever possible.

We also highlight the importance of understanding watershed-specific climatic conditions before implementing a hydrological model. Optimization and calibration should be undertaken whenever possible, even if data is only available for another watershed in the same region, to address variables that may be influential for those particular conditions. We have shown that accounting for cryospheric conditions improved hydrological model results in an environmental region under low elevation, boreal sub-humid climate. However, other important climatic conditions, such as evapotranspiration, solar radiation, and slope are usually oversimplified in some hydrological models and would need specific attention. 
Author Contributions: Conceptualization, F.S., T.M.L., C.S., V.L.P., J.A.R., M.C.P. and G.M.E.P.; Methodology, F.S., T.M.L. and C.S.; Investigation, F.S., T.M.L., C.S., V.L.P., J.A.R., M.C.P. and G.M.E.P.; Data Curation, T.M.L.; Writing-Original Draft Preparation, F.S., T.M.L., C.S., V.L.P.; Writing-Review \& Editing, F.S., T.M.L., C.S., V.L.P., J.A.R., M.C.P. and G.M.E.P.; Supervision, J.A.R., M.C.P. and G.M.E.P.; Funding Acquisition, J.A.R., M.C.P. and G.M.E.P.

Funding: This work was supported by: Scholarships from the Consejo Nacional de Investigaciones Científicas y Técnicas to F.S., V.P. and C.S.; Queen Elizabeth II Scholarships to T.M.L.; the Inter-American Institute for Global Change Research (IAI) grant number CRN3038, which is supported by the US National Science Foundation (Grant GEO-1128040, CBET-1204841 and 1226839 and, EF-1137327). Computations were performed on resources and with support provided by the Centre for Advanced Computing (CAC) at Queen's University in Kingston, Ontario. The CAC is funded by: the Canada Foundation for Innovation, the Government of Ontario, and Queen's University.

Acknowledgments: We would like to thank the project Sensing the Americas' Freshwater Ecosystem Risk from Climate Change which was funded by the Inter-American Institute for Global Change Research (CRN3038) via grants from the US National Science Foundation (Grant GEO-1128040, EF-1137327), the Universidad Nacional del Sur, and the Consejo Nacional de Investigaciones Científicas y Técnicas.

Conflicts of Interest: The authors declare no conflict of interest.

\section{Appendix A}

Table A1. Data types and sources required to run the InVEST model.

\begin{tabular}{|c|c|c|c|}
\hline Data Type & Data Source & $\begin{array}{l}\text { Temporal } \\
\text { Resolution }\end{array}$ & $\begin{array}{l}\text { Pixel Spatial } \\
\text { Resolution }\end{array}$ \\
\hline $\begin{array}{l}\text { Digital Elevation Model } \\
\text { (DEM) }\end{array}$ & $\begin{array}{l}\text { Hydrologically conditioned elevation } \\
\text { http://hydrosheds.org/download }\end{array}$ & - & $90 \mathrm{~m}$ \\
\hline $\begin{array}{l}\text { Watershed boundary } \\
\text { shapefiles }\end{array}$ & $\begin{array}{l}\text { http://www.bafg.de/GRDC/EN/02_srvcs / 22_gslrs / } \\
\text { 222_WSB/watershedBoundaries.html?nn=201570 }\end{array}$ & - & - \\
\hline Soils raster & $\begin{array}{l}\text { SoilGrids250m-Texture class (USDA system) at } 7 \\
\text { standard depths } \\
\text { http:/ / data.isric.org/geonetwork/srv/eng/catalog. } \\
\text { search\#/metadata/f9a3a4e0-27a8-4acc-861f- } \\
\text { 26c112699c3e }\end{array}$ & - & $250 \mathrm{~m}$ \\
\hline $\begin{array}{c}\text { Monthly reference } \\
\text { evapotranspiration }(\mathrm{ET})\end{array}$ & $\begin{array}{l}\text { http:/ / files.ntsg.umt.edu/data/NTSG_Products / } \\
\text { MOD16/MOD16A2_MONTHLY.MERRA_GMAO_ } \\
\text { 1kmALB/GEOTIFF_0.05degree }\end{array}$ & Monthly & 0.05 degree $(\sim 5.5 \mathrm{~km})$ \\
\hline Precipitation rasters & $\begin{array}{l}\text { https://www.esrl.noaa.gov/psd/data/gridded/data. } \\
\text { cpc.globalprecip.html }\end{array}$ & Daily & 0.5 degree $(\sim 55 \mathrm{~km})$ \\
\hline Temperature rasters & $\begin{array}{l}\text { https://www.esrl.noaa.gov/psd/data/gridded/data. } \\
\text { cpc.globaltemp.html }\end{array}$ & Daily & 0.5 degree $(\sim 55 \mathrm{~km})$ \\
\hline $\begin{array}{l}\text { Landuse/landcover } \\
\text { raster }\end{array}$ & https://landcover.usgs.gov/global_climatology.php & - & $500 \mathrm{~m}$ \\
\hline $\begin{array}{l}\text { Gauging station flow } \\
\text { data }\end{array}$ & $\begin{array}{l}\text { http://www.bafg.de/GRDC/EN/Home/homepage_ } \\
\text { node.html }\end{array}$ & Daily & - \\
\hline Lake data and shapefiles & http://www.hydrosheds.org/page/hydrolakes & - & - \\
\hline Climate variables & http://worldclim.org/version2 & Monthly & $5 \min (\sim 10 \mathrm{~km})$ \\
\hline
\end{tabular}




\section{Appendix B}

Table A2. Raw data used for PCA analysis.

\begin{tabular}{|c|c|c|c|c|c|c|c|c|c|}
\hline Watershed & Days.below.Zero.Mean & min_elev (m) & max_elev (m) & mean_elev (m) & vapr (kPa) & prec $(\mathrm{mm})$ & $\operatorname{srad}(\mathrm{kJ})$ & $\operatorname{tmax}\left({ }^{\circ} \mathrm{C}\right)$ & $\operatorname{tmin}\left({ }^{\circ} \mathrm{C}\right)$ \\
\hline 1 & 111.8 & 832.0 & 2392.0 & 1434.5 & 0.6 & 1375.1 & $13,114.6$ & 16.8 & -9.5 \\
\hline 2 & 83.4 & 263.0 & 2392.0 & 1023.6 & 0.6 & 952.1 & $13,189.4$ & 20.5 & -9.8 \\
\hline 3 & 129.6 & 142.0 & 2654.0 & 1386.2 & 0.6 & 1241.3 & $12,173.8$ & 16.5 & -10.0 \\
\hline 4 & 96.7 & 395.0 & 2365.0 & 1026.9 & 0.6 & 1044.3 & $13,062.2$ & 19.9 & -10.2 \\
\hline 5 & 111.7 & 314.0 & 2764.0 & 1279.2 & 0.6 & 1380.2 & $12,716.2$ & 17.9 & -10.3 \\
\hline 6 & 127.6 & 778.0 & 2734.0 & 1736.9 & 0.5 & 587.2 & $14,364.8$ & 17.7 & -10.4 \\
\hline 7 & 78.7 & 589.0 & 3116.0 & 1414.8 & 0.6 & 753.3 & $14,591.0$ & 20.4 & -10.4 \\
\hline 8 & 92.1 & 588.0 & 2237.0 & 1106.1 & 0.7 & 824.0 & $13,440.7$ & 20.4 & -10.5 \\
\hline 9 & 92.1 & 618.0 & 2237.0 & 1131.5 & 0.7 & 837.1 & $13,445.0$ & 20.3 & -10.5 \\
\hline 10 & 97.9 & 651.0 & 2037.0 & 1163.9 & 0.6 & 907.7 & $13,340.9$ & 20.0 & -10.5 \\
\hline 11 & 97.9 & 641.0 & 2037.0 & 1176.5 & 0.6 & 915.2 & $13,350.6$ & 19.9 & -10.6 \\
\hline 12 & 127.5 & 239.0 & 2687.0 & 1336.9 & 0.5 & 1050.8 & $12,741.9$ & 17.5 & -10.7 \\
\hline 13 & 126.4 & 468.0 & 2608.0 & 1826.4 & 0.5 & 710.3 & $12,686.3$ & 15.1 & -11.0 \\
\hline 14 & 115.9 & 657.0 & 2237.0 & 1374.3 & 0.6 & 841.9 & $13,492.6$ & 19.3 & -11.3 \\
\hline 15 & 123.5 & 636.0 & 2558.0 & 1562.8 & 0.5 & 793.0 & $12,447.8$ & 16.3 & -11.3 \\
\hline 16 & 106.1 & 639.0 & 2202.0 & 1345.0 & 0.6 & 654.1 & $12,259.7$ & 17.3 & -11.5 \\
\hline 17 & 110.3 & 295.0 & 2608.0 & 1446.3 & 0.5 & 644.8 & $12,515.7$ & 17.0 & -11.5 \\
\hline 18 & 130.9 & 529.0 & 2666.0 & 1590.8 & 0.5 & 803.4 & $12,735.1$ & 16.6 & -11.5 \\
\hline 19 & 103.6 & 277.0 & 2666.0 & 1424.0 & 0.5 & 726.2 & $12,871.8$ & 17.9 & -11.5 \\
\hline 20 & 119.8 & 531.0 & 2558.0 & 1412.4 & 0.5 & 680.7 & $12,390.4$ & 16.9 & -11.6 \\
\hline 21 & 81.1 & 592.0 & 2326.0 & 1443.7 & 0.6 & 965.1 & $12,906.3$ & 17.5 & -11.9 \\
\hline 22 & 87.7 & 440.0 & 2618.0 & 1584.1 & 0.5 & 524.1 & $13,801.6$ & 19.0 & -11.9 \\
\hline 23 & 91.4 & 250.0 & 2284.0 & 1089.1 & 0.6 & 582.8 & $12,602.8$ & 18.9 & -12.0 \\
\hline 24 & 100.4 & 287.0 & 2183.0 & 1085.2 & 0.6 & 596.3 & $12,566.3$ & 18.8 & -12.1 \\
\hline 25 & 109.1 & 297.0 & 2139.0 & 1077.7 & 0.6 & 606.8 & $12,544.6$ & 18.8 & -12.1 \\
\hline 26 & 80.3 & 513.0 & 2325.0 & 1369.4 & 0.6 & 817.9 & $12,808.2$ & 17.6 & -12.1 \\
\hline 27 & 71.5 & 312.0 & 2660.0 & 1477.0 & 0.5 & 1111.6 & $11,553.6$ & 15.6 & -12.2 \\
\hline 28 & 69.5 & 460.0 & 2707.0 & 1670.1 & 0.5 & 532.8 & $14,004.2$ & 19.0 & -12.2 \\
\hline 29 & 91.6 & 333.0 & 2236.0 & 1258.6 & 0.6 & 520.8 & $12,228.1$ & 18.0 & -12.3 \\
\hline 30 & 98.3 & 398.0 & 2362.0 & 1290.9 & 0.6 & 700.4 & $12,858.5$ & 18.4 & -12.6 \\
\hline 31 & 98.3 & 398.0 & 2362.0 & 1291.0 & 0.6 & 700.4 & $12,858.5$ & 18.4 & -12.6 \\
\hline 32 & 105.6 & 633.0 & 2362.0 & 1437.7 & 0.6 & 877.3 & $12,681.9$ & 17.0 & -12.8 \\
\hline
\end{tabular}


Table A2. Cont.

\begin{tabular}{|c|c|c|c|c|c|c|c|c|c|}
\hline Watershed & Days.below.Zero.Mean & min_elev (m) & max_elev (m) & mean_elev (m) & vapr (kPa) & prec $(\mathrm{mm})$ & srad (kJ) & $\operatorname{tmax}\left({ }^{\circ} \mathrm{C}\right)$ & $\operatorname{tmin}\left({ }^{\circ} \mathrm{C}\right)$ \\
\hline 33 & 93.0 & 352.0 & 2139.0 & 1377.7 & 0.5 & 810.6 & $12,621.0$ & 17.0 & -12.8 \\
\hline 34 & 93.3 & 565.0 & 2362.0 & 1337.1 & 0.6 & 719.8 & $12,794.3$ & 17.9 & -12.9 \\
\hline 35 & 109.3 & 648.0 & 2773.0 & 1730.2 & 0.5 & 1165.5 & $12,603.3$ & 15.3 & -13.1 \\
\hline 36 & 100.7 & 365.0 & 2776.0 & 1363.5 & 0.5 & 1375.0 & $12,153.5$ & 15.7 & -13.4 \\
\hline 37 & 106.7 & 1254.0 & 2961.0 & 1738.3 & 0.5 & 619.2 & $13,308.6$ & 18.1 & -13.6 \\
\hline 38 & 101.0 & 337.0 & 2801.0 & 1251.2 & 0.5 & 1035.8 & $12,051.9$ & 16.8 & -13.6 \\
\hline 39 & 95.1 & 1064.0 & 3037.0 & 1512.3 & 0.5 & 686.4 & $13,297.1$ & 19.1 & -13.7 \\
\hline 40 & 117.3 & 800.0 & 2367.0 & 1461.6 & 0.6 & 759.8 & $13,020.2$ & 17.7 & -13.7 \\
\hline 41 & 132.4 & 530.0 & 2832.0 & 1643.2 & 0.5 & 1334.2 & $12,433.4$ & 15.6 & -13.8 \\
\hline 42 & 142.6 & 756.0 & 3096.0 & 1628.8 & 0.5 & 599.6 & $11,224.1$ & 15.6 & -14.1 \\
\hline 43 & 113.4 & 1190.0 & 2622.0 & 1705.4 & 0.5 & 722.2 & $13,105.8$ & 17.7 & -14.2 \\
\hline 44 & 165.4 & 1132.0 & 2649.0 & 1528.8 & 0.4 & 620.4 & $11,826.0$ & 16.0 & -14.2 \\
\hline 45 & 122.6 & 657.0 & 2859.0 & 1286.1 & 0.5 & 916.8 & $11,560.2$ & 16.3 & -14.2 \\
\hline 46 & 132.8 & 710.0 & 2434.0 & 1334.9 & 0.5 & 1107.3 & 9901.3 & 13.6 & -14.3 \\
\hline 47 & 105.0 & 1090.0 & 2771.0 & 1860.1 & 0.4 & 602.4 & $13,406.9$ & 17.6 & -14.3 \\
\hline 48 & 110.1 & 1036.0 & 2915.0 & 1636.5 & 0.5 & 660.9 & $13,099.4$ & 17.9 & -14.4 \\
\hline 49 & 130.1 & 834.0 & 3115.0 & 1988.0 & 0.4 & 1068.8 & $12,577.0$ & 14.5 & -14.5 \\
\hline 50 & 95.1 & 1233.0 & 3092.0 & 1822.3 & 0.5 & 828.9 & $13,070.7$ & 16.9 & -14.5 \\
\hline 51 & 139.9 & 505.0 & 3183.0 & 1729.6 & 0.5 & 1289.7 & $12,419.5$ & 15.1 & -14.6 \\
\hline 52 & 160.5 & 1247.0 & 2770.0 & 1812.6 & 0.3 & 688.7 & $11,822.7$ & 14.6 & -14.8 \\
\hline 53 & 104.4 & 956.0 & 2975.0 & 1711.1 & 0.5 & 665.0 & $13,184.5$ & 18.0 & -14.9 \\
\hline 54 & 156.3 & 1410.0 & 3050.0 & 1983.0 & 0.4 & 691.2 & $12,851.3$ & 15.3 & -15.1 \\
\hline 55 & 153.7 & 936.0 & 3252.0 & 1831.5 & 0.3 & 811.8 & $11,574.9$ & 14.1 & -15.1 \\
\hline 56 & 156.3 & 1297.0 & 3085.0 & 1942.5 & 0.4 & 654.3 & $12,823.4$ & 16.5 & -15.2 \\
\hline 57 & 135.2 & 1030.0 & 3050.0 & 1653.7 & 0.5 & 615.3 & $12,968.0$ & 18.0 & -15.3 \\
\hline 58 & 138.9 & 571.0 & 2513.0 & 1215.8 & 0.5 & 719.7 & $11,193.0$ & 16.8 & -15.4 \\
\hline 59 & 154.6 & 1035.0 & 2950.0 & 1891.6 & 0.3 & 882.2 & $11,730.4$ & 13.3 & -15.4 \\
\hline 60 & 141.3 & 748.0 & 2513.0 & 1319.9 & 0.4 & 804.0 & $11,145.3$ & 15.9 & -15.5 \\
\hline 61 & 113.1 & 1054.0 & 3085.0 & 1672.8 & 0.5 & 599.1 & $12,855.9$ & 17.7 & -15.6 \\
\hline 62 & 158.9 & 971.0 & 3245.0 & 1901.9 & 0.3 & 908.7 & $11,706.9$ & 13.7 & -15.6 \\
\hline 63 & 118.6 & 1212.0 & 2583.0 & 1742.4 & 0.5 & 780.8 & $12,976.9$ & 17.0 & -15.7 \\
\hline 64 & 135.2 & 961.0 & 3085.0 & 1536.0 & 0.5 & 585.2 & $12,977.4$ & 18.7 & -15.7 \\
\hline 65 & 151.9 & 952.0 & 3627.0 & 1905.3 & 0.3 & 770.0 & $11,886.0$ & 14.5 & -15.8 \\
\hline 66 & 154.8 & 2.0 & 2435.0 & 1217.2 & 0.5 & 1263.1 & 9263.4 & 13.7 & -15.8 \\
\hline 67 & 142.4 & 861.0 & 2770.0 & 1405.4 & 0.4 & 620.6 & $11,904.4$ & 17.2 & -15.8 \\
\hline
\end{tabular}


Table A2. Cont.

\begin{tabular}{|c|c|c|c|c|c|c|c|c|c|}
\hline Watershed & Days.below.Zero.Mean & min_elev (m) & max_elev (m) & mean_elev (m) & vapr $(\mathbf{k P a})$ & prec $(\mathrm{mm})$ & $\operatorname{srad}(\mathrm{kJ})$ & $\operatorname{tmax}\left({ }^{\circ} \mathrm{C}\right)$ & $\operatorname{tmin}\left({ }^{\circ} \mathrm{C}\right)$ \\
\hline 68 & 141.8 & 1218.0 & 2506.0 & 1595.2 & 0.4 & 599.9 & $12,058.2$ & 16.2 & -15.8 \\
\hline 69 & 157.6 & 739.0 & 3378.0 & 1760.1 & 0.5 & 946.7 & $12,471.2$ & 15.6 & -15.8 \\
\hline 70 & 161.8 & 1296.0 & 3088.0 & 2034.9 & 0.4 & 699.4 & $12,523.6$ & 15.2 & -15.8 \\
\hline 71 & 144.0 & 573.0 & 2118.0 & 1200.8 & 0.5 & 792.6 & $10,945.2$ & 16.2 & -15.9 \\
\hline 72 & 139.6 & 997.0 & 3177.0 & 1849.2 & 0.4 & 725.2 & $12,837.8$ & 15.9 & -15.9 \\
\hline 73 & 158.8 & 1007.0 & 3627.0 & 2010.9 & 0.3 & 853.3 & $11,895.9$ & 14.2 & -16.1 \\
\hline 74 & 143.8 & 1368.0 & 3218.0 & 2082.3 & 0.4 & 708.7 & $12,520.9$ & 14.8 & -16.1 \\
\hline 75 & 164.5 & 1054.0 & 3094.0 & 1804.1 & 0.4 & 684.1 & $12,451.2$ & 16.2 & -16.2 \\
\hline 76 & 150.3 & 1056.0 & 3459.0 & 1872.4 & 0.4 & 686.5 & $12,597.4$ & 16.2 & -16.2 \\
\hline 77 & 150.3 & 1027.0 & 3459.0 & 1864.3 & 0.4 & 684.7 & $12,601.1$ & 16.3 & -16.3 \\
\hline 78 & 162.3 & 1224.0 & 3459.0 & 2066.6 & 0.4 & 754.2 & $12,485.0$ & 14.7 & -16.3 \\
\hline 79 & 174.2 & 1216.0 & 3430.0 & 2136.1 & 0.3 & 887.8 & $12,208.2$ & 14.1 & -16.4 \\
\hline 80 & 165.4 & 1176.0 & 3006.0 & 1770.0 & 0.5 & 762.2 & $12,471.5$ & 15.9 & -16.6 \\
\hline 81 & 134.7 & 925.0 & 2714.0 & 1404.2 & 0.5 & 595.3 & $12,107.3$ & 17.9 & -16.6 \\
\hline 82 & 152.3 & 984.0 & 3277.0 & 1740.1 & 0.4 & 675.0 & $12,512.7$ & 16.8 & -16.6 \\
\hline 83 & 168.6 & 1375.0 & 3459.0 & 2127.9 & 0.4 & 826.9 & $12,377.3$ & 14.4 & -16.7 \\
\hline 84 & 146.6 & 841.0 & 3251.0 & 1671.3 & 0.4 & 675.8 & $12,227.6$ & 16.7 & -16.8 \\
\hline 85 & 140.7 & 766.0 & 3378.0 & 1911.7 & 0.4 & 954.4 & $12,298.4$ & 15.2 & -16.8 \\
\hline 86 & 140.4 & 687.0 & 2461.0 & 1131.4 & 0.5 & 843.2 & $10,930.8$ & 16.5 & -17.0 \\
\hline 87 & 182.1 & 1341.0 & 3430.0 & 2164.2 & 0.3 & 973.4 & $12,139.1$ & 14.0 & -17.0 \\
\hline 88 & 156.7 & 704.0 & 2303.0 & 1330.6 & 0.4 & 658.9 & $10,566.7$ & 15.2 & -17.3 \\
\hline 89 & 183.7 & 1536.0 & 3123.0 & 2183.6 & 0.3 & 927.7 & $12,298.2$ & 14.4 & -17.8 \\
\hline 90 & 158.9 & 475.0 & 2455.0 & 1138.1 & 0.4 & 607.4 & $10,691.8$ & 16.5 & -17.9 \\
\hline 91 & 153.6 & 689.0 & 2042.0 & 1135.1 & 0.5 & 594.7 & $10,508.4$ & 16.1 & -18.3 \\
\hline 92 & 170.3 & 786.0 & 2780.0 & 1431.8 & 0.4 & 646.8 & $10,382.5$ & 15.0 & -18.5 \\
\hline 93 & 160.3 & 736.0 & 2307.0 & 1289.7 & 0.4 & 608.2 & $10,166.0$ & 15.1 & -19.1 \\
\hline 94 & 168.9 & 806.0 & 2356.0 & 1382.5 & 0.4 & 596.8 & $10,158.9$ & 14.8 & -19.4 \\
\hline 95 & 171.9 & 1680.0 & 2093.0 & 1881.8 & 0.4 & 526.9 & 9147.8 & 13.6 & -19.4 \\
\hline 96 & 178.1 & 795.0 & 2141.0 & 1340.8 & $\begin{array}{l}0.4 \\
0.4\end{array}$ & 574.9 & 8816.6 & 14.3 & -19.4 \\
\hline 97 & 168.1 & 725.0 & 2332.0 & 1406.2 & 0.4 & 601.0 & $10,089.3$ & 14.5 & -19.5 \\
\hline 98 & 188.5 & 678.0 & 2324.0 & 1491.3 & 0.4 & 608.7 & 9919.3 & 14.2 & -19.9 \\
\hline 99 & 179.3 & 712.0 & 2533.0 & 1473.1 & 0.4 & 666.5 & $10,157.7$ & 14.5 & -20.1 \\
\hline 100 & 150.7 & 645.0 & 2123.0 & 1224.6 & 0.4 & 630.4 & 9175.7 & 13.7 & -20.2 \\
\hline 101 & 161.1 & 620.0 & 2360.0 & 1146.6 & 0.4 & 527.9 & 9271.7 & 15.1 & -20.6 \\
\hline
\end{tabular}


Table A2. Cont.

\begin{tabular}{|c|c|c|c|c|c|c|c|c|c|}
\hline Watershed & Days.below.Zero.Mean & min_elev (m) & max_elev (m) & mean_elev (m) & vapr $(\mathbf{k P a})$ & prec $(\mathrm{mm})$ & $\operatorname{srad}(\mathrm{kJ})$ & $\operatorname{tmax}\left({ }^{\circ} \mathrm{C}\right)$ & $\operatorname{tmin}\left({ }^{\circ} \mathrm{C}\right)$ \\
\hline 102 & 179.4 & 756.0 & 2401.0 & 1522.0 & 0.4 & 469.1 & 9005.2 & 14.6 & -20.6 \\
\hline 103 & 206.7 & 759.0 & 2771.0 & 1541.2 & 0.3 & 650.1 & 9987.1 & 14.1 & -20.6 \\
\hline 104 & 199.3 & 785.0 & 2069.0 & 1381.1 & 0.4 & 620.8 & 9242.8 & 14.6 & -20.9 \\
\hline 105 & 217.3 & 520.0 & 2298.0 & 1356.3 & 0.4 & 571.4 & 9713.3 & 15.3 & -21.0 \\
\hline 106 & 222.3 & 715.0 & 2710.0 & 1573.6 & 0.3 & 616.7 & 9693.9 & 14.2 & -21.0 \\
\hline 107 & 192.4 & 869.0 & 2201.0 & 1328.9 & 0.4 & 546.3 & 9332.2 & 16.0 & -23.1 \\
\hline 108 & 184.2 & 908.0 & 1982.0 & 1288.3 & 0.4 & 534.0 & 9404.4 & 16.6 & -23.5 \\
\hline 109 & 33.7 & 294.0 & 611.0 & 417.1 & 1.1 & 767.6 & $16,022.2$ & 34.0 & -6.9 \\
\hline 110 & 40.3 & 336.0 & 505.0 & 418.4 & 1.1 & 855.4 & $15,635.2$ & 32.8 & -7.4 \\
\hline 111 & 39.7 & 448.0 & 670.0 & 552.6 & 1.0 & 671.9 & $16,219.2$ & 33.6 & -7.8 \\
\hline 112 & 58.6 & -23.0 & 204.0 & 70.4 & 1.0 & 1237.8 & $13,436.4$ & 26.6 & -7.8 \\
\hline 113 & 44.4 & 273.0 & 506.0 & 392.4 & 1.1 & 896.5 & $15,325.2$ & 32.2 & -8.3 \\
\hline 114 & 54.3 & -26.0 & 631.0 & 170.2 & 1.0 & 1151.4 & $13,444.4$ & 28.0 & -8.6 \\
\hline 115 & 64.1 & 42.0 & 631.0 & 206.4 & 1.0 & 1152.5 & $13,353.4$ & 27.6 & -9.1 \\
\hline 116 & 46.3 & 620.0 & 903.0 & 765.8 & 1.0 & 542.2 & $16,615.3$ & 33.6 & -9.3 \\
\hline 117 & 62.9 & 92.0 & 949.0 & 378.1 & 1.0 & 1009.9 & $13,102.7$ & 26.7 & -9.5 \\
\hline 118 & 53.3 & 364.0 & 1063.0 & 628.1 & 1.0 & 615.7 & $15,958.4$ & 33.1 & -9.9 \\
\hline 119 & 70.2 & 185.0 & 949.0 & 427.1 & 1.0 & 1002.4 & $12,974.1$ & 26.2 & -9.9 \\
\hline 120 & 106.4 & 24.0 & 207.0 & 109.4 & 0.8 & 1477.3 & $12,518.3$ & 22.0 & -10.0 \\
\hline 121 & 94.6 & -3.0 & 308.0 & 80.8 & 0.8 & 1548.8 & $11,086.5$ & 18.8 & -10.1 \\
\hline 122 & 54.9 & 794.0 & 1465.0 & 1105.0 & 0.8 & 441.0 & $16,670.5$ & 32.5 & -10.2 \\
\hline 123 & 65.3 & 47.0 & 396.0 & 191.6 & 0.9 & 1247.0 & $13,199.6$ & 26.2 & -10.5 \\
\hline 124 & 74.9 & 175.0 & 425.0 & 292.8 & 1.0 & 1037.7 & $12,833.2$ & 25.6 & -10.6 \\
\hline 125 & 61.9 & 49.0 & 525.0 & 189.7 & 1.0 & 1212.0 & $13,223.2$ & 27.4 & -10.6 \\
\hline 126 & 71.3 & 186.0 & 343.0 & 243.7 & 1.0 & 888.6 & $13,133.3$ & 27.7 & -10.8 \\
\hline 127 & 93.0 & 168.0 & 373.0 & 239.8 & 0.9 & 800.4 & $12,738.6$ & 26.2 & -11.2 \\
\hline 128 & 65.8 & 352.0 & 681.0 & 512.8 & 1.0 & 723.4 & $15,173.8$ & 31.3 & -11.2 \\
\hline 129 & 75.8 & 186.0 & 311.0 & 250.2 & 1.0 & 962.6 & $13,172.3$ & 27.4 & -11.4 \\
\hline 130 & 72.5 & 255.0 & 413.0 & 336.7 & $\begin{array}{l}1.0 \\
1.1\end{array}$ & 897.2 & $14,381.4$ & 30.0 & -11.5 \\
\hline 131 & 78.4 & 172.0 & 798.0 & 526.4 & 0.9 & 1065.3 & $12,773.0$ & 24.9 & -11.5 \\
\hline 132 & 77.0 & 315.0 & 576.0 & 420.8 & 0.9 & 1142.1 & $12,753.9$ & 24.8 & -11.5 \\
\hline 133 & 81.0 & 304.0 & 648.0 & 475.8 & 0.9 & 1114.5 & $12,795.6$ & 25.3 & -11.6 \\
\hline 134 & 64.3 & 788.0 & 1368.0 & 1068.9 & 0.8 & 461.0 & $15,814.3$ & 31.3 & -11.6 \\
\hline 135 & 76.0 & 145.0 & 295.0 & 223.4 & 1.0 & 978.4 & $13,166.1$ & 27.5 & -11.7 \\
\hline
\end{tabular}


Table A2. Cont.

\begin{tabular}{|c|c|c|c|c|c|c|c|c|c|}
\hline Watershed & Days.below.Zero.Mean & min_elev (m) & max_elev (m) & mean_elev (m) & vapr $(\mathrm{kPa})$ & prec $(\mathrm{mm})$ & $\operatorname{srad}(\mathrm{kJ})$ & $\operatorname{tmax}\left({ }^{\circ} \mathrm{C}\right)$ & $\operatorname{tmin}\left({ }^{\circ} \mathrm{C}\right)$ \\
\hline 136 & 94.5 & 24.0 & 283.0 & 171.1 & 0.8 & 1390.5 & $12,385.3$ & 22.5 & -11.7 \\
\hline 137 & 89.5 & 173.0 & 299.0 & 223.9 & 0.9 & 970.1 & $12,772.1$ & 24.7 & -11.7 \\
\hline 138 & 85.1 & 231.0 & 366.0 & 284.6 & 0.9 & 810.5 & $12,781.8$ & 26.1 & -11.7 \\
\hline 139 & 71.9 & 194.0 & 422.0 & 316.0 & 1.1 & 913.1 & $14,201.4$ & 29.6 & -11.7 \\
\hline 140 & 71.1 & 275.0 & 444.0 & 353.5 & 1.0 & 813.7 & $14,630.9$ & 30.7 & -11.7 \\
\hline 141 & 72.9 & 142.0 & 295.0 & 219.7 & 1.0 & 979.0 & $13,196.0$ & 27.6 & -11.7 \\
\hline 142 & 91.5 & 195.0 & 299.0 & 234.5 & 0.9 & 974.9 & $12,764.4$ & 24.6 & -11.7 \\
\hline 143 & 68.3 & 142.0 & 277.0 & 205.2 & 1.1 & 957.0 & $13,434.3$ & 28.3 & -11.8 \\
\hline 144 & 69.6 & 501.0 & 681.0 & 601.9 & 1.0 & 676.1 & $15,244.7$ & 31.1 & -11.8 \\
\hline 145 & 82.0 & 177.0 & 368.0 & 249.2 & 1.0 & 862.5 & $12,867.2$ & 26.7 & -11.8 \\
\hline 146 & 80.6 & 213.0 & 378.0 & 277.3 & 1.0 & 912.0 & $12,870.4$ & 26.4 & -11.8 \\
\hline 147 & 86.1 & 2.0 & 780.0 & 296.8 & 0.9 & 1189.8 & $13,020.4$ & 26.0 & -11.9 \\
\hline 148 & 71.4 & 329.0 & 514.0 & 399.8 & 1.0 & 759.2 & $14,680.7$ & 30.6 & -12.0 \\
\hline 149 & 90.1 & 154.0 & 411.0 & 289.1 & 0.9 & 1003.9 & $12,772.5$ & 24.3 & -12.1 \\
\hline 150 & 83.0 & 219.0 & 383.0 & 297.5 & 1.0 & 870.2 & $12,788.8$ & 26.3 & -12.1 \\
\hline 151 & 78.3 & 31.0 & 566.0 & 231.8 & 0.9 & 1145.5 & $13,067.3$ & 25.8 & -12.2 \\
\hline 152 & 94.8 & 200.0 & 326.0 & 262.0 & 0.9 & 1012.6 & $12,740.9$ & 24.2 & -12.2 \\
\hline 153 & 71.6 & 117.0 & 287.0 & 212.5 & 1.0 & 945.5 & $13,818.4$ & 28.7 & -12.2 \\
\hline 154 & 86.5 & 237.0 & 352.0 & 281.5 & 0.9 & 802.3 & $12,746.7$ & 26.2 & -12.2 \\
\hline 155 & 85.1 & 211.0 & 366.0 & 264.9 & 0.9 & 770.6 & $12,734.4$ & 25.9 & -12.2 \\
\hline 156 & 90.2 & -12.0 & 351.0 & 106.7 & 0.9 & 1073.4 & $13,017.0$ & 26.2 & -12.3 \\
\hline 157 & 113.8 & -21.0 & 307.0 & 138.0 & 0.8 & 1443.9 & $12,170.8$ & 21.7 & -12.3 \\
\hline 158 & 86.1 & 134.0 & 366.0 & 254.3 & 0.9 & 771.1 & $12,727.1$ & 25.9 & -12.3 \\
\hline 159 & 83.8 & 231.0 & 791.0 & 492.4 & 0.9 & 897.8 & $12,595.8$ & 24.3 & -12.4 \\
\hline 160 & 76.5 & 130.0 & 287.0 & 218.7 & 1.0 & 945.8 & $13,788.5$ & 28.6 & -12.4 \\
\hline 161 & 88.8 & 93.0 & 1236.0 & 490.3 & 0.9 & 1137.2 & $12,845.1$ & 24.3 & -12.4 \\
\hline 162 & 78.9 & 559.0 & 1007.0 & 777.3 & 0.9 & 585.2 & $15,076.3$ & 30.3 & -12.6 \\
\hline 163 & 100.1 & 217.0 & 411.0 & 318.2 & 0.9 & 1025.9 & $12,752.9$ & 23.9 & -12.6 \\
\hline 164 & 102.9 & 221.0 & 359.0 & 293.4 & 0.9 & 1069.2 & $12,706.8$ & 23.6 & -12.6 \\
\hline 165 & 96.9 & 207.0 & 303.0 & 234.1 & 0.9 & 758.0 & $12,675.5$ & 24.8 & -12.6 \\
\hline 166 & 100.3 & 267.0 & 652.0 & 444.2 & 0.9 & 1056.2 & $12,519.7$ & 24.0 & -12.6 \\
\hline 167 & 84.6 & 63.0 & 780.0 & 343.8 & 0.9 & 1171.7 & $12,944.6$ & 25.5 & -12.6 \\
\hline 168 & 98.1 & 71.0 & 640.0 & 252.1 & 0.9 & 1134.0 & $12,482.5$ & 24.5 & -12.7 \\
\hline 169 & 82.3 & 925.0 & 1504.0 & 1155.7 & 0.7 & 409.3 & $15,110.3$ & 29.7 & -12.8 \\
\hline
\end{tabular}


Table A2. Cont.

\begin{tabular}{|c|c|c|c|c|c|c|c|c|c|}
\hline Watershed & Days.below.Zero.Mean & min_elev (m) & max_elev (m) & mean_elev (m) & vapr $(\mathbf{k P a})$ & prec $(\mathrm{mm})$ & $\operatorname{srad}(\mathrm{kJ})$ & $\operatorname{tmax}\left({ }^{\circ} \mathrm{C}\right)$ & $\operatorname{tmin}\left({ }^{\circ} \mathrm{C}\right)$ \\
\hline 170 & 100.2 & 281.0 & 1004.0 & 548.4 & 0.9 & 1085.5 & $12,653.4$ & 23.8 & -12.9 \\
\hline 171 & 93.9 & 427.0 & 795.0 & 604.8 & 0.9 & 1064.8 & $12,588.4$ & 23.6 & -12.9 \\
\hline 172 & 91.3 & 230.0 & 706.0 & 491.5 & 0.9 & 1067.0 & $12,547.3$ & 23.7 & -13.0 \\
\hline 173 & 123.7 & 32.0 & 351.0 & 192.7 & 0.7 & 1428.9 & $11,021.9$ & 19.6 & -13.0 \\
\hline 174 & 100.1 & 292.0 & 1166.0 & 621.0 & 0.8 & 1150.6 & $12,697.6$ & 23.4 & -13.0 \\
\hline 175 & 79.3 & 780.0 & 1304.0 & 1058.8 & 0.8 & 494.7 & $15,036.9$ & 29.8 & -13.0 \\
\hline 176 & 94.5 & 404.0 & 795.0 & 583.9 & 0.9 & 1062.1 & $12,568.8$ & 23.6 & -13.0 \\
\hline 177 & 97.4 & 243.0 & 817.0 & 470.8 & 0.9 & 1068.7 & $12,603.5$ & 24.1 & -13.0 \\
\hline 178 & 79.5 & 688.0 & 1227.0 & 905.6 & 0.8 & 536.0 & $14,866.2$ & 29.8 & -13.2 \\
\hline 179 & 107.6 & 144.0 & 351.0 & 229.5 & 0.9 & 1033.3 & $12,646.2$ & 22.4 & -13.2 \\
\hline 180 & 76.6 & 275.0 & 470.0 & 371.2 & 1.0 & 837.8 & $14,176.4$ & 29.3 & -13.2 \\
\hline 181 & 130.2 & 5.0 & 347.0 & 199.1 & 0.7 & 1601.6 & $11,043.4$ & 19.6 & -13.3 \\
\hline 182 & 108.1 & 245.0 & 436.0 & 354.4 & 0.9 & 970.6 & $12,771.5$ & 23.5 & -13.3 \\
\hline 183 & 89.2 & 327.0 & 785.0 & 564.2 & 0.9 & 985.1 & $12,547.1$ & 23.6 & -13.3 \\
\hline 184 & 79.9 & 150.0 & 304.0 & 213.2 & 1.0 & 940.4 & $13,625.8$ & 28.1 & -13.4 \\
\hline 185 & 108.1 & 331.0 & 436.0 & 379.6 & 0.9 & 988.0 & $12,754.3$ & 23.3 & -13.5 \\
\hline 186 & 100.7 & 185.0 & 536.0 & 380.6 & 0.9 & 957.4 & $12,763.7$ & 23.1 & -13.6 \\
\hline 187 & 97.8 & 212.0 & 381.0 & 294.2 & 0.9 & 808.7 & $12,628.7$ & 25.1 & -13.9 \\
\hline 188 & 98.1 & 170.0 & 476.0 & 255.4 & 0.9 & 781.1 & $12,609.4$ & 25.1 & -14.0 \\
\hline 189 & 86.1 & 174.0 & 364.0 & 263.5 & 1.0 & 918.0 & $13,284.9$ & 27.1 & -14.1 \\
\hline 190 & 135.5 & 42.0 & 530.0 & 359.7 & 0.8 & 1572.3 & $11,655.9$ & 19.8 & -14.1 \\
\hline 191 & 98.5 & 189.0 & 522.0 & 315.1 & 0.9 & 862.6 & $12,746.0$ & 23.1 & -14.1 \\
\hline 192 & 84.9 & 1240.0 & 1820.0 & 1431.6 & 0.6 & 353.4 & $14,867.8$ & 27.9 & -14.3 \\
\hline 193 & 86.1 & 199.0 & 378.0 & 291.9 & 1.0 & 865.5 & $13,755.2$ & 28.5 & -14.3 \\
\hline 194 & 95.7 & 135.0 & 395.0 & 279.2 & 0.9 & 813.6 & $13,016.1$ & 25.3 & -14.3 \\
\hline 195 & 88.9 & 917.0 & 1424.0 & 1111.6 & 0.7 & 376.3 & $14,419.2$ & 28.1 & -14.3 \\
\hline 196 & 98.7 & 178.0 & 521.0 & 339.9 & 0.9 & 814.5 & $12,566.8$ & 24.6 & -14.3 \\
\hline 197 & 88.1 & 1036.0 & 1499.0 & 1244.4 & 0.6 & 366.2 & $14,665.2$ & 28.2 & -14.3 \\
\hline 198 & $\begin{array}{l}00.1 \\
113.5\end{array}$ & 15.0 & 1561.0 & $\begin{array}{c}124+.4 \\
308.8\end{array}$ & 0.8 & 1118.0 & $\begin{array}{l}14,000.2 \\
12,800.0\end{array}$ & 24.7 & -14.4 \\
\hline 199 & 85.7 & 309.0 & 464.0 & 396.1 & 1.0 & 792.6 & $13,988.3$ & 28.6 & -14.4 \\
\hline 200 & 90.3 & 438.0 & 969.0 & 669.6 & 0.8 & 434.9 & $14,373.6$ & 30.3 & -14.4 \\
\hline 201 & 108.2 & 858.0 & 1398.0 & 1115.0 & 0.6 & 413.8 & $13,491.2$ & 22.8 & -14.5 \\
\hline 202 & 103.7 & 12.0 & 329.0 & 154.2 & 0.8 & 1290.6 & $12,435.1$ & 22.3 & -14.7 \\
\hline 203 & 115.7 & 161.0 & 414.0 & 257.9 & 0.9 & 966.1 & $12,696.1$ & 23.1 & -14.7 \\
\hline
\end{tabular}


Table A2. Cont.

\begin{tabular}{|c|c|c|c|c|c|c|c|c|c|}
\hline Watershed & Days.below.Zero.Mean & min_elev (m) & max_elev (m) & mean_elev (m) & vapr $(\mathrm{kPa})$ & prec $(\mathrm{mm})$ & $\operatorname{srad}(\mathrm{kJ})$ & $\operatorname{tmax}\left({ }^{\circ} \mathrm{C}\right)$ & $\operatorname{tmin}\left({ }^{\circ} \mathrm{C}\right)$ \\
\hline 204 & 139.7 & 831.0 & 1994.0 & 1171.1 & 0.5 & 653.2 & $11,374.0$ & 17.4 & -14.8 \\
\hline 205 & 86.4 & 199.0 & 459.0 & 353.7 & 1.0 & 818.1 & $13,853.2$ & 28.5 & -14.8 \\
\hline 206 & 136.1 & 811.0 & 1634.0 & 1176.9 & 0.4 & 594.3 & $11,659.2$ & 17.8 & -14.8 \\
\hline 207 & 111.3 & 67.0 & 1252.0 & 404.5 & 0.8 & 1123.0 & $12,555.6$ & 23.7 & -14.9 \\
\hline 208 & 89.9 & 198.0 & 378.0 & 290.9 & 1.0 & 882.0 & $13,438.2$ & 27.2 & -14.9 \\
\hline 209 & 106.5 & 175.0 & 439.0 & 273.5 & 0.8 & 717.6 & $12,460.3$ & 23.9 & -15.1 \\
\hline 210 & 125.3 & 57.0 & 1561.0 & 372.4 & 0.8 & 1148.9 & $12,678.9$ & 23.9 & -15.1 \\
\hline 211 & 92.9 & 185.0 & 393.0 & 273.8 & 0.9 & 830.4 & $13,138.1$ & 26.3 & -15.2 \\
\hline 212 & 98.6 & 686.0 & 1221.0 & 873.8 & 0.7 & 432.2 & $14,259.9$ & 28.5 & -15.2 \\
\hline 213 & 136.1 & 706.0 & 1292.0 & 900.4 & 0.5 & 562.5 & $11,703.3$ & 19.2 & -15.3 \\
\hline 214 & 89.5 & 283.0 & 459.0 & 368.7 & 1.0 & 799.8 & $13,798.5$ & 28.3 & -15.4 \\
\hline 215 & 137.4 & -1.0 & 758.0 & 320.0 & 0.7 & 1219.2 & $10,857.6$ & 18.3 & -15.6 \\
\hline 216 & 115.0 & 82.0 & 1084.0 & 469.2 & 0.8 & 1240.7 & $12,368.2$ & 22.9 & -15.7 \\
\hline 217 & 114.5 & 57.0 & 761.0 & 317.9 & 0.8 & 1045.4 & $12,410.9$ & 23.8 & -15.7 \\
\hline 218 & 156.8 & 128.0 & 1664.0 & 545.7 & 0.8 & 1309.0 & $12,529.6$ & 22.5 & -15.7 \\
\hline 219 & 105.3 & 33.0 & 385.0 & 115.4 & 0.9 & 953.1 & $12,491.4$ & 24.4 & -15.7 \\
\hline 220 & 96.9 & 263.0 & 408.0 & 343.5 & 1.0 & 844.8 & $13,563.2$ & 27.8 & -15.8 \\
\hline 221 & 112.5 & 979.0 & 1572.0 & 1142.3 & 0.6 & 470.0 & $13,137.9$ & 21.7 & -15.8 \\
\hline 222 & 112.1 & 154.0 & 335.0 & 232.0 & 0.8 & 819.3 & $12,285.3$ & 22.2 & -15.9 \\
\hline 223 & 96.2 & 299.0 & 507.0 & 409.9 & 0.9 & 730.1 & $13,798.0$ & 28.1 & -15.9 \\
\hline 224 & 121.2 & 81.0 & 455.0 & 228.1 & 0.9 & 936.5 & $12,585.6$ & 23.6 & -15.9 \\
\hline 225 & 109.0 & 20.0 & 232.0 & 116.7 & 0.8 & 1182.4 & $12,402.6$ & 23.2 & -15.9 \\
\hline 226 & 118.1 & 16.0 & 174.0 & 83.8 & 0.8 & 1151.4 & $12,303.1$ & 23.1 & -16.0 \\
\hline 227 & 96.9 & 337.0 & 480.0 & 415.5 & 0.9 & 691.3 & $13,835.8$ & 28.3 & -16.2 \\
\hline 228 & 128.6 & 289.0 & 1587.0 & 625.1 & 0.8 & 1149.5 & $12,358.6$ & 22.1 & -16.2 \\
\hline 229 & 139.5 & 825.0 & 1370.0 & 1140.6 & 0.5 & 611.4 & $11,857.1$ & 18.7 & -16.2 \\
\hline 230 & 116.8 & 186.0 & 354.0 & 240.8 & 0.8 & 810.2 & $12,287.3$ & 22.2 & -16.2 \\
\hline 231 & 92.7 & 200.0 & 422.0 & 334.9 & 0.9 & 873.1 & $13,289.3$ & 26.7 & -16.2 \\
\hline 232 & 113.0 & 81.0 & 1298.0 & 367.4 & 0.8 & 1140.7 & $12,351.0$ & 22.9 & -16.3 \\
\hline 233 & 109.7 & 36.0 & 1358.0 & 492.7 & 0.8 & 1039.1 & $12,335.1$ & 22.4 & -16.3 \\
\hline 234 & 144.3 & 2.0 & 539.0 & 265.4 & 0.6 & 1184.1 & $10,589.6$ & 17.0 & -16.3 \\
\hline 235 & 118.2 & 12.0 & 1896.0 & 422.3 & 0.8 & 1135.1 & $12,470.1$ & 22.9 & -16.3 \\
\hline 236 & 113.0 & 902.0 & 1572.0 & 1050.7 & 0.6 & 444.3 & $13,183.2$ & 22.1 & -16.4 \\
\hline 237 & 99.3 & 293.0 & 397.0 & 347.8 & 1.0 & 798.8 & $13,570.2$ & 27.7 & -16.4 \\
\hline
\end{tabular}


Table A2. Cont.

\begin{tabular}{|c|c|c|c|c|c|c|c|c|c|}
\hline Watershed & Days.below.Zero.Mean & min_elev (m) & max_elev (m) & mean_elev (m) & vapr $(\mathrm{kPa})$ & prec $(\mathrm{mm})$ & $\operatorname{srad}(\mathrm{kJ})$ & $\operatorname{tmax}\left({ }^{\circ} \mathrm{C}\right)$ & $\operatorname{tmin}\left({ }^{\circ} \mathrm{C}\right)$ \\
\hline 238 & 136.1 & 599.0 & 2047.0 & 980.8 & 0.5 & 613.0 & $11,008.3$ & 17.6 & -16.4 \\
\hline 239 & 107.5 & 769.0 & 1572.0 & 994.2 & 0.6 & 415.7 & $13,256.1$ & 22.7 & -16.4 \\
\hline 240 & 142.6 & 124.0 & 1085.0 & 346.1 & 0.8 & 1255.4 & $12,277.7$ & 22.5 & -16.5 \\
\hline 241 & 99.1 & 324.0 & 507.0 & 426.7 & 0.9 & 728.9 & $13,683.2$ & 27.6 & -16.5 \\
\hline 242 & 107.5 & 808.0 & 1572.0 & 1005.1 & 0.6 & 422.2 & $13,228.7$ & 22.5 & -16.5 \\
\hline 243 & 100.9 & 712.0 & 1097.0 & 870.6 & 0.6 & 307.7 & $13,940.6$ & 27.8 & -16.5 \\
\hline 244 & 123.9 & 80.0 & 1827.0 & 457.0 & 0.8 & 1118.3 & $12,364.6$ & 22.7 & -16.5 \\
\hline 245 & 138.5 & 635.0 & 1592.0 & 885.5 & 0.5 & 699.8 & $11,008.9$ & 18.3 & -16.6 \\
\hline 246 & 104.1 & 246.0 & 430.0 & 352.4 & 0.9 & 825.4 & $13,360.8$ & 27.2 & -16.6 \\
\hline 247 & 113.7 & 70.0 & 391.0 & 156.0 & 0.8 & 1103.5 & $12,370.8$ & 23.6 & -16.7 \\
\hline 248 & 106.8 & 317.0 & 574.0 & 458.2 & 0.9 & 611.2 & $13,854.8$ & 28.2 & -16.8 \\
\hline 249 & 99.3 & 240.0 & 436.0 & 354.8 & 0.9 & 843.7 & $13,290.1$ & 26.9 & -16.9 \\
\hline 250 & 133.0 & 655.0 & 1610.0 & 1054.4 & 0.5 & 586.5 & $11,914.1$ & 19.1 & -16.9 \\
\hline 251 & 130.7 & 151.0 & 1029.0 & 436.9 & 0.8 & 1092.8 & $12,325.7$ & 22.7 & -16.9 \\
\hline 252 & 139.8 & 492.0 & 1656.0 & 889.3 & 0.5 & 557.6 & $11,841.4$ & 19.7 & -16.9 \\
\hline 253 & 97.9 & 751.0 & 1995.0 & 950.3 & 0.6 & 324.4 & $13,717.7$ & 26.0 & -17.0 \\
\hline 254 & 132.5 & 609.0 & 1524.0 & 844.6 & 0.5 & 607.4 & $10,984.0$ & 18.4 & -17.1 \\
\hline 255 & 136.9 & 975.0 & 1560.0 & 1148.7 & 0.5 & 598.0 & $12,148.0$ & 19.3 & -17.1 \\
\hline 256 & 130.5 & 651.0 & 1201.0 & 847.8 & 0.5 & 576.2 & $11,916.9$ & 20.0 & -17.1 \\
\hline 257 & 114.9 & 754.0 & 1010.0 & 841.6 & 0.7 & 406.3 & $13,874.9$ & 26.9 & -17.1 \\
\hline 258 & 139.3 & 692.0 & 1026.0 & 823.6 & 0.5 & 480.9 & $11,549.4$ & 19.5 & -17.1 \\
\hline 259 & 104.1 & 289.0 & 436.0 & 367.1 & 0.9 & 824.9 & $13,253.5$ & 26.7 & -17.2 \\
\hline 260 & 145.9 & 545.0 & 990.0 & 790.2 & 0.5 & 478.5 & $11,463.1$ & 19.4 & -17.3 \\
\hline 261 & 114.1 & 576.0 & 1010.0 & 771.4 & 0.7 & 416.9 & $13,850.2$ & 27.3 & -17.3 \\
\hline 262 & 134.7 & 819.0 & 2714.0 & 1179.9 & 0.5 & 586.9 & $12,159.2$ & 19.1 & -17.4 \\
\hline 263 & 115.9 & 741.0 & 1033.0 & 821.2 & 0.7 & 409.3 & $13,816.0$ & 27.0 & -17.5 \\
\hline 264 & 134.3 & 178.0 & 704.0 & 387.8 & 0.8 & 1203.9 & $12,226.3$ & 22.2 & -17.5 \\
\hline 265 & 135.8 & 943.0 & 1414.0 & 1083.4 & 0.5 & 594.8 & $12,126.1$ & 19.8 & -17.5 \\
\hline 266 & 104.1 & 228.0 & 412.0 & 326.3 & 0.9 & 758.5 & $13,232.1$ & 26.9 & -17.6 \\
\hline 267 & 117.7 & 205.0 & 577.0 & 342.6 & 0.8 & 791.1 & $12,593.6$ & 24.4 & -17.6 \\
\hline 268 & 138.5 & 174.0 & 489.0 & 332.2 & 0.8 & 943.3 & $12,422.7$ & 22.3 & -17.6 \\
\hline 269 & 134.9 & 714.0 & 2714.0 & 1121.4 & 0.5 & 584.6 & $12,151.4$ & 19.1 & -17.7 \\
\hline 270 & 126.2 & 197.0 & 480.0 & 323.8 & 0.8 & 793.6 & $12,338.5$ & 23.6 & -17.7 \\
\hline 271 & 149.9 & 926.0 & 2007.0 & 1255.7 & 0.5 & 604.3 & $12,407.3$ & 19.4 & -17.7 \\
\hline
\end{tabular}


Table A2. Cont.

\begin{tabular}{|c|c|c|c|c|c|c|c|c|c|}
\hline Watershed & Days.below.Zero.Mean & min_elev (m) & max_elev (m) & mean_elev (m) & vapr $(\mathbf{k P a})$ & prec $(\mathrm{mm})$ & $\operatorname{srad}(\mathrm{kJ})$ & $\operatorname{tmax}\left({ }^{\circ} \mathrm{C}\right)$ & $\operatorname{tmin}\left({ }^{\circ} \mathrm{C}\right)$ \\
\hline 272 & 126.9 & 258.0 & 1117.0 & 534.9 & 0.8 & 1163.1 & $12,191.4$ & 21.6 & -17.7 \\
\hline 273 & 152.9 & 989.0 & 1976.0 & 1263.3 & 0.5 & 603.2 & $12,588.7$ & 20.1 & -17.7 \\
\hline 274 & 133.2 & 907.0 & 1865.0 & 1181.0 & 0.5 & 496.8 & $12,807.1$ & 20.9 & -17.8 \\
\hline 275 & 125.0 & 266.0 & 1089.0 & 498.9 & 0.7 & 1293.3 & $12,164.3$ & 21.4 & -17.8 \\
\hline 276 & 125.2 & 739.0 & 1424.0 & 1047.9 & 0.6 & 383.0 & $13,520.8$ & 23.2 & -17.8 \\
\hline 277 & 118.2 & 17.0 & 544.0 & 228.1 & 0.8 & 1130.1 & $12,280.3$ & 22.0 & -17.9 \\
\hline 278 & 142.7 & 719.0 & 1214.0 & 857.0 & 0.5 & 554.6 & $10,820.6$ & 18.4 & -17.9 \\
\hline 279 & 121.7 & 660.0 & 911.0 & 783.6 & 0.7 & 414.9 & $13,712.5$ & 26.7 & -17.9 \\
\hline 280 & 144.5 & 883.0 & 1546.0 & 1109.4 & 0.5 & 614.8 & $12,504.5$ & 20.2 & -18.0 \\
\hline 281 & 125.2 & 734.0 & 1335.0 & 905.2 & 0.6 & 393.5 & $13,521.2$ & 23.7 & -18.1 \\
\hline 282 & 120.9 & 90.0 & 1262.0 & 441.7 & 0.7 & 1073.2 & $12,327.9$ & 21.9 & -18.2 \\
\hline 283 & 137.8 & 875.0 & 1186.0 & 1016.9 & 0.5 & 574.6 & $12,270.3$ & 20.1 & -18.2 \\
\hline 284 & 118.9 & 503.0 & 911.0 & 708.7 & 0.7 & 425.1 & $13,655.2$ & 26.8 & -18.3 \\
\hline 285 & 113.1 & 181.0 & 536.0 & 333.4 & 0.9 & 835.6 & $12,756.8$ & 25.1 & -18.4 \\
\hline 286 & 121.5 & 564.0 & 924.0 & 688.3 & 0.7 & 423.7 & $13,614.9$ & 26.8 & -18.4 \\
\hline 287 & 134.9 & 720.0 & 2338.0 & 1037.8 & 0.5 & 588.4 & $12,313.2$ & 19.9 & -18.4 \\
\hline 288 & 142.1 & 855.0 & 1133.0 & 976.3 & 0.5 & 590.4 & $12,557.1$ & 20.5 & -18.4 \\
\hline 289 & 125.2 & 173.0 & 677.0 & 342.0 & 0.8 & 1264.8 & $12,250.5$ & 21.9 & -18.5 \\
\hline 290 & 134.5 & 732.0 & 978.0 & 827.6 & 0.6 & 368.7 & $13,380.9$ & 25.8 & -18.5 \\
\hline 291 & 113.8 & 262.0 & 425.0 & 330.9 & 0.9 & 703.9 & $13,055.5$ & 26.8 & -18.6 \\
\hline 292 & 132.6 & 306.0 & 539.0 & 400.0 & 0.8 & 1010.2 & $12,458.4$ & 21.6 & -18.6 \\
\hline 293 & 121.4 & 525.0 & 997.0 & 672.2 & 0.7 & 425.2 & $13,573.7$ & 26.7 & -18.7 \\
\hline 294 & 139.1 & 875.0 & 1065.0 & 972.3 & 0.6 & 585.9 & $12,319.8$ & 20.3 & -18.7 \\
\hline 295 & 119.9 & 298.0 & 536.0 & 399.7 & 0.8 & 829.1 & $12,607.8$ & 24.3 & -18.9 \\
\hline 296 & 136.3 & 660.0 & 1140.0 & 835.4 & 0.6 & 538.5 & $11,989.7$ & 20.1 & -18.9 \\
\hline 297 & 120.0 & 83.0 & 517.0 & 244.9 & 0.8 & 863.3 & $12,529.8$ & 22.9 & -19.0 \\
\hline 298 & 147.6 & 575.0 & 1067.0 & 797.1 & 0.6 & 500.3 & $11,865.2$ & 20.2 & -19.0 \\
\hline 299 & 149.7 & 718.0 & 1194.0 & 905.6 & 0.6 & 561.6 & $12,094.4$ & 19.9 & -19.1 \\
\hline 300 & 136.1 & 748.0 & 993.0 & 889.6 & 0.6 & 362.1 & $13,455.2$ & 26.9 & -19.1 \\
\hline 301 & 115.4 & 203.0 & 547.0 & 352.2 & 0.8 & 816.3 & $12,660.2$ & 25.2 & -19.1 \\
\hline 302 & 139.9 & 785.0 & 1002.0 & 876.9 & 0.6 & 501.4 & $12,639.6$ & 20.8 & -19.1 \\
\hline 303 & 125.6 & 208.0 & 568.0 & 398.3 & 0.8 & 831.2 & $12,255.0$ & 23.5 & -19.2 \\
\hline 304 & 135.3 & 838.0 & 1160.0 & 972.3 & 0.6 & 414.2 & $13,520.6$ & 23.1 & -19.2 \\
\hline 305 & 131.7 & 313.0 & 598.0 & 473.9 & 0.8 & 804.1 & $12,169.8$ & 22.8 & -19.2 \\
\hline
\end{tabular}


Table A2. Cont.

\begin{tabular}{|c|c|c|c|c|c|c|c|c|c|}
\hline Watershed & Days.below.Zero.Mean & min_elev (m) & max_elev (m) & mean_elev (m) & vapr $(\mathbf{k P a})$ & prec $(\mathrm{mm})$ & $\operatorname{srad}(\mathrm{kJ})$ & $\operatorname{tmax}\left({ }^{\circ} \mathrm{C}\right)$ & $\operatorname{tmin}\left({ }^{\circ} \mathrm{C}\right)$ \\
\hline 306 & 130.9 & 61.0 & 914.0 & 404.6 & 0.7 & 1176.5 & $12,244.6$ & 21.2 & -19.2 \\
\hline 307 & 129.6 & 654.0 & 925.0 & 792.1 & 0.6 & 531.3 & $12,501.4$ & 21.1 & -19.3 \\
\hline 308 & 147.6 & 589.0 & 1379.0 & 826.5 & 0.6 & 518.7 & $11,860.0$ & 20.2 & -19.4 \\
\hline 309 & 139.9 & 842.0 & 1105.0 & 936.1 & 0.6 & 517.0 & $12,636.5$ & 20.6 & -19.4 \\
\hline 310 & 127.3 & 9.0 & 754.0 & 371.1 & 0.7 & 1151.1 & $12,148.3$ & 20.8 & -19.4 \\
\hline 311 & 122.3 & 314.0 & 553.0 & 422.6 & 0.8 & 830.2 & $12,410.4$ & 23.8 & -19.4 \\
\hline 312 & 120.2 & 256.0 & 385.0 & 321.8 & 0.8 & 562.3 & $13,077.7$ & 26.8 & -19.5 \\
\hline 313 & 122.1 & 159.0 & 527.0 & 287.1 & 0.8 & 1073.3 & $12,413.8$ & 22.1 & -19.5 \\
\hline 314 & 147.5 & 568.0 & 1350.0 & 924.8 & 0.5 & 562.6 & $11,896.6$ & 19.6 & -19.5 \\
\hline 315 & 133.9 & 459.0 & 576.0 & 506.2 & 0.8 & 800.0 & $12,255.3$ & 23.1 & -19.5 \\
\hline 316 & 131.6 & 684.0 & 1160.0 & 893.9 & 0.6 & 397.4 & $13,506.9$ & 23.3 & -19.6 \\
\hline 317 & 137.1 & 853.0 & 1050.0 & 932.4 & 0.6 & 384.8 & $13,531.5$ & 23.4 & -19.7 \\
\hline 318 & 148.8 & 655.0 & 1366.0 & 1004.7 & 0.6 & 569.1 & $11,999.5$ & 19.4 & -19.7 \\
\hline 319 & 137.7 & 655.0 & 1002.0 & 786.2 & 0.6 & 476.7 & $12,675.3$ & 21.1 & -19.7 \\
\hline 320 & 127.6 & 905.0 & 1466.0 & 1075.6 & 0.6 & 361.1 & $13,592.8$ & 24.3 & -19.8 \\
\hline 321 & 145.7 & 652.0 & 1045.0 & 827.2 & 0.5 & 508.9 & $10,952.8$ & 18.6 & -19.9 \\
\hline 322 & 150.1 & 729.0 & 1248.0 & 967.7 & 0.6 & 568.4 & $12,030.4$ & 19.6 & -19.9 \\
\hline 323 & 133.1 & 35.0 & 667.0 & 307.0 & 0.7 & 1110.9 & $12,043.0$ & 20.6 & -20.0 \\
\hline 324 & 125.2 & 917.0 & 1439.0 & 1104.4 & 0.6 & 365.3 & $13,572.8$ & 24.4 & -20.0 \\
\hline 325 & 122.7 & 268.0 & 623.0 & 353.3 & 0.8 & 509.1 & $13,087.5$ & 27.1 & -20.1 \\
\hline 326 & 118.9 & 38.0 & 869.0 & 383.3 & 0.8 & 1107.4 & $12,359.6$ & 21.7 & -20.1 \\
\hline 327 & 140.0 & 280.0 & 650.0 & 475.6 & 0.7 & 1067.7 & $12,220.8$ & 21.3 & -20.1 \\
\hline 328 & 139.5 & 148.0 & 650.0 & 348.9 & 0.7 & 1087.6 & $12,091.1$ & 21.0 & -20.2 \\
\hline 329 & 122.4 & 254.0 & 603.0 & 364.0 & 0.8 & 598.9 & $12,912.0$ & 26.0 & -20.2 \\
\hline 330 & 131.3 & 729.0 & 1311.0 & 961.2 & 0.6 & 393.3 & $13,540.0$ & 24.0 & -20.3 \\
\hline 331 & 131.0 & 832.0 & 1466.0 & 1038.1 & 0.6 & 351.7 & $13,598.1$ & 24.8 & -20.3 \\
\hline 332 & 137.5 & 8.0 & 638.0 & 293.2 & 0.7 & 1078.3 & $11,986.8$ & 20.8 & -20.3 \\
\hline 333 & 136.9 & 857.0 & 1439.0 & 1086.2 & 0.6 & 353.0 & $13,583.7$ & 24.8 & -20.4 \\
\hline 334 & 131.4 & 659.0 & 871.0 & $\begin{array}{l}724.5 \\
720.5\end{array}$ & 0.6 & 500.7 & $12,377.7$ & $\begin{array}{l}24.0 \\
20.7\end{array}$ & -20.4 \\
\hline 335 & 143.8 & 682.0 & 788.0 & 737.8 & 0.6 & 482.4 & $12,534.4$ & 21.1 & -20.6 \\
\hline 336 & 138.1 & 155.0 & 780.0 & 364.1 & 0.7 & 1116.6 & $12,057.6$ & 20.9 & -20.6 \\
\hline 337 & 123.7 & 118.0 & 916.0 & 381.7 & 0.7 & 1081.9 & $12,327.5$ & 21.6 & -20.7 \\
\hline 338 & 139.5 & 767.0 & 998.0 & 881.3 & 0.6 & 356.2 & $13,565.7$ & 26.2 & -20.8 \\
\hline 339 & 161.1 & 613.0 & 1036.0 & 776.5 & 0.5 & 457.4 & $11,381.5$ & 19.7 & -20.8 \\
\hline
\end{tabular}


Table A2. Cont.

\begin{tabular}{|c|c|c|c|c|c|c|c|c|c|}
\hline Watershed & Days.below.Zero.Mean & min_elev (m) & max_elev (m) & mean_elev (m) & vapr $(\mathbf{k P a})$ & prec $(\mathrm{mm})$ & $\operatorname{srad}(\mathrm{kJ})$ & $\operatorname{tmax}\left({ }^{\circ} \mathrm{C}\right)$ & $\operatorname{tmin}\left({ }^{\circ} \mathrm{C}\right)$ \\
\hline 340 & 126.5 & 188.0 & 412.0 & 326.1 & 0.8 & 774.4 & $12,409.4$ & 24.0 & -20.8 \\
\hline 341 & 135.5 & 792.0 & 1003.0 & 885.2 & 0.6 & 364.5 & $13,532.4$ & 24.6 & -20.8 \\
\hline 342 & 159.2 & 642.0 & 951.0 & 771.7 & 0.5 & 464.9 & $11,275.3$ & 19.3 & -20.9 \\
\hline 343 & 151.1 & 534.0 & 1216.0 & 746.3 & 0.6 & 537.6 & $11,983.6$ & 20.3 & -21.0 \\
\hline 344 & 148.5 & 741.0 & 880.0 & 787.9 & 0.6 & 346.0 & $13,110.1$ & 23.1 & -21.0 \\
\hline 345 & 140.6 & 539.0 & 777.0 & 648.3 & 0.7 & 404.0 & $13,226.2$ & 24.5 & -21.0 \\
\hline 346 & 127.8 & 242.0 & 472.0 & 345.2 & 0.8 & 490.8 & $12,911.9$ & 26.3 & -21.0 \\
\hline 347 & 155.1 & 123.0 & 894.0 & 552.9 & 0.7 & 1473.8 & $12,162.4$ & 20.3 & -21.0 \\
\hline 348 & 141.5 & 539.0 & 777.0 & 643.3 & 0.7 & 405.0 & $13,222.1$ & 24.5 & -21.0 \\
\hline 349 & 140.4 & 119.0 & 636.0 & 343.2 & 0.7 & 1084.2 & $12,037.6$ & 21.1 & -21.1 \\
\hline 350 & 138.2 & 631.0 & 1016.0 & 730.6 & 0.6 & 516.9 & $12,215.7$ & 20.7 & -21.1 \\
\hline 351 & 164.6 & 454.0 & 1094.0 & 806.7 & 0.5 & 459.8 & $11,277.5$ & 19.6 & -21.2 \\
\hline 352 & 147.1 & 619.0 & 729.0 & 681.0 & 0.6 & 407.7 & $12,617.2$ & 21.3 & -21.3 \\
\hline 353 & 142.5 & 625.0 & 880.0 & 757.5 & 0.6 & 339.1 & $13,194.3$ & 24.0 & -21.3 \\
\hline 354 & 132.6 & 395.0 & 652.0 & 495.0 & 0.7 & 445.1 & $13,007.8$ & 26.1 & -21.4 \\
\hline 355 & 141.5 & 243.0 & 616.0 & 455.0 & 0.7 & 1028.7 & $12,142.5$ & 20.8 & -21.6 \\
\hline 356 & 154.3 & 551.0 & 773.0 & 667.1 & 0.5 & 437.4 & $11,659.7$ & 20.6 & -21.6 \\
\hline 357 & 135.6 & 404.0 & 657.0 & 491.2 & 0.7 & 431.4 & $13,033.6$ & 25.8 & -21.6 \\
\hline 358 & 145.6 & 629.0 & 904.0 & 715.9 & 0.6 & 403.2 & $12,918.2$ & 22.1 & -21.6 \\
\hline 359 & 141.0 & 499.0 & 757.0 & 606.2 & 0.7 & 425.7 & $13,160.8$ & 24.7 & -21.7 \\
\hline 360 & 142.7 & 203.0 & 665.0 & 469.1 & 0.7 & 765.3 & $12,061.4$ & 21.4 & -21.7 \\
\hline 361 & 131.3 & 371.0 & 583.0 & 446.4 & 0.8 & 668.6 & $12,618.9$ & 24.7 & -21.8 \\
\hline 362 & 154.2 & 533.0 & 958.0 & 690.6 & 0.6 & 500.9 & $11,838.0$ & 20.1 & -21.8 \\
\hline 363 & 143.2 & 720.0 & 870.0 & 776.6 & 0.6 & 352.5 & $13,099.8$ & 23.0 & -22.0 \\
\hline 364 & 150.3 & 597.0 & 741.0 & 678.4 & 0.6 & 404.7 & $12,723.4$ & 21.4 & -22.0 \\
\hline 365 & 142.7 & 687.0 & 870.0 & 772.1 & 0.6 & 348.4 & $13,118.9$ & 23.0 & -22.0 \\
\hline 366 & 148.7 & 561.0 & 777.0 & 653.3 & 0.6 & 410.1 & $12,593.0$ & 21.2 & -22.0 \\
\hline 367 & 143.2 & 614.0 & 736.0 & 670.8 & 0.6 & 478.3 & $12,287.3$ & 20.8 & -22.2 \\
\hline 368 & 151.8 & 550.0 & 694.0 & 617.4 & 0.6 & 451.9 & $11,715.6$ & 20.7 & -22.3 \\
\hline 369 & 153.7 & 556.0 & 1008.0 & 727.8 & 0.6 & 512.6 & $11,907.7$ & 19.8 & -22.4 \\
\hline 370 & 134.9 & 303.0 & 560.0 & 404.7 & 0.7 & 682.7 & $12,174.7$ & 23.2 & -22.4 \\
\hline 371 & 158.9 & 555.0 & 746.0 & 642.4 & 0.5 & 433.2 & $11,572.3$ & 20.8 & -22.5 \\
\hline 372 & 158.1 & 437.0 & 734.0 & 566.5 & 0.5 & 458.5 & $11,393.2$ & 21.0 & -22.6 \\
\hline 373 & 143.6 & 669.0 & 855.0 & 759.9 & 0.6 & 364.8 & $13,081.9$ & 22.7 & -22.6 \\
\hline
\end{tabular}


Table A2. Cont.

\begin{tabular}{|c|c|c|c|c|c|c|c|c|c|}
\hline Watershed & Days.below.Zero.Mean & min_elev (m) & max_elev (m) & mean_elev (m) & vapr $(\mathbf{k P a})$ & prec $(\mathrm{mm})$ & $\operatorname{srad}(\mathrm{kJ})$ & $\operatorname{tmax}\left({ }^{\circ} \mathrm{C}\right)$ & $\operatorname{tmin}\left({ }^{\circ} \mathrm{C}\right)$ \\
\hline 374 & 147.7 & 218.0 & 617.0 & 402.7 & 0.7 & 918.4 & $12,070.8$ & 20.4 & -22.6 \\
\hline 375 & 143.5 & 549.0 & 669.0 & 589.0 & 0.7 & 416.7 & $13,081.6$ & 24.0 & -22.7 \\
\hline 376 & 140.5 & 554.0 & 741.0 & 621.6 & 0.6 & 486.8 & $12,192.6$ & 20.5 & -22.7 \\
\hline 377 & 144.1 & 600.0 & 729.0 & 654.0 & 0.6 & 471.3 & $12,322.7$ & 20.8 & -22.8 \\
\hline 378 & 144.7 & 442.0 & 780.0 & 571.9 & 0.7 & 442.3 & $12,966.3$ & 24.0 & -23.0 \\
\hline 379 & 155.5 & 493.0 & 679.0 & 578.1 & 0.7 & 411.6 & $12,932.2$ & 22.7 & -23.0 \\
\hline 380 & 145.9 & 438.0 & 674.0 & 494.6 & 0.7 & 491.9 & $12,784.3$ & 23.8 & -23.0 \\
\hline 381 & 154.0 & 490.0 & 696.0 & 605.0 & 0.7 & 432.7 & $12,839.9$ & 22.8 & -23.0 \\
\hline 382 & 147.7 & 517.0 & 842.0 & 653.3 & 0.7 & 435.8 & $12,958.6$ & 23.3 & -23.1 \\
\hline 383 & 152.9 & 545.0 & 663.0 & 599.5 & 0.6 & 353.8 & $13,070.6$ & 23.0 & -23.1 \\
\hline 384 & 148.0 & 564.0 & 781.0 & 657.8 & 0.6 & 461.4 & $12,237.8$ & 20.2 & -23.1 \\
\hline 385 & 146.5 & 380.0 & 722.0 & 493.0 & 0.7 & 507.7 & $12,759.8$ & 23.6 & -23.2 \\
\hline 386 & 154.5 & 543.0 & 687.0 & 611.3 & 0.5 & 457.5 & $11,632.0$ & 21.0 & -23.2 \\
\hline 387 & 152.1 & 458.0 & 690.0 & 549.3 & 0.7 & 394.5 & $12,920.0$ & 23.0 & -23.2 \\
\hline 388 & 146.7 & 604.0 & 731.0 & 658.0 & 0.6 & 485.2 & $12,215.0$ & 20.4 & -23.3 \\
\hline 389 & 143.5 & 217.0 & 722.0 & 469.4 & 0.7 & 510.2 & $12,708.7$ & 23.7 & -23.3 \\
\hline 390 & 147.1 & 169.0 & 563.0 & 384.7 & 0.7 & 979.5 & $12,212.5$ & 20.7 & -23.3 \\
\hline 391 & 144.5 & 273.0 & 722.0 & 478.7 & 0.7 & 509.5 & $12,715.6$ & 23.6 & -23.3 \\
\hline 392 & 144.5 & 326.0 & 722.0 & 481.8 & 0.7 & 510.0 & $12,725.1$ & 23.6 & -23.4 \\
\hline 393 & 157.2 & 433.0 & 855.0 & 612.8 & 0.5 & 439.4 & $11,433.7$ & 20.9 & -23.5 \\
\hline 394 & 144.1 & 540.0 & 864.0 & 664.7 & 0.6 & 475.4 & $12,172.2$ & 20.0 & -23.5 \\
\hline 395 & 147.9 & 637.0 & 708.0 & 665.5 & 0.6 & 484.7 & $12,264.1$ & 20.7 & -23.5 \\
\hline 396 & 159.1 & 550.0 & 692.0 & 632.7 & 0.6 & 446.7 & $12,712.9$ & 21.9 & -23.6 \\
\hline 397 & 139.9 & 220.0 & 643.0 & 438.4 & 0.7 & 1025.0 & $12,182.2$ & 20.8 & -23.6 \\
\hline 398 & 159.7 & 523.0 & 708.0 & 633.0 & 0.6 & 409.5 & $12,552.8$ & 20.8 & -23.7 \\
\hline 399 & 146.4 & 325.0 & 525.0 & 393.4 & 0.7 & 714.7 & $12,024.6$ & 22.4 & -23.7 \\
\hline 400 & 146.3 & 310.0 & 556.0 & 419.5 & 0.7 & 764.5 & $12,015.2$ & 22.4 & -23.7 \\
\hline 401 & 155.5 & 259.0 & 477.0 & 318.3 & 0.7 & 937.0 & $12,114.1$ & 21.0 & -23.8 \\
\hline 402 & 154.7 & 477.0 & 685.0 & 536.0 & 0.7 & 462.2 & $12,680.7$ & 22.3 & -23.9 \\
\hline 403 & 147.1 & 545.0 & 864.0 & 644.8 & 0.6 & 496.7 & $12,092.4$ & 19.9 & -23.9 \\
\hline 404 & 160.8 & 339.0 & 1075.0 & 693.0 & 0.5 & 447.1 & $11,055.5$ & 20.0 & -23.9 \\
\hline 405 & 137.1 & 232.0 & 405.0 & 328.0 & 0.8 & 558.0 & $12,419.2$ & 23.8 & -23.9 \\
\hline 406 & 146.7 & 349.0 & 525.0 & 406.8 & 0.7 & 742.4 & $11,990.1$ & 22.3 & -23.9 \\
\hline 407 & 149.2 & 337.0 & 465.0 & 382.0 & 0.7 & 687.6 & $12,003.4$ & 22.2 & -24.1 \\
\hline
\end{tabular}


Table A2. Cont.

\begin{tabular}{|c|c|c|c|c|c|c|c|c|c|}
\hline Watershed & Days.below.Zero.Mean & min_elev (m) & max_elev (m) & mean_elev (m) & vapr $(\mathbf{k P a})$ & prec $(\mathrm{mm})$ & $\operatorname{srad}(\mathrm{kJ})$ & $\operatorname{tmax}\left({ }^{\circ} \mathrm{C}\right)$ & $\operatorname{tmin}\left({ }^{\circ} \mathrm{C}\right)$ \\
\hline 408 & 140.9 & 260.0 & 394.0 & 329.1 & 0.7 & 617.6 & $12,367.7$ & 23.4 & -24.1 \\
\hline 409 & 139.4 & 302.0 & 396.0 & 354.5 & 0.7 & 619.8 & $12,449.8$ & 23.3 & -24.2 \\
\hline 410 & 155.9 & 468.0 & 685.0 & 538.9 & 0.7 & 466.7 & $12,624.6$ & 22.0 & -24.2 \\
\hline 411 & 144.3 & 218.0 & 341.0 & 286.0 & 0.7 & 614.6 & $12,400.6$ & 23.3 & -24.2 \\
\hline 412 & 144.6 & 222.0 & 307.0 & 248.6 & 0.8 & 525.6 & $12,599.5$ & 23.8 & -24.2 \\
\hline 413 & 149.7 & 264.0 & 689.0 & 505.3 & 0.7 & 515.5 & $12,492.6$ & 21.9 & -24.4 \\
\hline 414 & 145.7 & 222.0 & 719.0 & 341.6 & 0.7 & 504.9 & $12,564.6$ & 23.2 & -24.4 \\
\hline 415 & 149.3 & 339.0 & 573.0 & 454.0 & 0.7 & 752.4 & $11,976.6$ & 21.8 & -24.4 \\
\hline 416 & 149.9 & 216.0 & 828.0 & 429.1 & 0.7 & 513.9 & $12,474.4$ & 22.2 & -24.5 \\
\hline 417 & 148.4 & 202.0 & 577.0 & 330.8 & 0.7 & 828.1 & $11,999.1$ & 21.0 & -24.5 \\
\hline 418 & 160.1 & 519.0 & 589.0 & 559.9 & 0.6 & 425.5 & $12,613.0$ & 21.8 & -24.6 \\
\hline 419 & 152.1 & 267.0 & 828.0 & 534.9 & 0.7 & 516.2 & $12,476.8$ & 21.8 & -24.6 \\
\hline 420 & 148.7 & 188.0 & 539.0 & 326.5 & 0.7 & 826.3 & $11,930.7$ & 20.5 & -24.7 \\
\hline 421 & 150.7 & 311.0 & 455.0 & 379.2 & 0.7 & 643.0 & $12,099.2$ & 22.2 & -24.7 \\
\hline 422 & 147.9 & 278.0 & 719.0 & 423.3 & 0.7 & 495.8 & $12,577.7$ & 22.8 & -24.7 \\
\hline 423 & 150.3 & 227.0 & 541.0 & 439.7 & 0.7 & 867.4 & $11,949.9$ & 19.4 & -24.8 \\
\hline 424 & 160.1 & 498.0 & 669.0 & 563.0 & 0.6 & 453.2 & $12,508.0$ & 21.6 & -24.8 \\
\hline 425 & 156.5 & 478.0 & 754.0 & 589.4 & 0.6 & 471.1 & $11,959.5$ & 20.0 & -24.9 \\
\hline 426 & 173.1 & 291.0 & 761.0 & 462.3 & 0.5 & 1026.5 & $10,772.8$ & 17.1 & -24.9 \\
\hline 427 & 151.5 & 624.0 & 869.0 & 688.3 & 0.6 & 498.6 & $11,875.5$ & 19.8 & -24.9 \\
\hline 428 & 156.6 & 413.0 & 738.0 & 486.2 & 0.6 & 453.6 & $12,160.9$ & 20.7 & -25.0 \\
\hline 429 & 146.8 & 577.0 & 810.0 & 661.5 & 0.6 & 505.2 & $11,981.4$ & 20.0 & -25.0 \\
\hline 430 & 158.5 & 337.0 & 1059.0 & 594.9 & 0.5 & 435.1 & $10,855.0$ & 20.1 & -25.0 \\
\hline 431 & 159.0 & 407.0 & 601.0 & 471.6 & 0.6 & 463.0 & $12,290.8$ & 20.8 & -25.1 \\
\hline 432 & 159.6 & 435.0 & 780.0 & 632.3 & 0.6 & 518.7 & $12,464.7$ & 21.1 & -25.1 \\
\hline 433 & 156.5 & 523.0 & 751.0 & 623.5 & 0.7 & 500.0 & $12,535.1$ & 21.5 & -25.1 \\
\hline 434 & 157.7 & 354.0 & 625.0 & 469.1 & 0.6 & 423.3 & $12,508.9$ & 22.0 & -25.1 \\
\hline 435 & 155.5 & 588.0 & 751.0 & 657.1 & 0.7 & 503.5 & $12,521.4$ & 21.3 & -25.1 \\
\hline 436 & 160.5 & 497.0 & 661.0 & 574.3 & 0.6 & 484.2 & $12,463.4$ & 21.3 & -25.1 \\
\hline 437 & 143.6 & 540.0 & 867.0 & 636.4 & 0.6 & 495.2 & $12,000.8$ & 20.1 & -25.1 \\
\hline 438 & 145.8 & 187.0 & 532.0 & 362.8 & 0.7 & 769.4 & $11,963.1$ & 21.3 & -25.1 \\
\hline 439 & 159.7 & 298.0 & 811.0 & 535.7 & 0.6 & 537.5 & $12,330.7$ & 21.0 & -25.2 \\
\hline 440 & 152.3 & 207.0 & 489.0 & 329.3 & 0.7 & 825.5 & $11,926.7$ & 20.9 & -25.2 \\
\hline 441 & 159.5 & 466.0 & 593.0 & 506.4 & 0.6 & 451.7 & $12,430.9$ & 21.5 & -25.3 \\
\hline
\end{tabular}


Table A2. Cont.

\begin{tabular}{|c|c|c|c|c|c|c|c|c|c|}
\hline Watershed & Days.below.Zero.Mean & min_elev (m) & max_elev (m) & mean_elev (m) & vapr $(\mathbf{k P a})$ & prec $(\mathrm{mm})$ & $\operatorname{srad}(\mathrm{kJ})$ & $\operatorname{tmax}\left({ }^{\circ} \mathrm{C}\right)$ & $\operatorname{tmin}\left({ }^{\circ} \mathrm{C}\right)$ \\
\hline 442 & 153.6 & 99.0 & 661.0 & 275.5 & 0.7 & 971.8 & $12,078.4$ & 20.7 & -25.3 \\
\hline 443 & 149.8 & 246.0 & 770.0 & 547.4 & 0.6 & 473.1 & $11,722.1$ & 20.1 & -25.3 \\
\hline 444 & 147.9 & 381.0 & 556.0 & 447.6 & 0.7 & 749.6 & $11,922.6$ & 22.5 & -25.4 \\
\hline 445 & 162.3 & 419.0 & 766.0 & 575.6 & 0.6 & 524.2 & $12,353.8$ & 20.7 & -25.5 \\
\hline 446 & 157.5 & 278.0 & 766.0 & 530.1 & 0.6 & 522.2 & $12,392.9$ & 21.2 & -25.5 \\
\hline 447 & 153.2 & 181.0 & 427.0 & 296.3 & 0.7 & 816.3 & $11,893.6$ & 21.0 & -25.7 \\
\hline 448 & 179.6 & 127.0 & 680.0 & 402.9 & 0.5 & 901.9 & $10,509.4$ & 15.6 & -25.7 \\
\hline 449 & 162.0 & 365.0 & 707.0 & 518.1 & 0.6 & 469.4 & $12,329.3$ & 21.2 & -25.7 \\
\hline 450 & 162.5 & 354.0 & 765.0 & 554.3 & 0.6 & 479.6 & $12,256.3$ & 20.9 & -25.7 \\
\hline 451 & 150.4 & 189.0 & 438.0 & 324.3 & 0.7 & 599.0 & $12,120.6$ & 22.1 & -25.8 \\
\hline 452 & 154.8 & 342.0 & 483.0 & 394.0 & 0.7 & 659.4 & $11,972.5$ & 21.8 & -25.8 \\
\hline 453 & 152.6 & 350.0 & 458.0 & 401.8 & 0.7 & 731.5 & $11,875.5$ & 23.1 & -25.9 \\
\hline 454 & 155.1 & 348.0 & 483.0 & 405.4 & 0.7 & 678.0 & $11,920.1$ & 21.8 & -25.9 \\
\hline 455 & 154.3 & 437.0 & 578.0 & 478.5 & 0.7 & 742.5 & $11,897.6$ & 21.7 & -26.0 \\
\hline 456 & 154.9 & 211.0 & 291.0 & 252.2 & 0.7 & 528.1 & $12,340.3$ & 22.5 & -26.0 \\
\hline 457 & 159.5 & 263.0 & 911.0 & 384.2 & 0.5 & 411.8 & $11,231.3$ & 21.1 & -26.0 \\
\hline 458 & 161.3 & 351.0 & 743.0 & 485.8 & 0.5 & 416.6 & $11,019.7$ & 21.0 & -26.2 \\
\hline 459 & 206.7 & 517.0 & 1490.0 & 854.0 & 0.4 & 485.8 & 9836.7 & 17.9 & -26.3 \\
\hline 460 & 151.2 & 244.0 & 838.0 & 514.1 & 0.6 & 430.7 & $11,545.6$ & 20.3 & -26.6 \\
\hline 461 & 153.9 & 270.0 & 665.0 & 502.7 & 0.6 & 450.5 & $11,601.7$ & 20.3 & -26.6 \\
\hline 462 & 152.4 & 261.0 & 581.0 & 369.9 & 0.6 & 418.1 & $11,525.5$ & 20.7 & -26.8 \\
\hline 463 & 180.3 & 60.0 & 408.0 & 225.9 & 0.6 & 801.6 & $11,531.1$ & 19.8 & -27.0 \\
\hline 464 & 158.7 & 366.0 & 468.0 & 407.4 & 0.6 & 694.3 & $11,824.2$ & 21.9 & -27.1 \\
\hline 465 & 196.9 & 895.0 & 1523.0 & 1142.8 & 0.4 & 513.3 & 9804.4 & 17.4 & -27.3 \\
\hline 466 & 175.2 & 261.0 & 1000.0 & 757.3 & 0.4 & 422.9 & $10,925.0$ & 19.0 & -27.3 \\
\hline 467 & 155.3 & 234.0 & 671.0 & 446.5 & 0.6 & 446.4 & $11,431.7$ & 20.3 & -27.3 \\
\hline 468 & 162.9 & 186.0 & 849.0 & 413.3 & 0.5 & 406.0 & $11,245.6$ & 20.8 & -27.6 \\
\hline 469 & 162.7 & 257.0 & 794.0 & 360.0 & 0.5 & 392.3 & $11,104.4$ & 21.3 & -27.7 \\
\hline 470 & 160.5 & 282.0 & 417.0 & 340.6 & 0.6 & 648.4 & $11,794.2$ & 21.7 & -27.9 \\
\hline 471 & 160.5 & 207.0 & 619.0 & 438.9 & 0.6 & 449.8 & $11,321.1$ & 20.5 & -27.9 \\
\hline 472 & 165.5 & 282.0 & 596.0 & 402.7 & 0.5 & 451.5 & $11,246.0$ & 20.1 & -27.9 \\
\hline 473 & 159.8 & -3.0 & 190.0 & 91.9 & 0.6 & 706.1 & $11,752.8$ & 20.7 & -28.2 \\
\hline 474 & 168.9 & 208.0 & 310.0 & 247.3 & 0.6 & 518.4 & $11,936.9$ & 21.8 & -28.3 \\
\hline 475 & 161.5 & 260.0 & 465.0 & 374.8 & 0.6 & 697.3 & $11,747.7$ & 21.6 & -28.4 \\
\hline
\end{tabular}


Table A2. Cont.

\begin{tabular}{|c|c|c|c|c|c|c|c|c|c|}
\hline Watershed & Days.below.Zero.Mean & min_elev (m) & max_elev (m) & mean_elev (m) & vapr $(\mathbf{k P a})$ & prec $(\mathrm{mm})$ & $\operatorname{srad}(\mathrm{kJ})$ & $\operatorname{tmax}\left({ }^{\circ} \mathrm{C}\right)$ & $\operatorname{tmin}\left({ }^{\circ} \mathrm{C}\right)$ \\
\hline 476 & 180.3 & 286.0 & 789.0 & 445.6 & 0.5 & 372.8 & $10,796.2$ & 20.5 & -28.4 \\
\hline 477 & 166.7 & 243.0 & 436.0 & 322.8 & 0.6 & 706.2 & $11,728.3$ & 21.1 & -28.7 \\
\hline 478 & 179.3 & 292.0 & 360.0 & 341.2 & 0.5 & 360.0 & $10,857.7$ & 21.0 & -28.9 \\
\hline 479 & 174.4 & 163.0 & 265.0 & 217.0 & 0.6 & 516.5 & $11,803.9$ & 21.6 & -29.1 \\
\hline 480 & 165.3 & 154.0 & 356.0 & 234.9 & 0.6 & 647.1 & $11,666.7$ & 20.4 & -29.4 \\
\hline 481 & 174.5 & 403.0 & 633.0 & 509.8 & 0.5 & 514.7 & $11,430.5$ & 19.4 & -29.4 \\
\hline 482 & 178.0 & 341.0 & 618.0 & 442.6 & 0.5 & 551.4 & $11,524.2$ & 19.8 & -29.5 \\
\hline 483 & 180.2 & 65.0 & 154.0 & 113.3 & 0.6 & 592.4 & $11,518.6$ & 18.6 & -30.1 \\
\hline 484 & 187.1 & 411.0 & 638.0 & 492.8 & 0.5 & 499.2 & $11,251.4$ & 19.0 & -30.7 \\
\hline 485 & 182.0 & 191.0 & 276.0 & 238.5 & 0.6 & 504.8 & $11,727.6$ & 20.9 & -30.9 \\
\hline 486 & 188.5 & 108.0 & 203.0 & 159.7 & 0.5 & 498.3 & $11,525.1$ & 20.1 & -31.3 \\
\hline 487 & 185.5 & 185.0 & 387.0 & 253.3 & 0.5 & 513.6 & $11,572.0$ & 20.2 & -31.4 \\
\hline 488 & 192.9 & 165.0 & 366.0 & 235.4 & 0.5 & 498.8 & $11,423.1$ & 19.7 & -31.8 \\
\hline 489 & 200.2 & 58.0 & 268.0 & 149.0 & 0.5 & 449.3 & $11,361.6$ & 18.4 & -32.4 \\
\hline 490 & 200.9 & 147.0 & 351.0 & 235.3 & 0.5 & 467.6 & $11,275.8$ & $\begin{array}{l}10.7 \\
18.8\end{array}$ & -32.6 \\
\hline 491 & 202.7 & 55.0 & 251.0 & 159.0 & 0.5 & 448.0 & $11,206.2$ & 17.9 & -32.7 \\
\hline 492 & 0.0 & -27.0 & 39.0 & 9.7 & 2.0 & 1230.0 & $17,244.4$ & 33.3 & 10.4 \\
\hline 493 & 0.0 & -18.0 & 59.0 & 22.7 & 2.0 & 1235.7 & $17,459.4$ & 33.9 & 10.3 \\
\hline 494 & 0.0 & -14.0 & 114.0 & 36.9 & 2.0 & 1282.6 & $17,270.0$ & 33.9 & 10.0 \\
\hline 495 & 0.0 & -28.0 & 63.0 & 11.9 & 2.0 & 1246.5 & $17,198.1$ & 33.3 & 9.9 \\
\hline 496 & 0.0 & -21.0 & 96.0 & 28.0 & 1.9 & 1290.2 & $17,166.6$ & 33.8 & 8.5 \\
\hline 497 & 0.0 & -27.0 & 96.0 & 27.3 & 1.9 & 1298.5 & $17,154.2$ & 33.9 & 8.4 \\
\hline 498 & 0.0 & -33.0 & 93.0 & 23.9 & 1.9 & 1301.5 & $17,000.2$ & 33.8 & 7.6 \\
\hline 499 & 0.3 & -28.0 & 72.0 & 25.8 & 1.8 & 1342.4 & $16,699.5$ & 34.0 & 5.7 \\
\hline 500 & 0.5 & 61.0 & 169.0 & 106.7 & 1.7 & 1047.9 & $16,154.1$ & 35.3 & 3.9 \\
\hline 501 & 0.1 & 715.0 & 726.0 & 721.4 & 1.5 & 653.3 & $17,112.8$ & 35.0 & 3.7 \\
\hline 502 & 0.5 & -19.0 & 140.0 & 70.2 & 1.7 & 1422.7 & $16,435.1$ & 34.1 & 3.6 \\
\hline 503 & 0.7 & 8.0 & 111.0 & 49.7 & 1.7 & 1422.1 & $16,373.3$ & 34.2 & 3.5 \\
\hline 504 & 0.7 & $\begin{array}{l}0.0 \\
4.0\end{array}$ & 140.0 & 80.7 & 1.6 & 1366.0 & $16,348.2$ & 34.1 & 3.4 \\
\hline 505 & 0.3 & -17.0 & 121.0 & 55.5 & 1.7 & 1251.8 & $16,232.4$ & 34.4 & 3.3 \\
\hline 506 & 0.9 & 206.0 & 616.0 & 417.3 & 1.6 & 874.1 & $16,779.6$ & 34.8 & 3.1 \\
\hline 507 & 1.6 & 22.0 & 156.0 & 79.7 & 1.6 & 1512.8 & $16,273.1$ & 33.9 & $\begin{array}{l}0.1 \\
2.7\end{array}$ \\
\hline 508 & 2.3 & 8.0 & 209.0 & 96.6 & 1.6 & 1378.9 & $16,189.5$ & 33.8 & 2.5 \\
\hline 509 & 1.1 & -10.0 & 180.0 & 103.4 & 1.7 & 1606.6 & $16,129.7$ & 33.9 & 2.5 \\
\hline
\end{tabular}


Table A2. Cont.

\begin{tabular}{|c|c|c|c|c|c|c|c|c|c|}
\hline Watershed & Days.below.Zero.Mean & min_elev (m) & max_elev (m) & mean_elev (m) & vapr $(\mathbf{k P a})$ & prec $(\mathrm{mm})$ & $\operatorname{srad}(\mathrm{kJ})$ & $\operatorname{tmax}\left({ }^{\circ} \mathrm{C}\right)$ & $\operatorname{tmin}\left({ }^{\circ} \mathrm{C}\right)$ \\
\hline 510 & 1.9 & -13.0 & 200.0 & 98.9 & 1.6 & 1507.0 & $16,173.4$ & 33.8 & 2.1 \\
\hline 511 & 1.7 & 10.0 & 241.0 & 112.8 & 1.6 & 1111.4 & $16,097.9$ & 34.8 & 2.1 \\
\hline 512 & 0.0 & 7.0 & 1953.0 & 707.8 & 1.0 & 430.6 & $18,401.7$ & 31.0 & 1.9 \\
\hline 513 & 2.7 & 22.0 & 169.0 & 114.6 & 1.6 & 1560.8 & $16,035.9$ & 33.7 & 1.7 \\
\hline 514 & 3.1 & 59.0 & 236.0 & 142.9 & 1.6 & 1062.7 & $16,138.4$ & 34.7 & 1.5 \\
\hline 515 & 2.2 & -23.0 & 208.0 & 95.9 & 1.6 & 1515.9 & $16,148.1$ & 34.2 & 1.4 \\
\hline 516 & 3.5 & 264.0 & 537.0 & 402.8 & 1.4 & 742.2 & $17,051.0$ & 34.7 & 1.1 \\
\hline 517 & 0.0 & 2.0 & 2051.0 & 698.9 & 0.9 & 402.0 & $18,484.1$ & 32.4 & 1.0 \\
\hline 518 & 2.6 & -6.0 & 208.0 & 103.5 & 1.6 & 1492.7 & $16,076.3$ & 34.1 & 0.7 \\
\hline 519 & 2.7 & -20.0 & 206.0 & 79.7 & 1.5 & 1212.5 & $15,985.3$ & 34.2 & 0.7 \\
\hline 520 & 3.8 & 10.0 & 1598.0 & 574.3 & 0.9 & 1592.8 & $14,638.3$ & 21.2 & 0.6 \\
\hline 521 & 3.5 & 363.0 & 752.0 & 602.0 & 1.3 & 626.2 & $17,569.6$ & 34.8 & 0.6 \\
\hline 522 & 4.8 & 193.0 & 497.0 & 348.5 & 1.4 & 813.1 & $16,960.5$ & 35.0 & 0.4 \\
\hline 523 & 5.3 & 43.0 & 200.0 & 113.0 & $\begin{array}{l}1.7 \\
1.5\end{array}$ & 1151.3 & $15,915.0$ & 34.6 & 0.3 \\
\hline 524 & 0.0 & 192.0 & 2071.0 & 975.7 & 0.8 & 564.3 & $18,173.3$ & 26.8 & 0.2 \\
\hline 525 & 4.9 & 194.0 & 454.0 & 329.2 & 1.4 & 804.2 & $16,953.4$ & 35.2 & 0.2 \\
\hline 526 & 0.2 & 18.0 & 1027.0 & 347.7 & 1.0 & 1187.3 & $15,970.2$ & 23.9 & 0.1 \\
\hline 527 & 5.2 & 69.0 & 207.0 & 133.0 & 1.5 & 1460.2 & $15,970.5$ & 33.9 & -0.1 \\
\hline 528 & 0.0 & 226.0 & 1226.0 & 745.2 & 0.9 & 836.1 & $17,088.1$ & 29.3 & -0.3 \\
\hline 529 & 4.5 & 108.0 & 408.0 & 242.9 & 1.4 & 1291.9 & $15,776.4$ & 33.2 & -0.4 \\
\hline 530 & 5.4 & 48.0 & 217.0 & 132.6 & 1.5 & 1455.0 & $15,879.3$ & 33.8 & -0.4 \\
\hline 531 & 6.6 & 103.0 & 397.0 & 236.2 & 1.4 & 932.2 & $16,467.2$ & 35.2 & -0.4 \\
\hline 532 & 5.1 & -28.0 & 226.0 & 47.7 & 1.4 & 1207.5 & $15,534.5$ & 33.6 & -0.5 \\
\hline 533 & 5.9 & 8.0 & 200.0 & 99.6 & 1.5 & 1440.8 & $15,810.0$ & 33.8 & -0.5 \\
\hline 534 & 9.9 & 38.0 & 1872.0 & 766.6 & 0.8 & 1840.6 & $14,333.4$ & 22.1 & -0.5 \\
\hline 535 & 5.2 & 88.0 & 217.0 & 145.5 & 1.5 & 1450.6 & $15,849.7$ & 33.7 & -0.7 \\
\hline 536 & 7.7 & 367.0 & 793.0 & 563.1 & 1.2 & 628.2 & $17,714.6$ & 35.4 & -0.8 \\
\hline 537 & 4.1 & 612.0 & 900.0 & 790.3 & $\begin{array}{l}1.2 \\
1.1\end{array}$ & 461.5 & $18,191.5$ & 35.3 & -1.0 \\
\hline 538 & $\begin{array}{l}4.1 \\
9.0\end{array}$ & 0.0 & 63.0 & 38.6 & $\begin{array}{l}1.1 \\
1.5\end{array}$ & 1388.7 & $15,493.8$ & 33.8 & -1.2 \\
\hline 539 & 6.1 & 117.0 & 538.0 & 218.9 & 1.4 & 1317.7 & $15,685.1$ & 32.9 & -1.3 \\
\hline 540 & 8.9 & 55.0 & 200.0 & 124.0 & 1.5 & 1451.6 & $15,716.7$ & 33.6 & -1.4 \\
\hline 541 & 6.1 & 37.0 & 1048.0 & 208.9 & 1.4 & 1276.4 & $15,716.7$ & 33.0 & -1.4 \\
\hline 542 & 6.2 & 186.0 & 699.0 & 322.2 & 1.4 & 1434.8 & $15,592.5$ & 32.4 & -1.5 \\
\hline 543 & 9.8 & -24.0 & 123.0 & 42.7 & 1.4 & 1203.9 & $15,118.2$ & 33.1 & -1.8 \\
\hline
\end{tabular}


Table A2. Cont.

\begin{tabular}{|c|c|c|c|c|c|c|c|c|c|}
\hline Watershed & Days.below.Zero.Mean & min_elev (m) & max_elev (m) & mean_elev (m) & vapr $(\mathbf{k P a})$ & prec $(\mathrm{mm})$ & $\operatorname{srad}(\mathrm{kJ})$ & $\operatorname{tmax}\left({ }^{\circ} \mathrm{C}\right)$ & $\operatorname{tmin}\left({ }^{\circ} \mathrm{C}\right)$ \\
\hline 544 & 8.4 & 13.0 & 557.0 & 114.2 & 1.4 & 1351.8 & $15,478.4$ & 33.7 & -1.8 \\
\hline 545 & 0.9 & 229.0 & 2673.0 & 1027.9 & 0.8 & 510.7 & $18,219.6$ & 28.7 & -1.9 \\
\hline 546 & 1.8 & -15.0 & 2279.0 & 781.7 & 0.8 & 1467.1 & $15,674.2$ & 24.0 & -2.0 \\
\hline 547 & 9.9 & 89.0 & 441.0 & 237.6 & 1.4 & 1440.9 & $15,514.6$ & 32.9 & -2.0 \\
\hline 548 & 8.6 & -33.0 & 267.0 & 70.5 & 1.3 & 1189.3 & $15,128.5$ & 32.9 & -2.1 \\
\hline 549 & 10.4 & 65.0 & 805.0 & 254.7 & 1.4 & 1311.4 & $15,673.6$ & 33.3 & -2.1 \\
\hline 550 & 10.5 & -23.0 & 267.0 & 87.4 & 1.3 & 1184.5 & $15,143.5$ & 32.8 & -2.1 \\
\hline 551 & 0.2 & 138.0 & 1313.0 & 615.2 & 0.9 & 451.9 & $17,621.5$ & 30.0 & -2.3 \\
\hline 552 & 11.9 & 102.0 & 404.0 & 213.5 & 1.4 & 1070.1 & $15,981.1$ & 34.2 & -2.4 \\
\hline 553 & 10.1 & 263.0 & 794.0 & 443.9 & 1.2 & 644.0 & $17,395.5$ & 36.2 & -2.4 \\
\hline 554 & 14.0 & 120.0 & 387.0 & 223.2 & 1.4 & 1084.8 & $15,940.2$ & 34.2 & -2.5 \\
\hline 555 & 10.5 & 329.0 & 794.0 & 508.5 & 1.2 & 611.2 & $17,599.9$ & 36.1 & -2.5 \\
\hline 556 & 14.3 & 99.0 & 813.0 & 246.2 & 1.4 & 1231.8 & $15,585.7$ & 33.3 & -2.5 \\
\hline 557 & 10.5 & 356.0 & 794.0 & 523.9 & $\begin{array}{l}1.7 \\
1.2\end{array}$ & 603.8 & $17,644.5$ & 36.1 & -2.6 \\
\hline 558 & 6.9 & 78.0 & 1312.0 & 299.8 & 1.3 & 1295.0 & $15,430.6$ & 32.0 & -2.6 \\
\hline 559 & 12.1 & 25.0 & 324.0 & 167.3 & 1.3 & 1158.7 & $15,170.9$ & 32.6 & -2.6 \\
\hline 560 & 10.2 & 157.0 & 1267.0 & 338.8 & 1.3 & 1450.5 & $15,314.7$ & 31.7 & -2.6 \\
\hline 561 & 9.6 & -26.0 & 224.0 & 67.9 & 1.3 & 1147.5 & $15,032.9$ & 32.9 & -2.7 \\
\hline 562 & 13.7 & 150.0 & 791.0 & 232.8 & 1.3 & 1235.5 & $15,519.9$ & 33.2 & -2.7 \\
\hline 563 & 14.3 & 78.0 & 224.0 & 148.2 & 1.4 & 1427.1 & $15,294.4$ & 33.0 & -2.9 \\
\hline 564 & 11.2 & 43.0 & 267.0 & 129.6 & 1.3 & 1143.0 & $15,078.7$ & 32.5 & -2.9 \\
\hline 565 & 10.7 & -18.0 & 224.0 & 77.2 & 1.3 & 1136.1 & $15,028.0$ & 32.8 & -3.0 \\
\hline 566 & 14.3 & 118.0 & 1747.0 & 356.3 & 1.2 & 1233.0 & $15,210.6$ & 31.3 & -3.0 \\
\hline 567 & 21.7 & 17.0 & 2608.0 & 748.7 & 0.8 & 1379.8 & $14,117.2$ & 21.5 & -3.1 \\
\hline 568 & 11.5 & 360.0 & 1076.0 & 713.6 & 1.1 & 556.3 & $17,793.6$ & 35.1 & -3.3 \\
\hline 569 & 9.7 & 133.0 & 1747.0 & 381.9 & 1.2 & 1244.5 & $15,164.3$ & 31.0 & -3.3 \\
\hline 570 & 4.2 & 268.0 & 2279.0 & 1116.8 & 0.7 & 1400.3 & $15,908.9$ & 23.8 & -3.4 \\
\hline 571 & 12.5 & 458.0 & 1076.0 & 767.3 & 1.1 & 535.9 & $17,902.3$ & 34.8 & -3.4 \\
\hline 572 & 20.7 & 173.0 & 411.0 & 280.6 & $\begin{array}{l}1.1 \\
1.3\end{array}$ & 948.6 & $15,981.5$ & 34.0 & -3.5 \\
\hline 573 & 12.2 & 203.0 & 1267.0 & 416.1 & 1.3 & 1504.7 & $15,119.7$ & 30.9 & -3.5 \\
\hline 574 & 10.0 & -19.0 & 194.0 & 69.8 & 1.3 & 1127.6 & $14,837.7$ & 32.2 & -3.7 \\
\hline 575 & 23.3 & 338.0 & 753.0 & 511.8 & 1.2 & 1225.6 & $15,270.8$ & 31.2 & -4.1 \\
\hline 576 & 25.5 & 33.0 & 2824.0 & 927.5 & 0.7 & 1115.7 & $14,655.4$ & 22.4 & -4.2 \\
\hline 577 & 23.7 & 210.0 & 598.0 & 360.6 & 1.2 & 1171.9 & $15,310.7$ & 32.3 & -4.2 \\
\hline
\end{tabular}


Table A2. Cont.

\begin{tabular}{|c|c|c|c|c|c|c|c|c|c|}
\hline Watershed & Days.below.Zero.Mean & min_elev (m) & max_elev (m) & mean_elev (m) & vapr $(\mathrm{kPa})$ & prec $(\mathrm{mm})$ & $\operatorname{srad}(\mathrm{kJ})$ & $\operatorname{tmax}\left({ }^{\circ} \mathrm{C}\right)$ & $\operatorname{tmin}\left({ }^{\circ} \mathrm{C}\right)$ \\
\hline 578 & 25.2 & 178.0 & 779.0 & 448.5 & 1.2 & 1187.1 & $15,206.5$ & 31.4 & -4.3 \\
\hline 579 & 27.0 & 598.0 & 1919.0 & 827.7 & 1.1 & 1525.5 & $15,117.9$ & 28.1 & -4.4 \\
\hline 580 & 23.5 & 631.0 & 1868.0 & 875.7 & 1.1 & 1799.4 & $15,199.2$ & 28.0 & -4.5 \\
\hline 581 & 25.1 & 186.0 & 1247.0 & 395.4 & 1.2 & 1210.0 & $14,862.0$ & 30.5 & -4.5 \\
\hline 582 & 21.7 & 89.0 & 2711.0 & 1149.8 & 0.7 & 1237.8 & $15,462.6$ & 23.5 & -4.6 \\
\hline 583 & 29.4 & 157.0 & 403.0 & 265.4 & 1.2 & 982.8 & $15,684.7$ & 33.7 & -4.7 \\
\hline 584 & 26.1 & 304.0 & 755.0 & 483.1 & 1.2 & 1166.4 & $15,173.3$ & 31.2 & -4.7 \\
\hline 585 & 26.9 & 52.0 & 203.0 & 124.6 & 1.3 & 1345.9 & $14,986.2$ & 32.3 & -4.8 \\
\hline 586 & 19.9 & 523.0 & 892.0 & 679.9 & 1.1 & 579.3 & $17,479.6$ & 34.8 & -4.9 \\
\hline 587 & 26.0 & 87.0 & 1271.0 & 318.9 & 1.2 & 1091.7 & $14,637.7$ & 30.6 & -4.9 \\
\hline 588 & 25.5 & 235.0 & 996.0 & 510.7 & 1.2 & 1454.7 & $14,644.0$ & 29.9 & -4.9 \\
\hline 589 & 31.1 & 143.0 & 1185.0 & 384.4 & 1.2 & 1091.8 & $14,575.4$ & 30.1 & -5.0 \\
\hline 590 & 25.5 & -7.0 & 3066.0 & 1303.7 & 0.7 & 1144.8 & $17,088.5$ & 26.0 & -5.1 \\
\hline 591 & 34.0 & 467.0 & 2005.0 & 982.9 & 1.1 & 1286.6 & $14,677.0$ & 26.9 & -5.5 \\
\hline 592 & 19.5 & 557.0 & 2369.0 & 1143.0 & 0.6 & 877.2 & $13,860.1$ & 18.6 & -5.6 \\
\hline 593 & 41.9 & 324.0 & 2824.0 & 1074.1 & 0.7 & 1004.2 & $14,877.3$ & 22.0 & -5.7 \\
\hline 594 & 27.5 & 568.0 & 1888.0 & 1148.9 & 1.0 & 1643.8 & $14,853.9$ & 26.0 & -5.7 \\
\hline 595 & 27.9 & 271.0 & 1254.0 & 510.0 & 1.2 & 1283.7 & $14,390.7$ & 29.4 & -5.7 \\
\hline 596 & 33.3 & 324.0 & 1421.0 & 646.0 & 1.1 & 1156.1 & $14,285.7$ & 28.7 & -5.9 \\
\hline 597 & 29.6 & 344.0 & 1254.0 & 672.7 & 1.1 & 1252.4 & $14,276.1$ & 28.4 & -5.9 \\
\hline 598 & 35.1 & 81.0 & 381.0 & 226.9 & 1.2 & 1154.7 & $15,188.2$ & 32.3 & -5.9 \\
\hline 599 & 37.7 & 660.0 & 1717.0 & 948.8 & 1.1 & 1255.5 & $14,465.6$ & 26.8 & -6.3 \\
\hline 600 & 25.1 & 546.0 & 1717.0 & 862.9 & 1.1 & 1160.0 & $14,406.5$ & 27.3 & -6.3 \\
\hline 601 & 35.1 & 91.0 & 451.0 & 261.1 & 1.2 & 1149.9 & $15,121.9$ & 31.9 & -6.4 \\
\hline 602 & 35.1 & 128.0 & 451.0 & 291.7 & 1.2 & 1136.5 & $15,080.9$ & 31.6 & -6.5 \\
\hline 603 & 36.7 & 287.0 & 529.0 & 410.6 & 1.2 & 1108.3 & $15,012.7$ & 31.1 & -6.6 \\
\hline 604 & 36.0 & 228.0 & 474.0 & 329.1 & 1.2 & 1138.0 & $15,044.0$ & 31.8 & -6.6 \\
\hline 605 & 34.7 & 90.0 & 483.0 & 298.0 & $\begin{array}{l}1.2 \\
1.2\end{array}$ & 1126.0 & $15,005.1$ & 31.4 & -6.7 \\
\hline 606 & 33.7 & 51.0 & 539.0 & 222.7 & $\begin{array}{l}1.2 \\
1.2\end{array}$ & 1142.7 & $14,976.3$ & 31.6 & -6.7 \\
\hline 607 & 37.9 & 190.0 & 483.0 & 338.9 & 1.2 & 1102.7 & $14,993.2$ & 31.2 & -6.7 \\
\hline 608 & 37.5 & 126.0 & 483.0 & 320.0 & 1.2 & 1106.4 & $14,961.4$ & 31.2 & -6.8 \\
\hline 609 & 47.3 & 469.0 & 1319.0 & 786.7 & 1.1 & 1031.4 & $13,919.0$ & 27.2 & -6.9 \\
\hline 610 & 36.9 & 204.0 & 531.0 & 363.3 & 1.2 & 1089.4 & $14,897.6$ & 31.2 & -6.9 \\
\hline 611 & 43.3 & 197.0 & 1043.0 & 525.4 & 1.1 & 1178.2 & $13,712.5$ & 28.2 & -6.9 \\
\hline
\end{tabular}


Table A2. Cont.

\begin{tabular}{|c|c|c|c|c|c|c|c|c|c|}
\hline Watershed & Days.below.Zero.Mean & min_elev (m) & max_elev (m) & mean_elev (m) & vapr $(\mathrm{kPa})$ & prec $(\mathrm{mm})$ & $\operatorname{srad}(\mathrm{kJ})$ & $\operatorname{tmax}\left({ }^{\circ} \mathrm{C}\right)$ & $\operatorname{tmin}\left({ }^{\circ} \mathrm{C}\right)$ \\
\hline 612 & 38.1 & 174.0 & 531.0 & 351.2 & 1.2 & 1084.6 & $14,878.9$ & 31.2 & -7.0 \\
\hline 613 & 36.1 & 51.0 & 539.0 & 266.0 & 1.2 & 1125.4 & $14,935.5$ & 31.3 & -7.0 \\
\hline 614 & 40.3 & 167.0 & 324.0 & 269.5 & 1.2 & 1152.4 & $14,050.7$ & 30.0 & -7.0 \\
\hline 615 & 34.3 & 130.0 & 1314.0 & 496.3 & 1.0 & 1036.6 & $14,118.4$ & 28.4 & -7.0 \\
\hline 616 & 43.9 & 134.0 & 319.0 & 234.7 & 1.2 & 1169.5 & $14,119.2$ & 29.8 & -7.2 \\
\hline 617 & 39.2 & 95.0 & 527.0 & 280.6 & 1.2 & 1045.4 & $14,714.2$ & 30.8 & -7.4 \\
\hline 618 & 47.8 & 124.0 & 1892.0 & 621.8 & 0.7 & 486.0 & $14,106.2$ & 24.4 & -7.7 \\
\hline 619 & 51.9 & 74.0 & 587.0 & 192.6 & 1.0 & 1052.8 & $13,648.4$ & 29.3 & -7.7 \\
\hline 620 & 45.2 & 168.0 & 319.0 & 246.1 & 1.1 & 1146.4 & $13,942.3$ & 29.5 & -7.8 \\
\hline 621 & 55.6 & 70.0 & 1775.0 & 713.9 & 0.7 & 447.3 & $14,365.0$ & 24.5 & -8.0 \\
\hline 622 & 47.9 & 86.0 & 180.0 & 136.7 & 1.2 & 1123.7 & $14,209.4$ & 30.6 & -8.0 \\
\hline 623 & 44.3 & 203.0 & 484.0 & 314.6 & 1.1 & 976.7 & $15,034.1$ & 31.9 & -8.1 \\
\hline 624 & 50.3 & 89.0 & 196.0 & 151.7 & 1.2 & 1058.6 & $14,328.0$ & 30.5 & -8.3 \\
\hline 625 & 47.5 & 79.0 & 236.0 & 146.3 & $\begin{array}{l}1.2 \\
1.2\end{array}$ & 1069.8 & $14,239.4$ & 30.5 & -8.3 \\
\hline 626 & 51.1 & 159.0 & 401.0 & 271.5 & $\begin{array}{l}1.2 \\
1.1\end{array}$ & 1076.7 & $13,645.5$ & 28.9 & -8.4 \\
\hline 627 & 53.7 & 195.0 & 487.0 & 311.9 & 1.1 & 1112.7 & $13,276.1$ & 28.4 & -8.4 \\
\hline 628 & 54.0 & 160.0 & 1467.0 & 653.3 & 1.0 & 1010.4 & $13,623.9$ & 26.5 & -8.5 \\
\hline 629 & 53.1 & 415.0 & 1472.0 & 808.7 & 1.0 & 1138.7 & $13,742.4$ & 26.3 & -8.5 \\
\hline 630 & 52.1 & 106.0 & 1467.0 & 543.4 & 1.0 & 1005.2 & $13,497.9$ & 26.8 & -8.8 \\
\hline 631 & 55.5 & 188.0 & 372.0 & 273.4 & 1.1 & 1015.9 & $13,314.6$ & 28.3 & -8.9 \\
\hline 632 & 52.1 & 144.0 & 1467.0 & 579.8 & 1.0 & 1024.2 & $13,463.4$ & 26.4 & -9.0 \\
\hline 633 & 46.7 & 160.0 & 332.0 & 242.6 & 1.1 & 1011.7 & $14,745.7$ & 31.1 & -9.0 \\
\hline 634 & 57.8 & 142.0 & 285.0 & 221.9 & 1.1 & 963.6 & $14,420.6$ & 30.6 & -9.0 \\
\hline 635 & 51.0 & 96.0 & 236.0 & 166.7 & 1.2 & 1035.2 & $14,102.5$ & 30.1 & -9.0 \\
\hline 636 & 71.5 & 383.0 & 1448.0 & 717.1 & 1.0 & 1282.4 & $13,348.7$ & 26.0 & -9.0 \\
\hline 637 & 47.5 & 321.0 & 1603.0 & 719.4 & 0.7 & 504.5 & $13,712.9$ & 23.9 & -9.1 \\
\hline 638 & 71.5 & 510.0 & 1448.0 & 784.6 & 1.0 & 1270.8 & $13,355.9$ & 25.5 & -9.2 \\
\hline 639 & 71.5 & 629.0 & 1472.0 & 946.9 & 0.9 & 1219.3 & $13,575.3$ & 24.9 & -9.3 \\
\hline 640 & 63.1 & 752.0 & 1603.0 & 961.1 & 0.7 & 740.9 & $13,615.4$ & 21.5 & -9.4 \\
\hline 641 & 58.3 & 140.0 & 359.0 & 257.9 & 1.1 & 1058.9 & $13,694.0$ & 28.8 & -9.4 \\
\hline 642 & 61.6 & 518.0 & 1448.0 & 994.8 & 0.9 & 1199.4 & $13,337.3$ & 24.2 & -9.5 \\
\hline 643 & 55.8 & 77.0 & 257.0 & 184.1 & 1.2 & 1009.9 & $14,053.4$ & 30.0 & -9.5 \\
\hline 644 & 66.3 & 486.0 & 1475.0 & 990.0 & 0.9 & 1226.3 & $13,338.9$ & 24.4 & -9.5 \\
\hline 645 & 63.8 & 147.0 & 359.0 & 266.3 & 1.1 & 1047.9 & $13,651.0$ & 28.6 & -9.7 \\
\hline
\end{tabular}


Table A2. Cont.

\begin{tabular}{|c|c|c|c|c|c|c|c|c|c|}
\hline Watershed & Days.below.Zero.Mean & min_elev (m) & max_elev (m) & mean_elev (m) & vapr $(\mathbf{k P a})$ & prec $(\mathrm{mm})$ & $\operatorname{srad}(\mathrm{kJ})$ & $\operatorname{tmax}\left({ }^{\circ} \mathrm{C}\right)$ & $\operatorname{tmin}\left({ }^{\circ} \mathrm{C}\right)$ \\
\hline 646 & 63.1 & 170.0 & 323.0 & 247.9 & 1.1 & 1037.4 & $13,682.7$ & 28.8 & -9.7 \\
\hline 647 & 55.7 & 108.0 & 241.0 & 192.8 & 1.2 & 1036.1 & $13,884.7$ & 29.6 & -9.7 \\
\hline 648 & 57.4 & 150.0 & 307.0 & 238.3 & 1.1 & 1001.9 & $14,330.8$ & 30.4 & -9.8 \\
\hline 649 & 54.3 & 113.0 & 257.0 & 193.2 & 1.1 & 1008.5 & $13,984.0$ & 29.8 & -9.8 \\
\hline 650 & 67.5 & 721.0 & 1007.0 & 793.4 & 0.9 & 1213.6 & $13,196.4$ & 25.1 & -9.8 \\
\hline 651 & 67.4 & 130.0 & 466.0 & 300.8 & 1.1 & 976.2 & $13,417.4$ & 28.1 & -9.8 \\
\hline 652 & 66.8 & 222.0 & 359.0 & 293.9 & 1.1 & 1043.7 & $13,574.9$ & 28.4 & -10.0 \\
\hline 653 & 67.5 & 224.0 & 385.0 & 318.8 & 1.1 & 1035.9 & $13,514.5$ & 28.0 & -10.2 \\
\hline 654 & 72.3 & 197.0 & 376.0 & 307.4 & 1.1 & 960.7 & $13,396.7$ & 28.1 & -10.3 \\
\hline 655 & 62.3 & 502.0 & 976.0 & 718.5 & 0.9 & 1083.8 & $13,066.6$ & 25.1 & -10.5 \\
\hline 656 & 65.7 & 229.0 & 376.0 & 286.3 & 1.1 & 983.4 & $13,425.8$ & 28.0 & -10.6 \\
\hline 657 & 17.6 & -35.0 & 1019.0 & 219.7 & 0.9 & 2078.3 & 9709.9 & 16.5 & -1.4 \\
\hline 658 & 8.9 & -21.0 & 1119.0 & 221.7 & 1.0 & 2143.4 & $11,357.7$ & 20.5 & -2.8 \\
\hline 659 & 6.4 & 8.0 & 1150.0 & 253.0 & 0.9 & 1768.9 & $11,671.4$ & 21.0 & -2.9 \\
\hline 660 & $\begin{array}{l}0.7 \\
10.7\end{array}$ & 11.0 & 2169.0 & 464.1 & 0.9 & 3121.6 & $11,241.4$ & 18.3 & -3.2 \\
\hline 661 & 50.0 & 92.0 & 4363.0 & 729.6 & 0.8 & 1944.2 & $12,047.2$ & 19.1 & -4.2 \\
\hline 662 & 17.9 & 28.0 & 2084.0 & 776.1 & 0.8 & 2840.0 & $11,338.5$ & 17.3 & -4.5 \\
\hline 663 & 20.9 & -27.0 & 4313.0 & 875.1 & 0.7 & 1852.0 & $12,105.0$ & 18.9 & -4.8 \\
\hline 664 & 33.7 & -24.0 & 3263.0 & 654.2 & 0.8 & 1591.2 & $11,650.7$ & 18.8 & -4.9 \\
\hline 665 & 41.6 & 69.0 & 2114.0 & 1110.1 & 0.7 & 2533.7 & $11,454.9$ & 15.6 & -5.1 \\
\hline 666 & 66.1 & -22.0 & 2365.0 & 739.8 & 0.8 & 2007.3 & $11,976.0$ & 19.0 & -5.4 \\
\hline 667 & 41.6 & 196.0 & 2114.0 & 1166.5 & 0.7 & 2597.2 & $11,473.1$ & 15.4 & -5.4 \\
\hline 668 & 46.7 & -26.0 & 3701.0 & 771.7 & 0.7 & 1942.7 & $12,278.5$ & 18.9 & -5.5 \\
\hline 669 & 55.1 & 171.0 & 3116.0 & 1092.0 & 0.7 & 1644.4 & $13,945.1$ & 18.9 & -5.5 \\
\hline 670 & 69.4 & 73.0 & 3693.0 & 957.3 & 0.7 & 1976.6 & $12,417.8$ & 18.1 & -6.0 \\
\hline 671 & 36.7 & 262.0 & 3116.0 & 1174.9 & 0.6 & 1609.1 & $13,987.6$ & 18.6 & -6.0 \\
\hline 672 & 83.7 & 308.0 & 3693.0 & 1238.3 & 0.6 & 1846.9 & $12,535.6$ & 17.0 & -7.1 \\
\hline 673 & 47.7 & -20.0 & 2623.0 & 1154.7 & 0.6 & 1576.7 & $11,833.1$ & 16.8 & -7.5 \\
\hline 674 & 85.8 & -33.0 & 3219.0 & 1113.2 & 0.6 & 1573.2 & $\begin{array}{l}11,000.1 \\
12,020.3\end{array}$ & $\begin{array}{l}10.0 \\
17.5\end{array}$ & -8.1 \\
\hline 675 & 116.3 & 72.0 & 3160.0 & 1144.4 & 0.6 & 1916.1 & $12,109.6$ & 17.2 & -8.3 \\
\hline 676 & 110.9 & 36.0 & 3219.0 & 1206.9 & 0.6 & 1559.3 & $12,095.3$ & 17.1 & -8.9 \\
\hline 677 & 128.7 & 18.0 & 1881.0 & 839.0 & 0.6 & 2244.7 & 9594.1 & 14.4 & -9.7 \\
\hline 678 & 76.7 & 17.0 & 2735.0 & 1377.6 & 0.5 & 1370.2 & $11,176.6$ & 15.8 & -10.7 \\
\hline 679 & 0.0 & 1343.0 & 5473.0 & 2300.3 & 0.8 & 383.1 & $17,379.4$ & 27.3 & -0.4 \\
\hline
\end{tabular}


Table A2. Cont.

\begin{tabular}{|c|c|c|c|c|c|c|c|c|c|}
\hline Watershed & Days.below.Zero.Mean & min_elev (m) & max_elev (m) & mean_elev (m) & vapr $(\mathbf{k P a})$ & prec $(\mathrm{mm})$ & $\operatorname{srad}(\mathrm{kJ})$ & $\operatorname{tmax}\left({ }^{\circ} \mathrm{C}\right)$ & $\operatorname{tmin}\left({ }^{\circ} \mathrm{C}\right)$ \\
\hline 680 & 0.9 & 1272.0 & 2830.0 & 1529.5 & 0.8 & 521.4 & $19,198.4$ & 33.9 & -2.1 \\
\hline 681 & 5.9 & 886.0 & 2558.0 & 1264.7 & 0.8 & 363.5 & $19,046.0$ & 34.0 & -2.8 \\
\hline 682 & 5.9 & 387.0 & 2389.0 & 1105.7 & 0.6 & 141.5 & $19,455.9$ & 34.9 & -4.3 \\
\hline 683 & 13.0 & 1035.0 & 2940.0 & 2000.0 & 0.7 & 467.6 & $19,143.1$ & 29.8 & -5.7 \\
\hline 684 & 14.4 & 1214.0 & 3601.0 & 2007.6 & 0.7 & 450.9 & $19,105.4$ & 29.9 & -6.2 \\
\hline 685 & 40.7 & 617.0 & 4254.0 & 1205.8 & 0.6 & 751.8 & $15,602.6$ & 24.6 & -7.9 \\
\hline 686 & 47.7 & 1303.0 & 2618.0 & 1753.6 & 0.7 & 410.0 & $17,808.2$ & 30.0 & -8.5 \\
\hline 687 & 29.7 & 1042.0 & 3457.0 & 2058.4 & 0.6 & 557.1 & $19,122.3$ & 27.8 & -8.6 \\
\hline 688 & 48.9 & 1497.0 & 3536.0 & 1992.6 & 0.7 & 444.1 & $18,552.7$ & 28.0 & -9.1 \\
\hline 689 & 36.9 & 1271.0 & 3446.0 & 1890.4 & 0.5 & 417.3 & $17,452.3$ & 26.2 & -9.5 \\
\hline 690 & 28.8 & 1038.0 & 3298.0 & 2074.9 & 0.6 & 458.3 & $19,234.0$ & 28.5 & -9.6 \\
\hline 691 & 21.5 & 1241.0 & 3294.0 & 2093.4 & 0.6 & 443.3 & $19,328.8$ & 28.9 & -9.9 \\
\hline 692 & 87.5 & 945.0 & 2697.0 & 1520.9 & 0.5 & 478.1 & $14,769.5$ & 21.0 & -10.1 \\
\hline 693 & 75.8 & 603.0 & 2559.0 & 1379.4 & 0.6 & 502.2 & $14,576.7$ & 21.1 & -10.2 \\
\hline 694 & 94.7 & 775.0 & 2449.0 & 1450.1 & 0.6 & 503.6 & $14,666.9$ & 20.8 & -10.3 \\
\hline 695 & 41.1 & 1303.0 & 3730.0 & 2052.6 & 0.4 & 327.6 & $17,702.5$ & 26.2 & -10.3 \\
\hline 696 & 101.0 & 1301.0 & 2917.0 & 1879.8 & 0.5 & 334.3 & $15,695.1$ & 23.3 & -10.4 \\
\hline 697 & 86.7 & 1185.0 & 2672.0 & 1546.1 & 0.6 & 651.0 & $15,273.4$ & 21.5 & -10.9 \\
\hline 698 & 98.8 & 1239.0 & 2512.0 & 1597.3 & 0.5 & 496.3 & $15,458.9$ & 22.3 & -11.1 \\
\hline 699 & 30.7 & 1418.0 & 3294.0 & 2262.6 & 0.6 & 456.6 & $19,268.1$ & 27.7 & -11.3 \\
\hline 700 & 92.5 & 1235.0 & 2672.0 & 1571.8 & 0.6 & 588.4 & $15,293.5$ & 21.8 & -11.4 \\
\hline 701 & 78.9 & 795.0 & 3253.0 & 1706.6 & 0.5 & 320.7 & $16,182.4$ & 25.6 & -11.5 \\
\hline 702 & 127.6 & 872.0 & 2867.0 & 1727.9 & 0.5 & 519.1 & $14,566.2$ & 19.9 & -11.6 \\
\hline 703 & 66.3 & 1718.0 & 4019.0 & 2260.4 & 0.6 & 446.4 & $17,935.2$ & 26.1 & -11.7 \\
\hline 704 & 81.3 & 1272.0 & 2381.0 & 1570.8 & 0.5 & 376.2 & $14,951.1$ & 21.6 & -11.7 \\
\hline 705 & 59.3 & 1910.0 & 3382.0 & 2254.8 & 0.6 & 341.2 & $18,721.0$ & 27.4 & -11.8 \\
\hline 706 & 54.9 & 1739.0 & 2790.0 & 2131.5 & 0.6 & 328.6 & $18,559.7$ & 28.5 & -12.1 \\
\hline 707 & 72.6 & 1169.0 & 3502.0 & 2020.9 & 0.5 & 258.7 & $17,365.9$ & 28.3 & -12.1 \\
\hline 708 & 111.4 & 624.0 & 3162.0 & 1563.0 & 0.5 & 542.8 & $15,034.1$ & 22.1 & -12.6 \\
\hline 709 & 87.1 & 923.0 & 3028.0 & 1742.2 & 0.5 & 397.9 & $13,946.9$ & 19.3 & -12.6 \\
\hline 710 & 124.7 & 767.0 & 3112.0 & 1787.6 & 0.5 & 516.4 & $15,353.9$ & 22.4 & -12.6 \\
\hline 711 & 110.8 & 1497.0 & 2986.0 & 2039.6 & 0.4 & 382.7 & $16,291.0$ & 23.8 & -12.7 \\
\hline 712 & 110.8 & 1685.0 & 2736.0 & 2029.3 & 0.4 & 381.2 & $16,302.5$ & 24.1 & -12.8 \\
\hline 713 & 104.3 & 1359.0 & 3172.0 & 1896.2 & 0.5 & 361.4 & $13,927.8$ & 19.9 & -12.9 \\
\hline
\end{tabular}


Table A2. Cont.

\begin{tabular}{|c|c|c|c|c|c|c|c|c|c|}
\hline Watershed & Days.below.Zero.Mean & min_elev (m) & max_elev (m) & mean_elev (m) & vapr $(\mathbf{k P a})$ & prec $(\mathrm{mm})$ & $\operatorname{srad}(\mathrm{kJ})$ & $\operatorname{tmax}\left({ }^{\circ} \mathrm{C}\right)$ & $\operatorname{tmin}\left({ }^{\circ} \mathrm{C}\right)$ \\
\hline 714 & 118.1 & 725.0 & 3162.0 & 1701.7 & 0.5 & 576.7 & $14,949.9$ & 20.8 & -13.0 \\
\hline 715 & 90.8 & 1202.0 & 3028.0 & 1931.7 & 0.5 & 407.2 & $14,064.6$ & 18.6 & -13.0 \\
\hline 716 & 84.8 & 770.0 & 2779.0 & 1220.0 & 0.6 & 357.4 & $13,748.5$ & 24.8 & -13.0 \\
\hline 717 & 129.1 & 990.0 & 3112.0 & 1944.9 & 0.4 & 543.1 & $15,163.2$ & 20.7 & -13.1 \\
\hline 718 & 89.2 & 1266.0 & 2794.0 & 1732.6 & 0.5 & 432.7 & $13,773.5$ & 22.0 & -13.1 \\
\hline 719 & 121.5 & 793.0 & 3162.0 & 1789.2 & 0.5 & 584.1 & $14,893.4$ & 19.9 & -13.2 \\
\hline 720 & 80.5 & 973.0 & 2997.0 & 1440.0 & 0.5 & 387.7 & $13,905.9$ & 24.6 & -13.3 \\
\hline 721 & 101.7 & 941.0 & 2819.0 & 1367.3 & 0.5 & 400.6 & $13,523.2$ & 22.2 & -13.4 \\
\hline 722 & 121.5 & 920.0 & 2690.0 & 1767.2 & 0.5 & 619.3 & $14,733.6$ & 19.5 & -13.4 \\
\hline 723 & 121.5 & 1413.0 & 2690.0 & 1806.3 & 0.5 & 633.2 & $14,620.2$ & 19.0 & -13.6 \\
\hline 724 & 98.4 & 1125.0 & 2590.0 & 1451.1 & 0.5 & 592.6 & $13,407.1$ & 20.2 & -13.7 \\
\hline 725 & 102.3 & 2088.0 & 3385.0 & 2574.0 & 0.4 & 443.4 & $17,839.1$ & 23.1 & -13.7 \\
\hline 726 & 110.5 & 918.0 & 3107.0 & 2154.0 & 0.4 & 495.7 & $14,553.0$ & 18.3 & -13.8 \\
\hline 727 & 89.4 & 1022.0 & 2831.0 & 1651.3 & 0.5 & 472.2 & $13,687.4$ & 20.0 & -13.8 \\
\hline 728 & 105.8 & 1154.0 & 2661.0 & 1429.5 & 0.5 & 423.9 & $13,444.1$ & 21.6 & -14.0 \\
\hline 729 & 107.5 & 1173.0 & 3755.0 & 2162.5 & 0.4 & 417.5 & $14,558.2$ & 21.0 & -14.2 \\
\hline 730 & 102.1 & 1038.0 & 2661.0 & 1315.1 & 0.5 & 419.5 & $13,465.3$ & 22.1 & -14.4 \\
\hline 731 & 131.7 & 1797.0 & 3221.0 & 2369.6 & 0.4 & 477.8 & $14,876.1$ & 17.7 & -14.5 \\
\hline 732 & 102.7 & 1959.0 & 3611.0 & 2226.8 & 0.5 & 324.7 & $15,545.4$ & 23.4 & -14.6 \\
\hline 733 & 141.1 & 1711.0 & 4060.0 & 2688.9 & 0.4 & 391.3 & $15,046.7$ & 17.8 & -14.6 \\
\hline 734 & 107.9 & 1408.0 & 3684.0 & 2239.3 & 0.4 & 325.0 & $14,704.5$ & 20.0 & -14.8 \\
\hline 735 & 125.9 & 1946.0 & 3908.0 & 2503.9 & 0.4 & 487.0 & $15,640.0$ & 21.1 & -15.1 \\
\hline 736 & 112.1 & 1515.0 & 3628.0 & 2174.2 & 0.5 & 385.8 & $16,397.8$ & 25.6 & -15.2 \\
\hline 737 & 102.3 & 802.0 & 2661.0 & 1155.8 & 0.6 & 381.0 & $13,541.1$ & 23.6 & -15.2 \\
\hline 738 & 131.7 & 1890.0 & 3145.0 & 2220.1 & 0.4 & 478.0 & $14,880.7$ & 18.6 & -15.4 \\
\hline 739 & 119.5 & 1728.0 & 3335.0 & 2151.2 & 0.5 & 322.1 & $16,013.7$ & 24.8 & -15.8 \\
\hline 740 & 130.0 & 1874.0 & 3978.0 & 2254.1 & 0.5 & 271.3 & $15,993.8$ & 23.4 & -15.8 \\
\hline 741 & 144.5 & 1379.0 & 3645.0 & 2435.6 & 0.4 & 607.5 & $14,165.5$ & 18.0 & -15.9 \\
\hline 742 & 99.2 & 2044.0 & 3815.0 & 2603.6 & $\begin{array}{l}0.4 \\
0.6\end{array}$ & 616.5 & $17,812.7$ & $\begin{array}{l}10.0 \\
23.7\end{array}$ & -16.3 \\
\hline 743 & 133.9 & 1906.0 & 2723.0 & 2137.2 & 0.5 & 484.0 & $15,171.8$ & 22.3 & -16.4 \\
\hline 744 & 142.4 & 1437.0 & 3345.0 & 1984.9 & 0.5 & 577.2 & $14,589.5$ & 21.6 & -16.6 \\
\hline 745 & 141.9 & 1546.0 & 3645.0 & 2537.9 & 0.4 & 614.7 & $14,227.1$ & 17.5 & -16.7 \\
\hline 746 & 154.0 & 1942.0 & 3740.0 & 2499.2 & 0.4 & 627.4 & $14,603.7$ & 18.1 & -16.8 \\
\hline 747 & 155.0 & 1511.0 & 3264.0 & 2039.1 & 0.5 & 627.4 & $14,495.7$ & 21.2 & -17.0 \\
\hline
\end{tabular}


Table A2. Cont.

\begin{tabular}{|c|c|c|c|c|c|c|c|c|c|}
\hline Watershed & Days.below.Zero.Mean & min_elev (m) & max_elev (m) & mean_elev (m) & vapr $(\mathbf{k P a})$ & prec $(\mathrm{mm})$ & $\operatorname{srad}(\mathbf{k J})$ & $\operatorname{tmax}\left({ }^{\circ} \mathrm{C}\right)$ & $\operatorname{tmin}\left({ }^{\circ} \mathrm{C}\right)$ \\
\hline 748 & 167.9 & 2059.0 & 3091.0 & 2495.1 & 0.4 & 665.6 & $14,493.4$ & 18.3 & -17.3 \\
\hline 749 & 144.2 & 1979.0 & 4118.0 & 2477.9 & 0.4 & 340.4 & $15,424.4$ & 20.6 & -17.4 \\
\hline 750 & 148.3 & 1979.0 & 4283.0 & 3009.7 & 0.4 & 525.5 & $16,624.6$ & 20.5 & -19.3 \\
\hline 751 & 153.3 & 2331.0 & 4181.0 & 3115.2 & 0.4 & 524.6 & $16,293.0$ & 19.3 & -19.4 \\
\hline
\end{tabular}




\section{References}

1. Brennan, D. Water policy reform in Australia: Lessons from the Victorian seasonal water market. Aust. J. Agric. Resour. Econ. 2006, 50, 403-423. [CrossRef]

2. Schröter, D.; Cramer, W.; Leemans, R.; Prentice, C.I.; Araújo, M.B.; Arnell, N.W.; Bondeau, A.; Bugmann, H.; Carter, T.R.; Gracia, C.A.; et al. Ecosystem service supply and vulnerability to global change in Europe. Science 2005, 310, 1333-1337. [CrossRef] [PubMed]

3. Allan, J.D. Landscapes and riverscapes: The influence of land use on stream ecosystems. Annu. Rev. Ecol. Evol. Syst. 2004, 35, 257-284. [CrossRef]

4. Pereira, D.D.R.; Martinez, M.A.; Pruski, F.F.; Silva, D.D.D. Hydrological simulation in a basin of typical tropical climate and soil using the SWAT model part I: Calibration and validation tests. J. Hydrol. Reg. Stud. 2016, 7, 14-37. [CrossRef]

5. Xue, L.; Yang, F.; Yang, C.; Wei, G.; Li, W.; He, X. Hydrological simulation and uncertainty analysis using the improved TOPMODEL in the arid Manas River basin, China. Sci. Rep. 2018, 8, 452. [CrossRef] [PubMed]

6. Canqiang, Z.; Wenhua, L.; Biao, Z.; Moucheng, L. Water yield of Xitiaoxi River Basin based on INVEST modeling. J. Resour. Ecol. 2012, 3, 50-54. [CrossRef]

7. USDA Agricultural Research Service. SWAT-Soil and Water Assessment Tool. Texas A\&M AgriLife Research. 2018. Available online: https:// data.nal.usda.gov/dataset/swat-soil-and-water-assessment-tool (accessed on 20 September 2018).

8. Krysanova, V.; Wechsung, F.; Arnold, J.; Srinivasan, R.; Williams, J. PIK Report Nr. 69 "SWIM (Soil and Water Integrated Model), User Manual"; Potsdam Institute for Climate Impact Research (PIK): Potsdam, Germany, 2002; 39p.

9. Refsgaard, J.C.; Sluijs, J.P.V.D.; Brown, J.; Keu, P.V.D. A framework for dealing with uncertainty due to model structure error. Adv. Water Resour. 2006, 29, 1586-1597. [CrossRef]

10. Matott, L.S.; Babendreier, J.E.; Purucker, S.T. Evaluating uncertainty in integrated environmental models: A review of concepts and tools. Water Resour. Res. 2009, 45, W06421. [CrossRef]

11. Vormoor, K.; Heistermann, M.; Bronstert, A.; Lawrence, D. Hydrological model parameter (in) stability- “Crash testing" the HBV model under contrasting flood seasonality conditions. Hydrol. Sci. J. 2018, 63, 991-1007. [CrossRef]

12. Bronstert, A. Rainfall-runoff modelling for assessing impacts of climate and land-use change. Hydrol. Process. 2004, 18, 567-570. [CrossRef]

13. Blöschl, G.; Montanari, A. Climate change impacts-Throwing the dice? Hydrol. Process. 2010, $24,374-381$. [CrossRef]

14. Vigerstol, K.L.; Aukema, J.E. A comparison of tools for modeling freshwater ecosystem services. J. Environ. Manag. 2011, 92, 2403-2409. [CrossRef] [PubMed]

15. Sharp, R.; Tallis, H.T.; Ricketts, T.; Guerry, A.D.; Ennaanay, D.; Wolny, S.; Olwero, N.; Vigerstol, K.; Pennington, D.; Mendoza, G.; et al. InVEST 3.0 User's Guide: The Natural Capital Project; Stanford University: Stanford, CA, USA, 2016.

16. Ochoa, V.; Urbina-Cardona, N. Tools for spatially modeling ecosystem services: Publication trends, conceptual reflections and future challenges. Ecosyst. Serv. 2017, 26, 155-169. [CrossRef]

17. Nelson, E.; Mendoza, G.; Regetz, J.; Polasky, S.; Tallis, H.; Cameron, D.; Chan, K.M.; Daily, G.C.; Goldstein, J.; Kareiva, P.M.; et al. Modeling multiple ecosystem services, biodiversity conservation, commodity production, and tradeoffs at landscape scales. Front. Ecol. Environ. 2009, 7, 4-11. [CrossRef]

18. Goldman, R.L.; Benitez, S.; Calvache, A.; Davidson, S.; Ennaanay, D.; McKenzie, E.; Tallis, H. TEEBcase: Water Funds for Conservation of Ecosystem Services in Watersheds. Colombia. 2010. Available online: http:/ / www.teebweb.org/ (accessesd on 15 May 2018).

19. Fu, Q.; Li, B.; Hou, Y.; Bi, X.; Zhang, X. Effects of land use and climate change on ecosystem services in Central Asia's arid regions: A case study in Altay Prefecture, China. Sci. Total Environ. 2017, 607, 633-646. [CrossRef] [PubMed]

20. Trisurat, Y.; Aekakkararungroj, A.; Ma, H.; Johnston, J.M. Basin-wide impacts of climate change on ecosystem services in the Lower Mekong Basin. Ecol. Res. 2018, 33, 73-86. [CrossRef] [PubMed] 
21. Redhead, J.W.; Stratford, C.; Sharps, K.; Jones, L.; Ziv, G.; Clarke, D.; Oliver, T.H.; Bullock, J.M. Empirical validation of the InVEST water yield ecosystem service model at a national scale. Sci. Total Environ. 2016, 569, 1418-1426. [CrossRef] [PubMed]

22. Hengl, T.; de Jesus, J.M.; Heuvelink, G.B.M.; Gonzalez, M.R.; Kilibarda, M.; Blagotić, A.; Shangguan, W.; Wright, M.N.; Geng, X.; Bauer-Marschallinger, B.; et al. SoilGrids250m: Global gridded soil information based on machine learning. PLoS ONE 2017, 12, e0169748. [CrossRef] [PubMed]

23. Broxton, P.D.; Zeng, X.; Sulla-Menashe, D.; Troch, P.A. A Global Land Cover Climatology Using MODIS Data. J. Appl. Meteorol. Climatol. 2014, 53, 1593-1605. [CrossRef]

24. Lehner, B.; Verdin, K.; Jarvis, A. New Global Hydrography Derived from Spaceborne Elevation Data. EOS Trans. Am. Geophys. Union 2011, 89, 93-94. [CrossRef]

25. GDAL/OGR Contributors. GDAL/OGR Geospatial Data Abstraction Software Library. Open Source Geospatial Foundation. 2018. Available online: https://www.gdal.org/ (accessed on 10 April 2018).

26. Global Runoff Data Centre Watershed Boundaries of GRDC Stations/Global Runoff Data Centre. 2011. Available online: https:/ /www.bafg.de/GRDC/EN/02_srvcs/22_gslrs/222_WSB/watershedBoundaries. html (accessed on 10 April 2018).

27. Darand, M.; Daneshvar, M.R.M. Regionalization of precipitation regimes in Iran using principal component analysis and hierarchical clustering analysis. Environ. Process. 2014, 1, 517-532. [CrossRef]

28. Benito, X.; Fritz, S.C.; Steinitz-Kannan, M.; Vélez, M.I.; McGlue, M.M. Lake regionalization and diatom metacommunity structuring in tropical South America. Ecol. Evol. 2018, 8, 7865-7878. [CrossRef] [PubMed]

29. Oksanen, J.; Blanchet, F.G.; Friendly, M.; Kindt, R.; Legendre, P.; McGlinn, D.; Minchin, P.R.; O’Hara, R.B.; Simpson, G.L.; Solymos, P.; et al. Vegan: Community Ecology Package. R Package Version 2.4-3. 2017. Available online: https:/ /CRAN.R-project.org/package=vegan (accessed on 10 April 2018).

30. Jackson, D.A. Stopping rules in principal components analysis: A comparison of heuristical and statistical approaches. Ecology 1993, 74, 2204-2214. [CrossRef]

31. Maechler, M.; Rousseeuw, P.; Struyf, A.; Hubert, M.; Hornik, K. Cluster: Cluster Analysis Basics and Extensions. R Package Version 2.0.6. 2017. Available online: https://cran.r-project.org/web/packages / cluster/ (accessed on 10 April 2018).

32. R Core Team. R: A Language and Environment for Statistical Computing; R Foundation for Statistical Computing: Vienna, Austria, 2017; Available online: https:/ / www.R-project.org/ (accessed on 10 April 2018).

33. Huss, M.; Bookhagen, B.; Huggel, C.; Jacobsen, D.; Bradley, R.S.; Clague, J.J.; Vuille, M.; Buytaert, W.; Cayan, D.R.; Greenwood, G.; et al. Toward mountains without permanent snow and ice. Earths Future 2017, 5, 418-435. [CrossRef]

34. Anderson, E. Snow Accumulation and Ablation Model—SNOW-17; US National Weather Service: Silver Spring, MD, USA, 2006.

35. Rivas-Martínez, S.; Rivas-Sáenz, S.; Penas, A.; Costa, M.; Sanchéz-Mata, D. Computerized Bioclimatic Maps of the World: Bioclimates of North America. Draf Map Series of April. 2010. Available online: http:/ / www.globalbioclimatics.org/form/maps.htm (accessed on 20 April 2018).

36. Abudu, S.; Sheng, Z.-P.; Cui, C.-L.; Saydi, M.; Sabzi, H.-Z.; King, J.P. Integration of aspect and slope in snowmelt runoff modeling in a mountain watershed. Water Sci. Eng. 2016, 9, 265-273. [CrossRef]

37. McGlynn, B.L.; Blöschl, G.; Borga, M.; Bormann, H.; Hurkmans, R.; Komma, J.; Nandagiri, L.; Uijlenhoet, R.; Wagener, T. A data acquisition framework for prediction of runoff in un-gauged basins. In Runoff Prediction in Ungauged Basins: Synthesis across Processes, Places and Scales; Blöschl, G., Sivapalan, M., Wagener, T., Viglione, A., Savenije, H., Eds.; Cambridge University Press: Cambridge, UK, 2013; pp. 29-52. [CrossRef]

38. Zhou, X.; Zhang, Y.; Wang, Y.; Zhang, H.; Vaze, J.; Zhang, L.; Yang, Y.; Zhou, Y. Benchmarking global land surface models against the observed mean annual runoff from 150 large basins. J. Hydrol. 2012, 470-471, 269-279. [CrossRef]

39. Sánchez-Canales, M.; López Benito, A.; Passuello, A.; Terrado, M.; Ziv, G.; Acuña, V.; Schuhmacher, M.; Elorza, F.J. Sensitivity analysis of ecosystem service valuation in a Mediterranean watershed. Sci. Total Environ. 2012, 440, 140-153. [CrossRef] [PubMed]

40. Boithias, L.; Acuña, V.; Vergoñós, L.; Ziv, G.; Marcé, R.; Sabater, S. Assessment of the water supply: Demand ratios in a Mediterranean basin under different global change scenarios and mitigation alternatives. Sci. Total Environ. 2014, 470-471, 567-577. [CrossRef] [PubMed] 
41. Hamel, P.; Guswa, A.G. Uncertainty analysis of a spatially explicit annual water-balance model: Case study of the Cape Fear basin, North Carolina. Hydrol. Earth Syst. Sci. 2015, 19, 839-853. [CrossRef]

42. Goodison, B.E.; Brown, R.D.; Crane, R.G. Cryospheric System. In EOS Science Plan; King, M.D., Greenstone, R., Bandeen, W., Eds.; 1998; Chapter 6. Available online: https://eospso.nasa.gov/sites/ default/files/publications/SciencePlan.pdf (accessed on 20 April 2018). 